\title{
Projeto de um sistema de desvio de obstáculos para robôs móveis baseado em computação reconfigurável
}

Jecel Mattos de Assumpção Júnior

Orientador: Prof. Dr. Eduardo Marques

Dissertação apresentada ao Instituto de Ciências Matemáticas e de Computação, como parte dos requisitos para obtenção do título de Mestre em Ciência da Computação e Matemática Computacional.

USP - São Carlos

Novembro de 2009 


\section{Agradecimentos}

Aos meus colegas do laboratório LCR e LRM, principalmente ao Denis Wolf pelo incentivo e idéia inicial do projeto de desvio de obstáculos e ao Vanderlei Bonato pelas discussões sobre vários projetos.

Ao meu orientador e amigo Prof. Dr. Eduardo Marques, por ter criado um espaço onde este trabalho pudesse ser realizado e por sua paciência enquanto eu explorava caminhos alternativos.

Ao meu pai por todo o incentivo e suporte financeiro e à minha falecida mãe por sua insistência de que eu deveria me envolver mais a fundo com a pesquisa acadêmica. 


\section{Resumo}

A área de robótica móvel se encontra numa fase de grande expansão, mas um dos obstáculos a ser vencido é o desenvolvimento de sistemas computacionais embarcados que combinem baixo consumo de energia com alta capacidade de processamento. A computação reconfigurável tem o potencial para atender esta demanda. Este trabalho visa avaliar as dificuldades no aproveitamento desta tecnologia através da implementação em hardware de um sistema de desvio de obstáculos para robôs móveis usando uma única câmera de baixo custo como sensor. Normalmente os algorítmos de fluxo óptico usados neste projeto são implementados inteiramente em software e sofrem várias restrições para poderem operar nos computadores embarcados nos robôs. O projeto descrito neste trabalho não tem estas restrições mas exige um esforço maior de desenvolvimento. 


\section{Abstract}

The area of mobile robotics is undergoing a tremendous expansion, but one of the obstacles to be dealt with is the development of embedded computational systems that combine low power consumption and high performance. Reconfigurable computing has the potential to meet these requirements. This project is an evaluation of the complexities of fully exploiting this technology through the hardware implementation of an obstacle avoidance system for mobile robots using a single, low cost camera as its sensor. Normally, the optic flow algorithms used in this project are implemented entirely in software and so suffer several limitations in order to run on computers embedded in the robots. The hardware described here does not have the same limitations but requires more development effort. 


\section{Sumário}

1 Introdução 1

1.1 Motivação . . . . . . . . . . . . . . . . . . . . . . . . 1

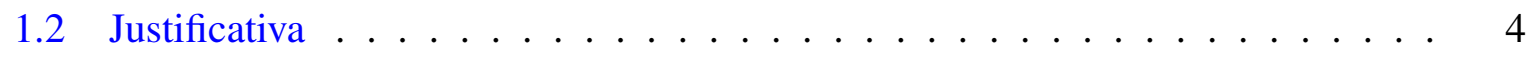

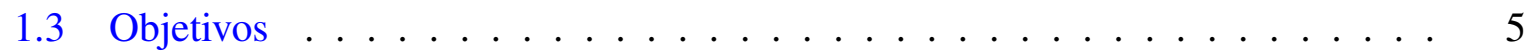

2 Computação Reconfigurável 6

2.1 Primeira Era da Computação Reconfigurável . . . . . . . . . . . . . . . . . 7

2.2 Componentes $(\mathrm{Re})$ configuráveis . . . . . . . . . . . . . . . . . . 9

2.2.1 Ferramentas de Desenvolvimento . . . . . . . . . . . . . . 14

2.3 FPGAs . . . . . . . . . . . . . . . . . . . 15

2.4 Reconfiguração Dinâmica e Parcial . . . . . . . . . . . . . . . . . . 18

3 Desvio de Obstáculos 21

3.1 Detetores de profundidade . . . . . . . . . . . . . . . 22

3.2 Sistemas baseados em Visão . . . . . . . . . . . . . . . . . . . 23

3.2.1 "Sonares Visuais" baseados em aprendizado de máquina . . . . . . . . 23

3.2 .2 Visão Estéreo . . . . . . . . . . . . . . . . . . . . 25

3.2 .3 Fluxo Óptico . . . . . . . . . . . . . . . . . . . . 26

3.2.4 Detecção de Obstáculos usando Fluxo Óptico . . . . . . . . . . . . . . 34

4 Implementação e Resultados $\quad 37$

4.1 Octave .............................. 40

4.1 .1 Filtros . . . . . . . . . . . . . . . 42

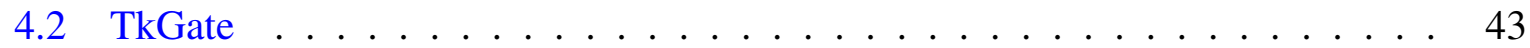

4.2.1 Placa de desenvolvimento DE2 . . . . . . . . . . . . . . . 47

$4.2 .2 \quad \mathrm{FPGA} \ldots \ldots \ldots \ldots \ldots \ldots$

4.3 Comparação dos Resultados . . . . . . . . . . . . . . . . . . . . 59 
5 Conclusões $\quad 61$

5.1 Contribuições deste trabalho . . . . . . . . . . . . . . . . . . . 61

5.2 Trabalhos futuros . . . . . . . . . . . . . . . . 62

Referências Bibliográficas $\quad 62$

A Listagem em Octave $\quad 69$

A.1 Fluxo Óptico . . . . . . . . . . . . . . . . . . . . . . . . . . 69

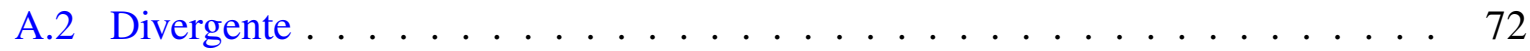

A.3 Representação via Cores . . . . . . . . . . . . . . . . . . 76

A.4 Leitura de Arquivos . . . . . . . . . . . . . . . . . . . . . 80 


\section{Lista de Figuras}

1.1 Robô Pioneer 3 AT do Laboratório de Robótica Móvel ICMC-USP com sensor laser e câmera . . . . . . . . . . . . . . . . . . . . 2

1.2 Robô Pioneer 3 DX com sistema embarcado baseado em FPGA do Laboratório de Computação Reconfigurável ICMC-USP . . . . . . . . . . . . . . . . . 3

1.3 Arquitetura do Processador IMAPCAR da NEC . . . . . . . . . . . . . . 4

2.1 LUT (Look Up Table) é o elemento básico da FPGA . . . . . . . . . . . . . 16

2.2 Metade superior do XC4V25LX da Xilinx . . . . . . . . . . . . . 20

3.1 Calculo de pronfundidade dado pares de imagens usando o software livre openvis3D (http://code.google.com/p/openvis3d/) . . . . . . . . . . . . . 25

3.2 A parte de cima mostra dois pedaços de imagens a serem comparados e a parte de baixo mostra 25 deslocamentos possíveis . . . . . . . . . . . . . . 29

3.3 Uso de pirâmides de imagens para reduzir o espaço de busca para deslocamentos grandes . . . . . . . . . . . . . . . . . . 30

3.4 A foto da esquerda mostra umas cadeiras como vistas por um robô que se aproxima delas em Camus et. al. (1996) enquanto a da direita mostra os vetores de fluxo correspondentes (apenas em pontos bem separados para ficar mais claro) . 32

3.5 Representação de vetores de deslocamento com cores e teste do algorítmo . . . 33

3.6 Máscaras usadas no cálculo da divergente e da rotacional . . . . . . . . . . . 35

4.1 Diagrama de blocos do sistema de visão monocular dentro de um exemplo de sistema completo de controle robótico [versão de 2007] . . . . . . . . . . . . . 38

4.2 Placa de FPGA ML401 com câmera montada num suporte para uso em robôs 39

4.3 Teste do Cálculo da Divergente . . . . . . . . . . . . . . . . . . 41

4.4 Teste do Filtro Temporal . . . . . . . . . . . . . . . . . . . . . . 42

4.5 Teste do Filtro Espacial . . . . . . . . . . . . . . . . . . . . . . . . . 42

4.6 Diagrama de blocos do algorítmo de fluxo óptico . . . . . . . . . . . . . . 44

4.7 Placa de desenvolvimento DE2-70 de Terasic com câmera . . . . . . . . . . . 47 
4.8 Diagrama de blocos da placa de desenvolvimento DE2-70 de Terasic com câmera e tela de cristal líquido . . . . . . . . . . . . . . . . . . . 48

4.9 Diagrama de blocos do circuito implementado na FPGA . . . . . . . . . . . 50

4.10 Diagrama de blocos do processador . . . . . . . . . . . . . 52

4.11 Instruções do processador . . . . . . . . . . . . . . . . . . . . 52

4.12 Diagrama de blocos do Fluxo Óptico . . . . . . . . . . . . . . . . 54

4.13 Diagrama de blocos do Comparador . . . . . . . . . . . . . 55

4.14 Diagrama de blocos da Diferença Absoluta . . . . . . . . . . . . . 56

4.15 Diagrama de blocos da Diferença de Pixels . . . . . . . . . . . . . 57

4.16 Diagrama de blocos da Diferença de Blocos de Pixels . . . . . . . . . . . 58

A.1 Fluxo óptico de um par de pirâmides de imagens ～. . . . . . . . . . . . . 70

A.2 Encontra a melhor aproximação de 3 por 3 pixels da imagem atual numa área de 5 por 5 na imagem anterior . . . . . . . . . . . . . . 71

A.3 Fluxo óptico de um par de imagens . . . . . . . . . . . . . . . . . . 71

A.4 Fluxo óptico falso para testar divergente . . . . . . . . . . . . . . . . . 72

A.5 Divergente de um par de pirâmides de fluxos ópticos . . . . . . . . . . 73

A.6 Divergente de um par de fluxos ópticos com blocos de 3 por 3 pixels . . . . . . 74

A.7 Divergente de um par de fluxos ópticos com blocos de 11 por 11 pixels . . . . . 75

A.8 Inicializa dados usados na figura A.7 . . . . . . . . . . . . . 77

A.9 Fluxo óptico de uma pirâmides de imagens representado por cores . . . . . . 77

A.10 Fluxo óptico de uma imagem representado por cores . . . . . . . . . . . 78

A.11 Cor correspondente a um deslocamento . . . . . . . . . . . . . . . 78

A.12 Legenda para a representação de vetores de deslocamento como cores . . . . 78

A.13 Divergente de uma pirâmide de fluxos ópticos representados por cores . . . . . 79

A.14 Divergente de um fluxo óptico representado por cores . . . . . . . . . . . . . 79

A.15 Toca um filme . . . . . . . . . . . . . . . . . . . 80

A.16 Toca um filme calculando o fluxo óptico de um quadro para outro e a divergente 81

A.17 Divide a resolução de uma imagem por dois usando uma média simples . . . . 81

A.18 Combina pirâmides de entrada e de saída numa única imagem . . . . . . . . . 81

A.19 Espalha os elementos de uma pirâmide por uma imagem maior . . . . . . . . . 82

A.20 Embute uma imagem numa maior usando zeros . . . . . . . . . . . . 83

A.21 Como da figura A.16 mas salva cada quadro num arquivo . . . . . . . . . . 83

A.22 Lê arquivos no formato PPM . . . . . . . . . . . . . . . . . . 84 


\section{Lista de Tabelas}

2.1 Classificação de Blocos Lógicos . . . . . . . . . . . . . . . . . . . . 9

2.2 Classificação de Sistemas Programáveis . . . . . . . . . . . . . . . . . 11

2.3 Características de algumas FPGAs disponíveis atualmente . . . . . . . . . . 17

3.1 Sensores externos para SLAM . . . . . . . . . . . . . 22

4.1 Uso da memória interna da FPGA . . . . . . . . . . . . . . . . . . . . 59

4.2 Implementações dos Algorítmos . . . . . . . . . . . . . . . . 60 


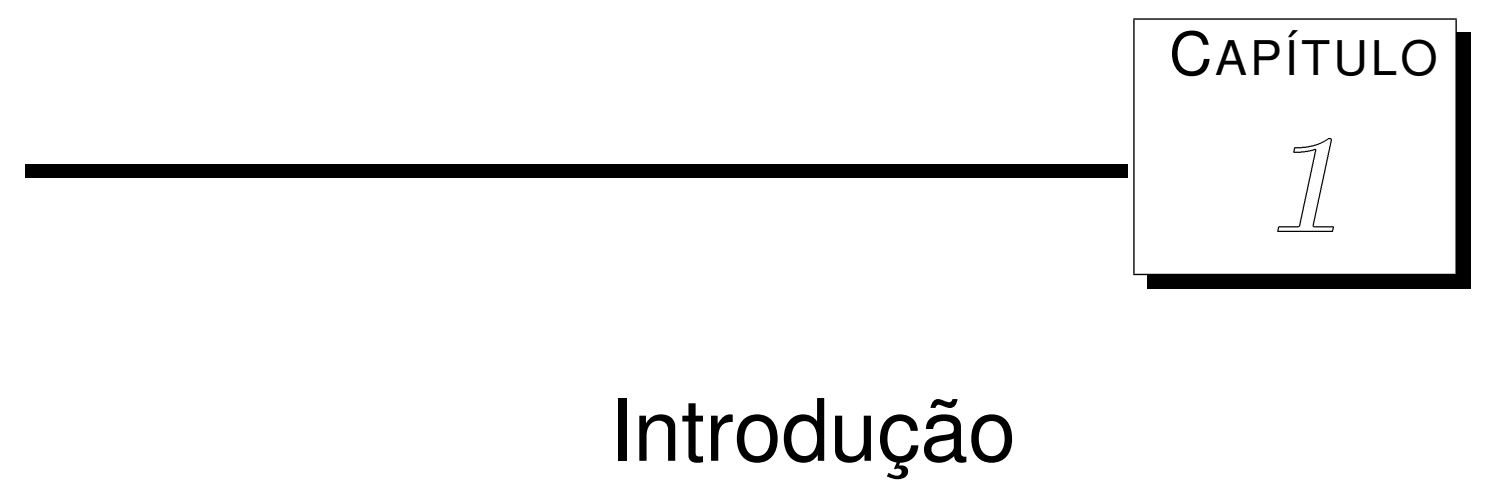

\subsection{Motivação}

A área da robótica móvel se encontra numa situação parecida com a dos microcomputadores antes da explosão da computação pessoal. As empresas tradicionais da robótica se concentram em modelos fixos e de alto custo voltados para aplicações industriais, deixando o caminho livre para que novas e pequenas empresas e grupos acadêmicos desenvolvam robôs pessoais de baixo custo. Isto exigirá plataformas computacionais embarcadas de alto desempenho com baixo custo financeiro e consumo de energia. Freqüentemente, o uso de sensores de baixo custo (como câmeras) implica grande esforço computacional enquanto que sensores com menor carga computacional (lasers ou sonares) têm um custo muito mais elevado.

Os robôs pessoais desenvolverão tarefas complexas em ambientes não estruturados (como na figura 1.1) em contraste com as tarefas repetitivas em ambientes fixos dos robôs industriais. Este fator também aumenta significativamente a capacidade computacional necessária.

Sendo estes robôs móveis, precisam incluir fisicamente os computadores que os controlam (figura 1.2). É possível se ter uma console remota, mas de um modo geral o canal de comunicação disponível via rádio é limitado. Assim, os problemas a serem resolvidos no de- 


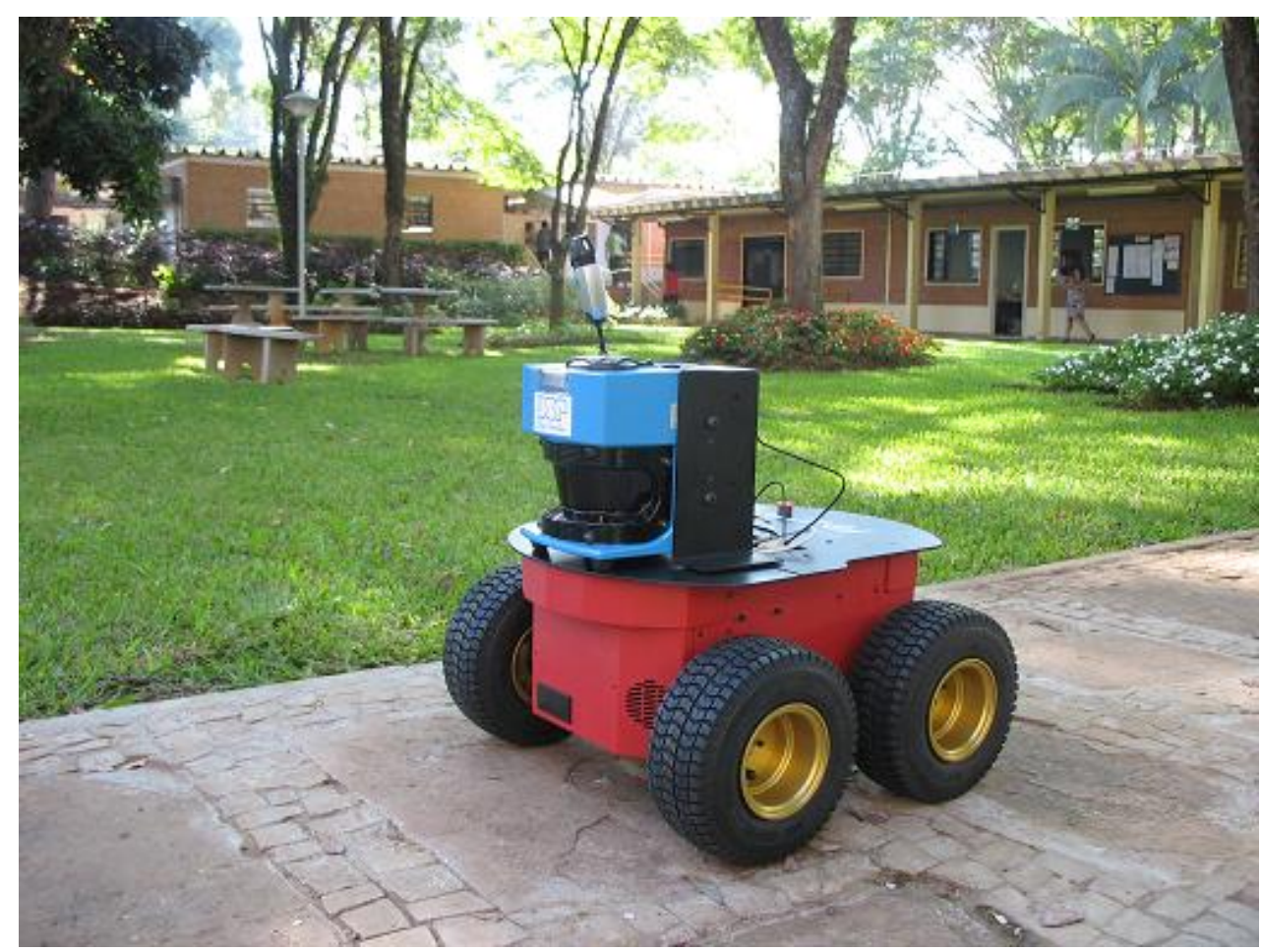

Figura 1.1: Robô Pioneer 3 AT do Laboratório de Robótica Móvel ICMC-USP com sensor laser e câmera

senvolvimento dos "cérebros" dos robôs são os típicos dos sistemas embarcados. Em alguns casos é possível o uso de PCs normais, como nos automóveis autônomos do desafio da DARPA de corrida pelo deserto como o descrito em Thrun et. al. (2006). Estes robôs tinham muito espaço interno, grande capacidade de dissipação de calor e bastante energia elétrica vinda dos geradores movidos pelos motores de combustão interna.

A computação reconfigurável pode ser uma maneira de conciliar a necessidade de alto desempenho e baixo consumo da maioria dos casos em que o robô não é uma caminhonete inteira. Aproveitando o paralelismo inerente às configurações de hardware dedicadas à aplicação, é possível operar um computador configurável a uma frequiência muito menor do que um PC precisaria (ou mesmo um computador embarcado convencional) para obter resultados semelhantes.

Uma das áreas da robótica móvel onde a necessidade de alta capacidade computacional é particularmente evidente é a da visão computacional. O cérebro humano processa grandes volumes de dados em paralelo e o próprio olho tem na retina a capacidade de operações simultâneas em todos os pontos de luz captados. Reproduzir isso num computador serial é um grande desafio. 


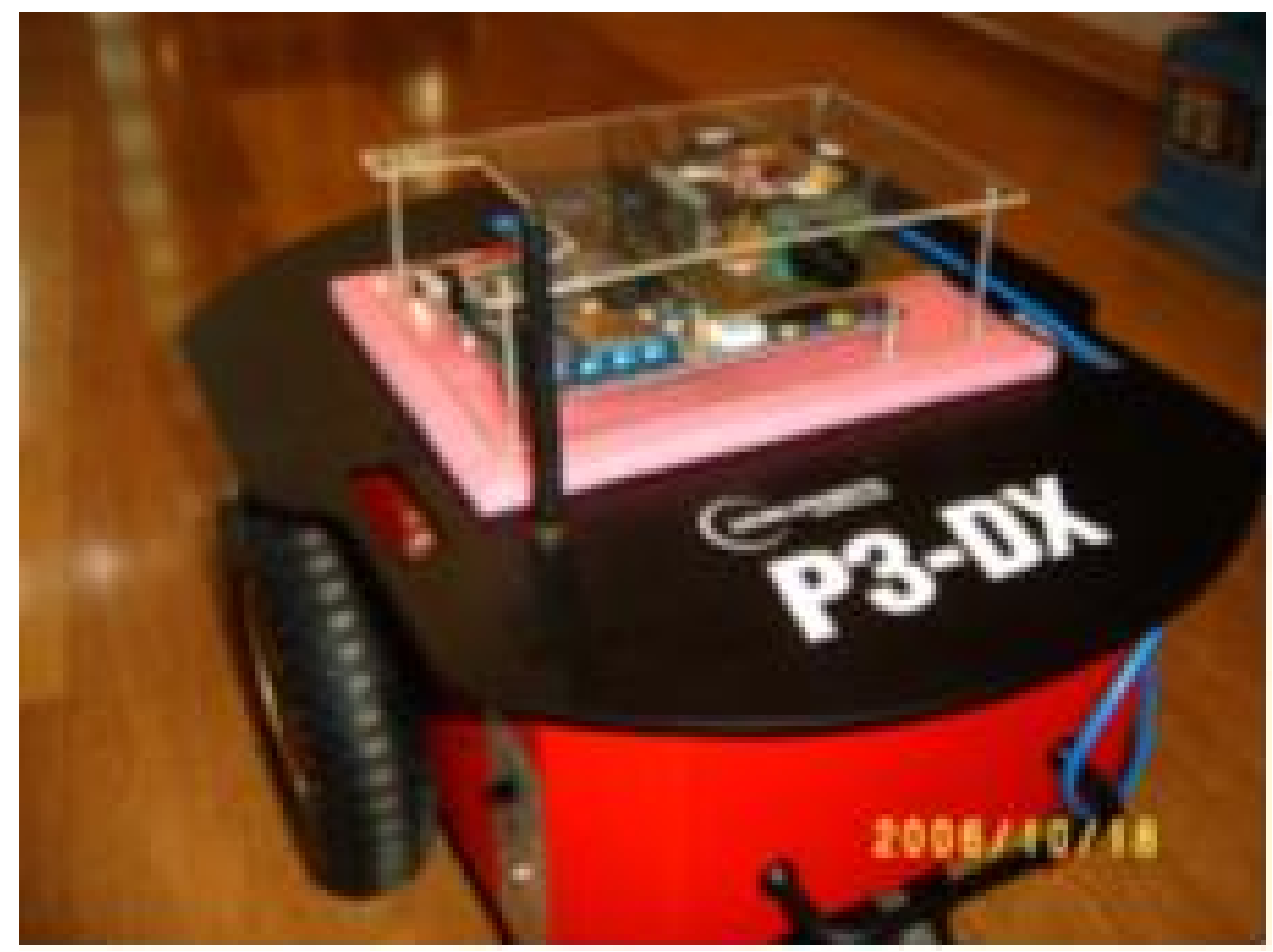

Figura 1.2: Robô Pioneer 3 DX com sistema embarcado baseado em FPGA do Laboratório de Computação Reconfigurável ICMC-USP

Mesmo uma câmera de baixa resolução capta um grande volume de dados ${ }^{1}$. Tratar e interpretar esta informação visível em tempo real exige uma solução de hardware e software de alto desempenho. Um exemplo de uma solução comercial para este problema é o processador Imapcar da NEC descrito em Okazaki et. al. (2006) e detalhado na figura 1.3. Este componente, que custa inicialmente 200 dolares, está sendo usado no automóvel Lexus LS460 da Toyota para evitar colisões em tempo real, inclusive com pedestres (que não são detectados por radares de proximidade já em uso em diversos automóveis). Um processador tipo RISC de 16 bits recebe instruções de um computador externo e controla os 128 Elementos de Processamento (EP) num paralelismo de instrução única e múltiplos dados (SIMD - single instruction, multiple data). Só que neste caso cada EP tem quatro unidades lógicas e aritméticas independentes controladas por uma palavra de instrução muito longa (VLIW - very long instruction word). Cada EP opera com dados de 8 bits, que é o tamanho dos componentes de cor enviados pelas câmeras (o circuito pode ser ligado a 3 câmeras digitais simultaneamente). Um total de 100 bilhões de operações simples podem ser realizadas a cada segundo e cada EP tem uma memória local de $2 \mathrm{~KB}$ e um

\footnotetext{
${ }^{1} 320$ × 240 × $30=2,3$ milhões de pixels por segundo, cada um com 3 canais de cores
} 


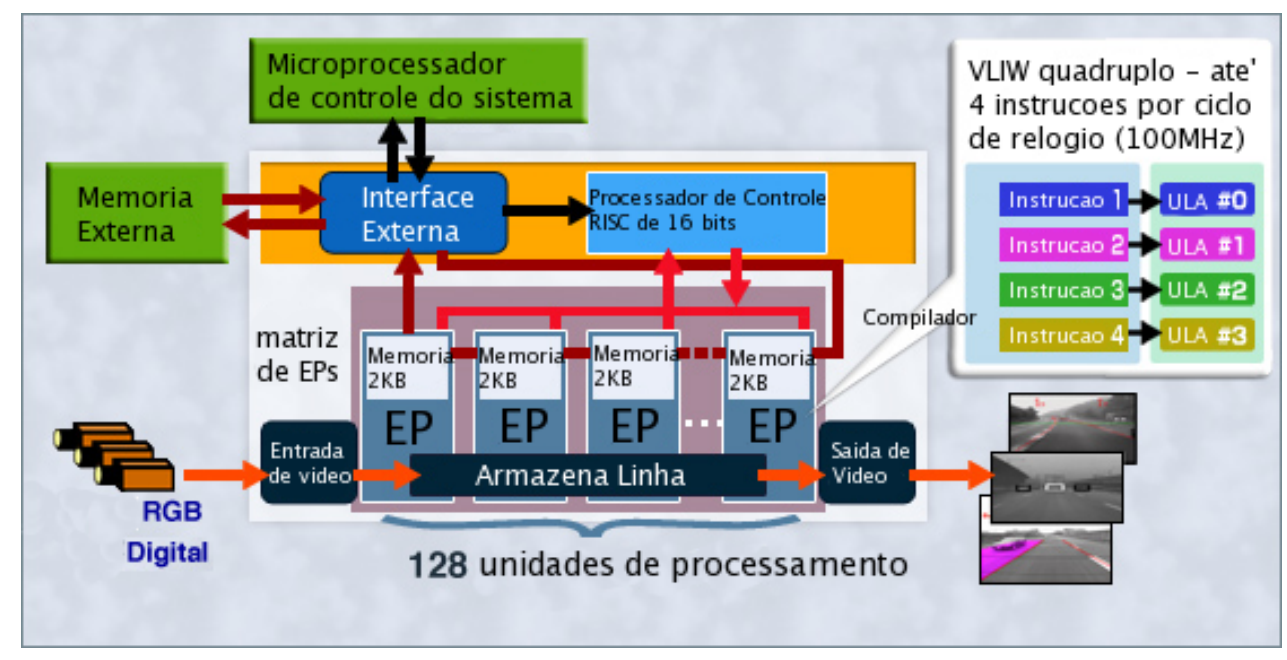

Figura 1.3: Arquitetura do Processador IMAPCAR da NEC

canal dedicado de comunicação com os vizinhos para que o acesso a dados de trechos da imagem não seja o fator limitante do sistema. A freqüência de operação de $100 \mathrm{MHz}$ foi escolhida para manter o consumo do componente abaixo de $2 \mathrm{~W}$.

O Imapcar é uma boa opção para a implementação de um subsistema relativamente independente capaz de aplicações simples, mas com grande volume de cálculos, de visão computacional. Para o desenvolvimento de sistemas integrados para robótica móvel seria necessário acesso a alguns dos fluxos de dados internos do circuito integrado, o que não é possível. Portanto, tratar informação visível em sistemas embarcados em tempo real exigirá nos próximos anos um esforço muito grande de pesquisa e desenvolvimento.

Dentro deste contexto, foi desenvolvido um sistema de desvio de obstáculos baseado em câmeras CMOS para ser acoplados aos robôs das figuras 1.1 e 1.2.

\subsection{Justificativa}

Estão sendo desenvolvidas soluções como em So (2007) onde um usuário pode misturar blocos de hardware e software a tempo de execução com a alocação automática de espaço nos circuitos reprogramáveis (FPGAs), mas de uma maneira geral o estado da arte da computação reconfigurável ainda exige mais conhecimentos de baixo nível que implementações em software usando computadores tradicionais. Os blocos do sistema mencionado se comunicam através de canais bem limitados. Em aplicações onde o desempenho é critíco, o desenvolvedor não tem como 
evitar de se envolver em detalhes de baixo nível típicos de projetos de hardware.

Ferramentas de alto nível podem eliminar muitas destas complicações. O projeto RoboArch em andamento no LCR (Laboratório de Computação Reconfigurável do ICMC-USP) visa, como detalhado em Bonato e Marques (2009), o modelamento de sistemas a nível de transações (TLM - Transaction Level Modelling). Numa fase seguinte uma combinação de ferramentas com diferentes níveis de automação podem implementar estas transações usando canais físicos de comunicação e simulações podem ser usadas para verificar a equivalência das duas descrições.

A experiência com o projeto manual de algo que está sendo automatizado geralmente ajuda bastante. O contraste entre o desenvolvimento descrito neste trabalho e uma versão posterior que aproveite os recursos do RoboArch permitirá uma avaliação bem objetiva das vantagens da ferramenta. E mesmo a versão atual do sistema de desvio de obstáculos pode ser usado como um módulo pronto para outros projetos do LCR.

\subsection{Objetivos}

Os objetivos principais deste trabalho são:

- Desenvolver um sistema de Desvio de Obstáculos baseado em Visão Monocular que sirva como módulo em outros projetos do Laboratório de Computação Reconfigurável e Laboratório de Robótica Móvel.

- Criar mais um exemplo de sistema que poderá servir de teste para futuras ferramentas para Computação Reconfigurável. 


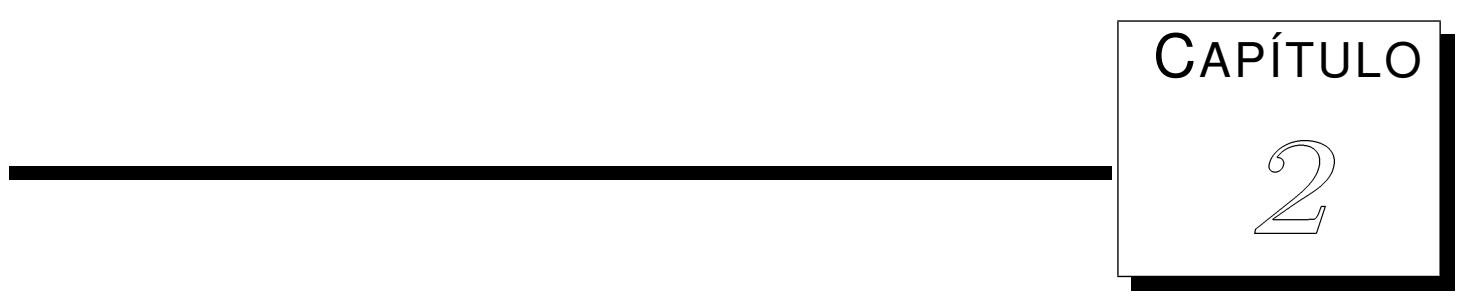

\section{Computação Reconfigurável}

O primeiro computador eletrônico, o ENIAC da Universidade da Pennsylvania (1946), era "programado" reconfigurando-se o seu hardware. Fios como os de antigas centrais telefônicas ligavam suas diferentes partes para resolver problemas específicos. Para um problema diferente os fios tinham que ser ligados de outra maneira. A geração seguinte de computadores usava a chamada "arquitetura de Von Neumann" (ainda em uso por todos os computadores atuais) na qual a programação era feita apenas trocando-se números na memória da máquina. A configuração do hardware permanecia fixa independente do problema a ser resolvido.

Diferentemente dos computadores tradicionais, um computador reconfigurável tem o seu hardware ajustado para melhorar o desempenho de um programa específico. Em outro momento o hardware pode ser ajustado de maneira diferente para resolver um segundo problema.

Onde não existe limite de custo ou gasto de energia é possível usar computadores reconfiguráveis de larga escala para resolver problemas típicos de supercomputadores. Já em sistemas embarcados, onde estes limites são muito reduzidos, os computadores reconfiguráveis são uma alternativa interessante aos processadores tradicionais e os processadores de sinais (DSP). 


\subsection{Primeira Era da Computação Reconfigurável}

Uma das maneiras de se dividir o projeto de um computador é em dois blocos: a unidade de controle e o caminho dos dados. Os elementos típicos de um caminho de dados são registradores, unidades aritméticas e lógicas, memórias, multiplexadores e/ou barramentos.

A unidade de controle tem como função gerar uma seqüência de pulsos nas linhas de controle do caminho de dados dependendo da instrução que está sendo executada e do estado da máquina. As técnicas conhecidas de projeto de máquinas de estados finitos podem ser usadas para isso, mas o resultado é complicado de se testar e alterar. A "microprogramação" foi introduzida por Maurice Wilkes (Wilkes (1951) e mais detalhada em Wilkes e Stringer (1953)) como uma alternativa mais estruturada onde a unidade de controle é, na verdade, um pequeno computador em si. Isto só é prático se este computador de controle for muitas vezes mais simples do que a máquina da qual é parte. A maioria das unidades de controle microprogramadas são essencialmente uma memória com dados realimentando parte dos endereços que são armazenados num registrador.

Com o desenvolvimento das memórias semicondutores nos anos 1970, tanto de programação permanente (ROMs e PROMs) como alteráveis (RAM), a microprogramação se tornou muito popular. Houve, então, interesse em reconfigurar computadores para cada aplicação que fossem executar. O caminho dos dados era fixo, de modo que a única reconfiguração possível era a troca do microprograma. No caso do computador portátil 5100 da IBM (antecessor do PC, o 5150) e seu processador PALM ("Put All Logic in Microcode"), o objetivo era ter compatibilidade com o IBM 1130 para usuários de Basic e com o IBM 360 para programadores de APL, sendo a reconfiguração feita por uma chave no painel frontal. Para o Burroughs B1700 os projetistas tomaram o máximo cuidado para que o caminho de dados fosse flexível o suficiente para não ser, apesar de fixo, um fator limitante na reconfigurabilidade da máquina.

O computador Alto desenvolvido no laboratório PARC da Xerox tinha mil palavras de ROM para microcódigo que implementava uma linguagem de máquina otimizada para o BCPL (antecessor da linguagem C) e mais 3 mil palavras em RAM para que o usuário pudesse carregar linguagens de máquina voltadas para outras aplicações. Thacker et. al. (1981) menciona as 
linguagens Smalltalk, Lisp e Mesa (um Pascal modular) como exemplos do uso deste recurso. Dado o tamanho minúsculo da memória de microprograma comparado com a memória principal, o custo elevado de desenvolvimento de microcódigo e o ganho significativo de desempenho com relação à linguagem de máquina, o melhor uso desta técnica era obtido quando usado nos pontos mais críticos da aplicação. Um bom exemplo disso é a instrução BitBLT criada para o Alto. Ela move um retângulo de bits na tela para outro lugar, combinando-os com os que já se encontram no destino. Na implementação original do Smalltalk não havia nenhum ponto mais crítico nas rotinas gráficas e não era possível usar a microprogramação para melhorar sua velocidade. O sistema foi, então, alterado para que rotinas de texto, desenho de linhas, de janelas e outras operações chamassem como sua única primitiva a cópia de retângulos. Com a maior parte do tempo de processamento sendo agora ocupado por esta única rotina, foi possível implementá-la como uma nova instrução usando o microcódigo (esta instrução está presente em todas as placas de vídeo modernas para PC).

Além do alto custo de microprogramação, mencionado acima, a restrição do caminho de dados fixo limitava o uso mais intenso desta tecnologia. Com a introdução de componentes de alta integração especializados em caminhos de dados, os circuitos "bit slice" dos quais o 2901 da AMD foi o mais popular, passou a ser possível a criação de caminhos de dados voltados para cada projeto. Isto tornou a microprogramação comum em aplicações com orçamentos suficientemente grandes e necessidades extremas de processamento de dados, tais como radares, computação gráfica, processamento de imagens e telecomunicações. Com a evolução dos microprocessadores de 32 bits, especialmente os processadores RISC que não usam unidade de controle microprogramada, um desempenho aceitável podia ser obtido em cima de produtos padronizados e a primeira era da computação configurável (ou parcialmente reconfigurável) chegou ao fim.

Os componentes descritos em seguida, no entanto, estavam surgindo nesta mesma época. Sua evolução nos anos 1990 permitiu a segunda era da computação reconfigurável. As lições aprendidas na primeira era, embora há muito esquecidas, voltaram a ser muito importantes. Mesmo técnicas mais específicas como a microprogramação podem representar um bom uso de modernos circuitos reprogramáveis para a criação de periféricos compactos, como em Wong et. 
al. (2001), ou para suporte a linguagens como Java em Schoeberl (2005).

\subsection{Componentes (Re)configuráveis}

\begin{tabular}{|c|c|c|c|c|c|c|c|}
\hline & \multicolumn{6}{|c|}{ plano E } \\
\hline & & fixo & tabrica & campo & reprogramável & sistema & execuçao \\
\hline \multirow{6}{*}{$\begin{array}{l}\tilde{0} \\
\text { O } \\
\text { ] } \\
\end{array}$} & fixo & TTLs & & PAL & GAL & PLD & \\
\hline & fábrica & ROM & PLA & & & & \\
\hline & campo & PROM & & FPLA & & & \\
\hline & reprogramável & EPROM & & & & & \\
\hline & sistema & Flash & & & & & \\
\hline & execução & RAM & & & & & \\
\hline
\end{tabular}

Tabela 2.1: Classificação de Blocos Lógicos

Uma forma universal de se descrever um circuito combinacional é a soma de produtos. As entradas e suas versões invertidas são combinadas de diversas formas com circuitos E (os produtos, que formam o "plano E" quando este tem um desenho regular no circuito integrado do qual faz parte) e as saídas destes são combinadas de diversas formas com circuitos Ou (as somas, que formam o "plano Ou"). A tabela 2.1 mostra os diferentes circuitos que podem ser obtidos dependendo da configurabilidade destes dois planos.

O caso extremo é quando tanto as somas quanto os produtos são definidos durante o projeto do circuito. Não existe nenhuma maneira de alterar isso. No circuito TTL 74LS54, por exemplo, o plano E sempre tem dois circuitos E de duas entradas e dois de três entradas enquanto o plano Ou tem um único Ou de quatro entradas. Se algo diferente disso for necessário, então um 74LS51 ou outro terá que ser usado.

Os demais componentes da coluna com plano E fixo no projeto são memórias. Neste caso existe uma porta E para cada combinação possível de endereços. Em uma memória com endereços de 12 bits, por exemplo, existem 4096 portas E de 12 entradas. O número de circuitos Ou depende da largura de cada palavra, sendo as opções mais populares de 1, 4 ou 8 bits. No caso da memória de apenas leitura (ROM - Read Only Memory) a ligação das saídas dos circuitos E às entradas dos Ou é feita durante a fabricação do componente. Mas apenas uma das várias máscaras usadas neste processo é específica para cada cliente. As demais são as mesmas para todos e definidas durante o projeto. Isto reduz bastante o custo comparado a um projeto $100 \%$ 
dedicado.

Em aplicações onde o número de unidades não é muito grande, o custo da criação de mesmo uma única máscara é excessivo. Por isso foram criadas as memórias programáveis em campo (PROM - Programmable ROM) onde a ligação dos circuitos E ao Ou é feita por pequenos fusíveis. Colocado num aparelho conhecido como "programador", o componente pode ter qualquer conjunto desejado de fusíveis eliminado por pulsos de tensão mais alta que a normal. Se a programação precisar ser alterada por qualquer motivo, o componente deverá ser jogado fora e outro "virgem" programado e colocado em seu lugar. A inconveniência disso para os clientes levou ao desenvolvimento de memórias apagáveis (EPROM - Erasable PROM). Estas voltam ao estado original se expostas à luz ultravioleta (ou, dependendo do modelo, a um pulso elétrico especial). Um passo adiante nesta evolução é a possibilidade de programar e apagar o componente enquanto ele está incorporado ao sistema final. As memórias EEPROM e Flash são assim e normalmente dispensam um aparelho especial de programação.

Os vários tipos de memória foram bem aproveitados como blocos lógicos programáveis. Com a realimentação de alguns dados para os endereços, como descrito acima na parte sobre microprogramação, as memórias podem implementar circuitos seqüenciais além dos combinacionais. A controladora de disquetes do Apple II, por exemplo, usava uma PROM para implementar toda a sua lógica complexa. O gerador de vídeo do Merlin 2 (deste autor) era baseado em uma EPROM. A memória estática ou dinâmica normal (RAM - Random Access Memory) pode ser reconfigurada o tempo todo durante a execução do sistema. Como perde todos os dados quando o aparelho é desligado, no entanto, o seu uso como bloco lógico não é conveniente.

Para a maioria dos circuitos lógicos, o uso de uma memória não é muito eficiente. No caso de 12 entradas todas as memórias têm 4096 circuitos E, o que representa um aproveitamento de apenas $0,7 \%$ em um projeto que precisa de 30 circuitos E. A solução é estender a configurabilidade do plano Ou para o plano E. Um circuito chamado PLA (Programmable Logic Array) tem uma estrutura regular que permite os dois planos serem configurados por uma única máscara. Na prática as PLAs não são disponíveis como componente isolado mas são incorporados dentro de circuitos mais complexos. Neste caso a configurabilidade visa apenas facilitar o projeto e não reduzir custos. Uma versão das PLA com fusíveis (FPLA - Field Programmable Logic 
Array) foi um dos primeiros circuitos integrados a ser comercializado mas não chegou a ficar popular.

Se o número de portas E necessários não é muito grande, a configuração do plano Ou não costuma variar muito. Assim, as PALs (Programmable Array Logic) abandonam parte da flexibilidade das FPLAs em troca de uma redução de custos. Elas se tornaram muito populares no início dos anos 1980 e, para facilitar o desenvolvimento, as GAL (Generic Array Logic) foram criadas. Elas podiam ser apagadas elétricamente num aparelho especial e depois reconfiguradas, mas em função do seu custo mais elevado costumavam ser substituídas por PALs, com as quais eram totalmente compatíveis, na produção. Com novas versões de PAL/GAL cada vez maiores foi adotado o termo genérico PLD (Programmable Logic Device - dispositivo lógico programável) para descrevê-los. A maioria dos PLDs modernos podem ser programados no próprio sistema final, o que é especialmente importante dado que os circuitos em soquetes deram lugar aos de montagem de superfície soldados diretamente nas placas de circuito impresso.

\begin{tabular}{|c|c|c|c|c|c|c|}
\hline & \multicolumn{5}{|c|}{ elemento básico } \\
\hline & & fixo & fábrica & campo & sistema & execução \\
\hline iี & fixo & ASIC & & & $\begin{array}{l}\text { Geometry } \\
\text { Engine }\end{array}$ & GPU \\
\hline : & fábrica & Gate & matriz de & & Structured & \\
\hline$\stackrel{\bar{\Xi}}{.}$ & campo & & & $\begin{array}{c}\text { FPGA } \\
\text { anti } \\
\text { fusível }\end{array}$ & & \\
\hline & sistema & FPOA & & & $\begin{array}{l}\text { FPGA } \\
\text { SRAM }\end{array}$ & \\
\hline & execução & Stretch & & & & TRIPS \\
\hline
\end{tabular}

Tabela 2.2: Classificação de Sistemas Programáveis

Numa escala maior do que a dos blocos lógicos, existem circuitos configuráveis capazes de implementar sistemas inteiros. A tabela 2.2 mostra uma possível classificação destes circuitos. A sua arquitetura geral é de um conjunto de elementos básicos ligados por um sistema de interconexão.

Quando todos os aspectos do circuito são projetados especificamente para determinada aplicação, o termo ASIC (Application Specific Integrated Circuit) é usado. O nome faz menos sentido para circuitos padrão, como memórias e microprocessadores, apesar das técnicas de 
projeto serem exatamente as mesmas. Uma alternativa para a redução de custo de projeto é o uso de uma biblioteca padrão de elementos básicos (Standard Cells), mas o custo de fabricação é o mesmo pois todas as máscaras precisam ser criadas para cada projeto. Isso poderia ser resolvido com a adoção de um único elemento básico, como a porta Não E de duas entradas, repetida num padrão regular ao longo de todo o circuito. Nesta matriz de portas (Gate Array), apenas a camada de metal para a interconexão precisa ser desenvolvida para cada aplicação. Este nome também é usado para circuitos onde os elementos básicos são transistores e uma segunda camada de metal é usada para configurá-los em diferentes portas lógicas. Na tabela foi usado o termo "matriz de transistores" para deixar clara a diferença, mas na indústria "matriz de portas" engloba os dois tipos de circuitos.

Com uma arquitetura comparável às matrizes de portas, mas, configuráveis no campo, as FPGA (Field Programmable Gate Array) serão detalhadas na seção 2.3. O primeiro tipo criado pela Xilinx em 1984 usava memórias estáticas (Static RAM) para guardar a configuração, o que ainda é a opção mais popular. Infelizmente isso significa que a configuração é perdida cada vez que o aparelho é desligado e precisa ser refeita a cada inicialização. Outras FPGAs usam memória Flash interna para guardar a configuração e evitar este problema e ocupam na tabela o mesmo espaço que as FPGAs baseadas em SRAM. Uma alternativa interessante em algumas aplicações é o uso de anti fusíveis (que normalmente são abertos mas entram em curto ao receber uma grande corrente do aparelho de programação). O roteamento feito com anti fusíveis é muito mais rápido do que o baseado em transistores de passagem usados nas demais alternativas, mas para o desenvolvimento é inconveniente já que para trocar a programação é necessário trocar o circuito por um novo.

Uma solução nova conhecida como "Structured ASIC" vem tentando ganhar um espaço no mercado nos últimos anos. Uma única máscara é usada para definir o roteamento para cada cliente mas os elementos básicos são parecidos com os das FPGAs ao invés de serem portas simples. Em vários casos estes elementos precisam ser reconfigurados usando uma memória externa cada vez que o aparelho é ligado. Isso permite alterações limitadas em campo - a lógica pode ser mudada mas o roteamento não.

O "Geometry Engine" de Clark (1982) tinha uma arquitetura fixa com processadores em 
"pipeline" configurados por microcódigo carregado durante a inicialização do sistema. Modelos posteriores de processadores gráficos para 3D eram, em geral, menos flexíveis em função do amadurecimento e padronização do algoritmos de geração de imagens. Por isso seriam facilmente classificados como ASICs na tabela 2.2. Versões mais recentes e avançadas de unidades de processamento gráfico (GPU), entretanto, se aproximam dos processadores de uso geral e recebem suas instruções em tempo de execução. A tendência é que os processadores tradicionais venham a ocupar este espaço também. Já não está sendo mais possível aumentar a frequiência do relógio de modo que atualmente está sendo aumentado o número de processadores em cada circuito integrado. No momento sua interconexão está praticamente limitada à partilha de memórias cache, mas com mais de quatro processadores será necessário o projeto de um sistema de comunicação de verdade.

Se a idéia é executar aplicações escritas em linguagens de programação tradicionais (ou modificações das mesmas) ao invés de implementar circuitos dedicados, a flexibilidade das FPGAs nem sempre vai ser aproveitada. A capacidade de criar um somador de 13 bits, por exemplo, não pode ser expressa em C. Assim surgiram alternativas onde os blocos básicos eram ULAs inteiras ou até frações de processadores completos. As matrizes de unidades aritméticas (FPAA - Field Programmable Arithmetic Array) ou matrizes de objetos (FPOA - Field Programmable Object Array) contam com elementos básicos otimizados para a linguagem C com uma interconexão que é configurada para implementar diretamente o fluxo de dados de determinado algoritmo. $\mathrm{O}$ problema é que apenas uma pequena parte de um programa pode ser transformada em hardware assim.

Quando uma pequena parte de um programa é identificada como trecho crítico, responsável pela maior parte do tempo de execução, uma alternativa é transformar esta parte numa instrução especial. Na época dos processadores com microcódigo isso era relativamente fácil, mas os processadores RISC foram projetados excluindo todas as instruções mais complexas. A ferramenta C2H (C to Hardware) da Altera facilita este tipo de transformação para o seu processador Nios II, mas tem diversas restrições. Em Pittman et. al. (2006) os blocos lógicos que implementam as novas instruções se encaixam melhor no resto do projeto de um processador MIPS tradicional. Estas duas alternativas ocupam o mesmo espaço na tabela que as FPGAs baseadas em SRAM, 
mas os processadores da Stretch Inc. podem alterar a interconexão durante a execução, criando uma nova instrução logo antes dela ser chamada pela primeira vez. Em cada instante ele pode ter até quatro instruções especiais, cada uma ligando as 256 ULAs e 32 multiplicadores de uma maneira diferente. No projeto ADRES as ULAs podem ser ligadas de maneira análoga, com operação relativamente independente durante os trechos mais paralelos de um programa. Nas partes seqüenciais elas são agrupadas para trabalharem juntas, como explicado em Bouwens et. al. (2007).

A arquitetura TRIPS, detalhada em Burger et. al. (2005), executa programas formados por seqüências de blocos de instruções que operam no modo fluxo de dados. Quando um novo bloco de até 128 instruções é carregado nas unidades de processamento, o roteamento é feito dinamicamente uma vez que Sankaralingam et. al. (2003) verificou que soluções fixas não permitem o aproveitamento máximo de paralelismo de instruções.

Cada um destes sistemas reconfiguráveis apresenta vantagens e problemas. Hartenstein (2001) compara os projetos de computadores reconfiguráveis de 1990 a 2000, principalmente os baseados em FPGA e FPAA. No resto deste trabalho o foco será exclusivamente nas FPGAs, que como mostram Compton e Hauck (2002), permitem uma variedade de máquinas reconfiguráveis.

\subsubsection{Ferramentas de Desenvolvimento}

As ferramentas de configuração evoluíram pela necessidade de projetos cada vez mais complexos e pela possibilidade de computadores cada vez mais potentes nos quais elas eram usadas. Inicialmente as PROMs e PALs eram configuradas criando-se manualmente um "mapa de fusíveis". Isso era equivalente a programar computadores diretamente em binário, de modo que foi criado o PALASM com o objetivo de elevar esta tarefa a pelo menos o nível de linguagem de montagem. O circuito era descrito como uma seqüência de equações do tipo somas de produtos. Apesar de ainda refletirem bem de perto a estrutura dos circuitos a serem programados, estas equações eram facilmente entendidas pelos projetistas.

Como circuitos tradicionalmente eram representados graficamente, na forma de esquemas, esta foi inicialmente a forma preferida de descrição de sistemas maiores, como os possibilitados 
pelas FPGAs. Isto funciona bem em pequena escala, mas em projetos maiores a densidade das descrições textuais se torna uma vantagem. As linguagens de descrição de hardware (HDL) desenvolvidas para o projeto de ASICs foram adaptadas para as PALs ao longo dos anos 1990. Quando estações de trabalho extremamente caras eram necessárias para o uso de linguagens como o VHDL ou Verilog, a Altera resolveu estender o PALASM com o nome AHDL para uso em PCs normais. Estes PCs foram ficando mais poderosos, entretanto, e as linguagens padrão (VHDL mais na Europa e no mundo acadêmico enquanto o Verilog é bastante usado na indústria dos Estados Unidos) acabaram dominando. Mesmo assim, projetos em que linguagens como Java ou Python são adaptadas para descrever hardware são muito comuns.

O usuário de todas estas ferramentas é o projetista de hardware, mas os programadores que desejam usar computadores reconfiguráveis tem sido obrigados a usá-las também.. O ideal seria poder enviar o código aplicativo desenvolvido para executar em PCs normais para alguma ferramenta e gerar automaticamente a configuração do hardware. Linguagens como System C ou Handel C procuram ser uma descrição unificada para todo o sistema, incluindo a parte de software e de hardware. Em aplicações de processamento digital de sinais é possível gerar hardware de descrições em Matlab, que é de um nível bem mais elevado que o C.

\subsection{FPGAs}

Da mesma forma que o mercado de processadores para PCs tem sido essencialmente uma disputa entre a Intel e a AMD, o mundo das FPGAs tem sido marcado pela competição entre a Xilinx e a Altera. Empresas grandes como a própria Intel, Texas Instruments, Philips, Lucent e outras participaram por um tempo deste mercado mas acabaram desistindo. Outras empresas continuam na disputa bem distantes das lideres, apesar de terem soluções interessantes: Lattice, Actel, QuickLogic, Achronix, SiliconBlue e Atmel.

Os blocos básicos de quase todas FPGAs são pequenas memórias que implementam diretamente as tabelas verdade de funções lógicas de 2 a 6 entradas, sendo 4 (uma memória de 16 posições por um bit) o tamanho mais popular, A figura 2.1 mostra um exemplo com 2 entradas. Normalmente cada bloco destes está associado a um elemento de memória tipo "flip-flop". Guardar apenas um bit em cada bloco não é muito eficiente, especialmente se ao lado do flip-flop 


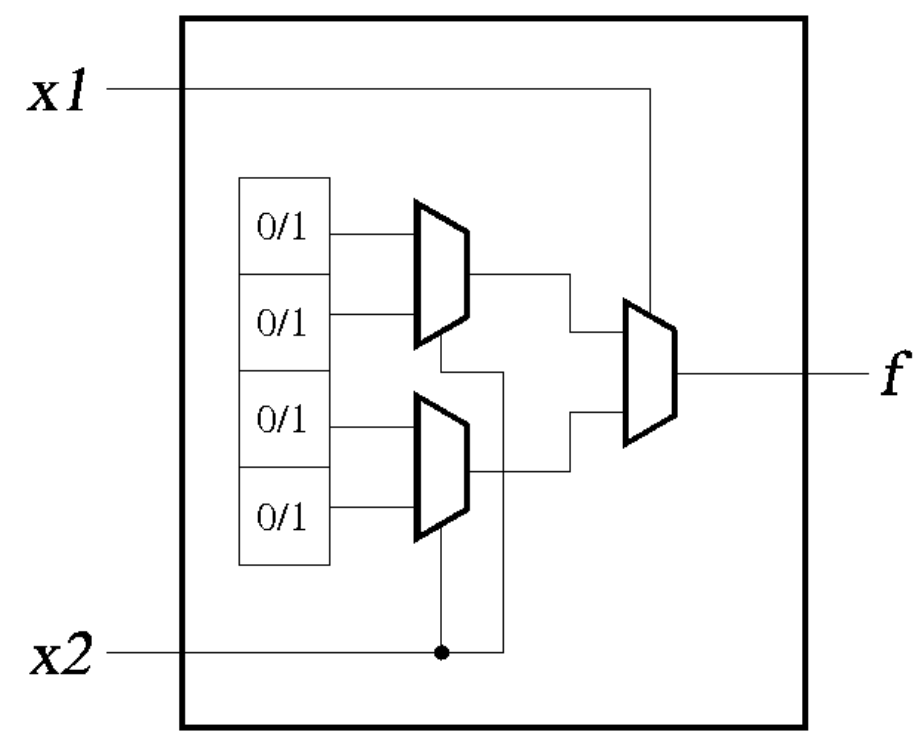

Figura 2.1: LUT (Look Up Table) é o elemento básico da FPGA

está uma LUT de quatro entradas que contém uma memória de 16 bits. Por isso muitas FPGAs modernas permitem que a LUT seja reconfigurada como uma memória ou como um registrador de deslocamento, fazendo com que este tipo de circuito tenha uma densidade 16 vezes maior do que em FPGAs mais antigas. Este recurso tem um custo, no entanto, e apenas uma fração dos blocos é usado assim. Por isso nas últimas gerações de FPGA da Xilinx apenas metade dos blocos tem este tipo de configuração.

A memória distribuída melhorou a densidade com seus 16 bits por bloco, mas uma memória especialmente projetada é ainda mais densa. A maiora das FPGAs atuais inclui memórias em bloco, com tamanhos de 4 a 144Kbits cada, sendo 18Kbits bem típico. Geralmente estas memórias são bem rápidas em relação a circuitos lógicos de vários níveis. Isso pode tornar atraente implementar algumas funções em software ou microcódigo ao invés de puramente em hardware.

Normalmente os blocos básicos complementam a LUT e o flip-flop com caminhos para acelerar a propagação do "vai um" quando estes blocos fazem parte de somadores ou de contadores. Estes caminhos especiais normalmente não fazem uso da interconexão normal da FPGA e só podem ser aproveitados quando os blocos básicos são usados numa ordem bem específica (elementos vizinhos numa única coluna, por exemplo). Uma função aritmética que costuma ocupar grandes frações das FPGAs quando implementada com blocos básicos normais é a multipli- 


\begin{tabular}{|c|c|c|c|c|c|}
\hline Fabricante & Família & $\begin{array}{c}\text { Portas } \\
\text { Lógicas } \\
\text { (mil) }\end{array}$ & $\begin{array}{l}\text { LUTs } \\
\text { (mil) }\end{array}$ & $\begin{array}{c}\text { Memória } \\
\text { (Kbits) }\end{array}$ & $\begin{array}{l}\text { Preço } \\
\text { (US\$) }\end{array}$ \\
\hline \multirow{9}{*}{ Altera } & Cyclone & & $2,9-20$ & $60-295$ & $10,70-108,57$ \\
\hline & Cyclone II & & $4,6-68$ & $120-1152$ & $12,80-422,40$ \\
\hline & Cyclone III & & $10,3-119$ & $414-3888$ & $12,80-3993,00$ \\
\hline & Cyclone IV & & $6-150$ & $270-6480$ & \\
\hline & Stratix & & $10,5-79$ & $920-7427$ & $190,00-9965,02$ \\
\hline & Stratix II & & $15,6-179,4$ & 419-9383 & $190,00-9435,02$ \\
\hline & Stratix IIGX & & $33,8-132,5$ & 1369-6747 & $490,00-7783,60$ \\
\hline & Stratix III & & $47,5-338$ & $1836-16272$ & $460,00-11427,96$ \\
\hline & Stratix IV & & $70-813$ & $6462-23130$ & 8449,99-9660,03 \\
\hline \multirow{13}{*}{ Xilinx } & Spartan II & $15-200$ & $0,4-5$ & $16-56$ & $7,10-45,00$ \\
\hline & Spartan IIE & $50-600$ & $1,7-5$ & $32-56$ & $12,55-170,00$ \\
\hline & Spartan 3 & $50-5000$ & $1,7-75$ & $72-1872$ & $10,10-85,60$ \\
\hline & Spartan 3E & $100-1600$ & $2-33$ & $72-648$ & $9,48-70,08$ \\
\hline & Spartan 3A & $50-1400$ & $1,6-25$ & $54-576$ & $5,52-70,92$ \\
\hline & Spartan 3AN & $50-1400$ & $1,6-25$ & 54-576 & $8,94-78,06$ \\
\hline & Spartan 3A DSP & $1800-3400$ & $37-54$ & $1512-2268$ & $51,72-93,48$ \\
\hline & Spartan 6 & & $3.8-147$ & $216-4824$ & \\
\hline & Virtex II & $40-8000$ & $0,5-104$ & $72-3024$ & $80,65-4177,01$ \\
\hline & Virtex II Pro & & 3-99 & 216-7992 & $126,00-7937,02$ \\
\hline & Virtex 4 & & $13,8-200$ & 864-9936 & $154,80-10165,20$ \\
\hline & Virtex 5 & & 30-331 & $1152-11664$ & $240,00-11734,80$ \\
\hline & Virtex 6 & & $74-760$ & $5616-32832$ & \\
\hline
\end{tabular}

Tabela 2.3: Características de algumas FPGAs disponíveis atualmente

cação. Algumas das maiores FPGAs incluem um ou mais processadores, mas a solução mais popular é a implementação de processadores usando os blocos lógicos e de memória normais do circuito. Este tipo de processador é conhecido como "soft core".

A tabela 2.3 mostra as famílias atuais da Altera e da Xilinx. O número de portas lógicas equivalentes era bastante usado pela Xilinx e facilitava comparações com ASICs, mas era uma medida meio subjetiva. Já o número de elementos lógicos é mais direto, sendo teoricamente suficiente a contagem de tabelas de busca (LUTs). A evolução da tecnologia complicou um pouco esta situação, mas assim mesmo a Xilinx passou a adotar esta medida tradicionalmente usada pela Altera, como pode ser visto na tabela 2.3. Os preços mostrados foram obtidos no catálogo da Digikey de novembro de 2009 e indicam preços para a compra de componentes individuais. Os fabricantes costumam fornecer cotações para grandes volumes com descontos significativos em relação aos números da tabela. Considerando que em 1999 uma Virtex da Xilinx de 300 mil 
portas custava US\$650 nestas mesmas condições, fica clara a razão das FPGAs terem passado de simples protótipos na produção de ASICs para componentes usados em produtos fabricados em média e até grande escala. A computação reconfigurável se beneficia diretamente desta transformação.

Os dois principais fabricantes dividem suas famílias nas de baixo custo (Cyclone para Altera e Spartan para Xilinx) e nas de alto desempenho (Stratix e Virtex, respectivamente). A competição acirrada faz com que as famílias equivalentes tenham preços e características quase iguais.

\subsection{Reconfiguração Dinâmica e Parcial}

A reconfiguração parcial e dinâmica era uma das características mais interessantes da família 6000 da Xilinx, que foi originalmente desenvolvida como um trabalho acadêmico, depois comercializado pela Algotronix que foi comprada pela Xilinx. Os bits da configuração podiam ser endereçados como memória normal por um dispositivo externo, como um microprocessador. Estes bits podiam ser alterados mesmos durante a operação da FPGA e apenas a parte alterada era afetada pela mudança.

Com a retirada da XC6000 do mercado muitos projetos interessantes de hardware evolutivo e de computação reconfigurável ficaram muito mais complicados. Em sistemas com mais de uma FPGA, como em Teixeira (2002), é possível trocar a configuração de uma das FPGAs sem perturbar as demais. A introdução da Virtex trouxe de volta uma forma mais limitada de configuração parcial que está presente em todos os produtos posteriores da Xilinx. O arquivo de configuração deixou de ser uma seqüência única de bits mas é agora um conjunto de quadros ("frames") independentes. Cada quadro tem um endereço indicando que parte da FPGA que será programado por ele, de forma que os quadros podem ser enviados fora de ordem, como detalhado em Xilinx (2007).

Para certos componentes, como a Virtex II, 4 e 5, a Xilinx garante que uma reconfiguração parcial, que siga certas regras de compatibilidade com a programação anterior, pode ser carregada na FPGA sem perturbar o funcionamento do componente. Isto permite a reconfiguração dinâmica onde parte da FPGA opera normalmente enquanto outra parte está sendo trocada. Em 
componentes com a opção ICAP nem é necessário um elemento externo: a própria FPGA pode gerar os bits de um quadro.

A figura 2.2 mostra a metade superior da Virtex 4 XC4V25LX que, é uma das que está sendo usada neste projeto. A metade inferior é espelhada em relação à superior, de modo que as duas "linhas 0" são vizinhas. Na Virtex, Virtex II e todas as Spartan um quadro fornece a configuração de uma coluna inteira. Como os blocos de entrada e saída dão uma volta completa no componente, cada coluna tem dois blocos deste tipo (um bem embaixo e outro em cima) além de blocos lógicos. Outras colunas contém blocos de memória. Na Virtex 4 em diante, cada coluna tem apenas um tipo de bloco. Além disso, um quadro configura apenas uma fração de uma coluna, como indicado na área escura da figura 2.2. O endereço de um quadro indica a coluna, metade superior/inferior e a linha, formando uma região única com área de 16 blocos lógicos.

Em Sedcole (2006), a capacidade da FPGA calcular os bits usados para configurar uma parte de uma coluna é usado para reconfigurar áreas ainda menores que 16 blocos de altura. A função Ou Exclusivo determina a diferença entre a programação anterior e a nova e evita alterar os bits das partes que não devem ser afetadas.

Para que a reconfiguração parcial funcione é necessário que a comunicação entre o bloco que está sendo trocado e o resto do sistema seja bem padronizado. Um conjunto bem limitado de "macros de barramento" precisa ser usado e as ferramentas devem usar apenas os blocos lógicos corretos. O nível de controle que o projetista precisa sobre a operação detalhada das ferramentas é muito maior do que em projetos normais. 


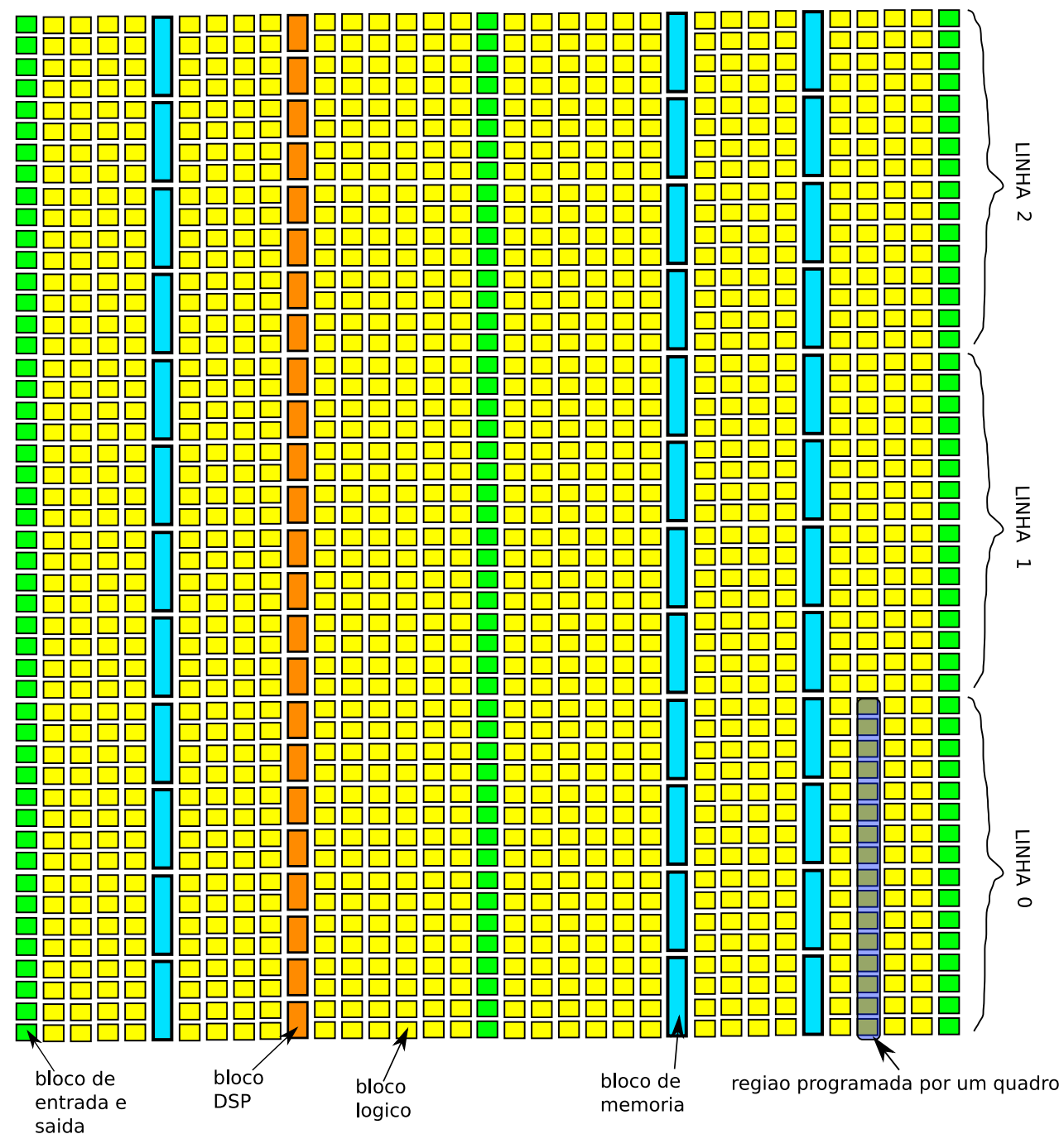

Figura 2.2: Metade superior do XC4V25LX da Xilinx 


\section{CAPÍTULO}

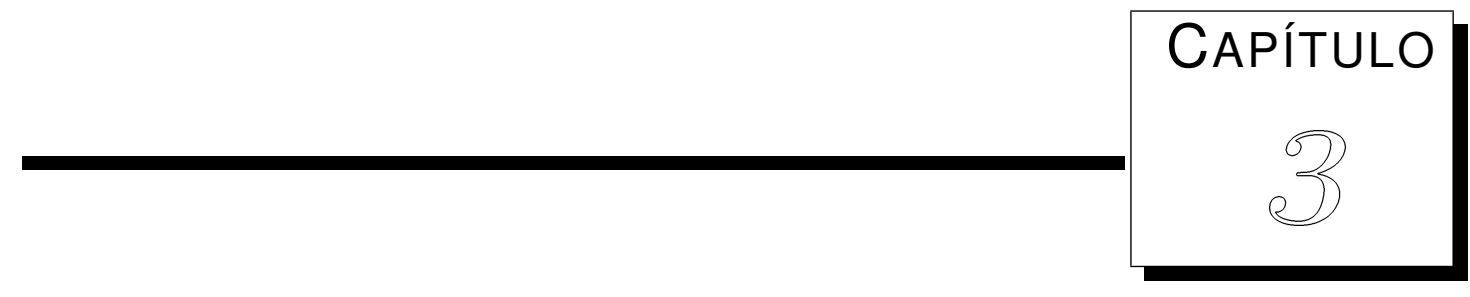

\section{Desvio de Obstáculos}

Robôs móveis precisam da capacidade de navegação por diferentes ambientes. Para isso podem usar um mapa predefinido, mas para robôs produzidos em massa será necessário que o mapa seja gerado pelo próprio robô como parte de sua operação normal. Um componente da tarefa de navegação é a determinação da posição do robô no mapa a cada instante. Enquanto a combinação das duas tarefas (conhecido como "SLAM" do inglês "Simultaneous Localization And Mapping" ou localização e mapeamento simultâneos Thrun et. al. (1998)) aumenta dramaticamente a complexidade de cada uma, o resultado é um sistema que é muito mais natural para as pessoas usarem do que ter que explicitamente fornecer mapas, ou então ter que primeiro participar de uma ou mais sessões de treinamento antes da operação normal do aparelho.

Uma escolha óbvia para a tarefa de localização é o uso de sensores internos. Giroscópios e odômetros podem indicar alterações relativas na posição enquanto que o GPS pode ser usado para descobrir a posição absoluta. Infelizmente, o GPS depende da visada de três ou mais satélites e isso não funciona dentro de casa ou mesmo em ambientes urbanos cheios de prédios altos. E sua precisão pode ser boa o suficiente para ajudar um motorista a navegar pelas ruas certas mas não basta para determinar se o robô está na cozinha ou na sala (supondo que o mapa de precisão suficiente esteja disponível). Os sensores de posição relativa são ainda piores já que 
o seu erro vai se acumulando ao longo do tempo. Além de tudo isso, um mapa nunca vai refletir alterações dinâmicas no ambiente como pessoas, animais, outros robôs, automóveis, portas que podem estar abertas ou fechadas e assim por diante. Por isso é fundamental que o robô inclua sensores que permitam que ele "olhe para fora".

\subsection{Detetores de profundidade}

Existem muitos tipos de sensores que poderiam ser usados para guiar um robô por um ambiente Everett (1995), mas os detetores de profundidade via laser são a escolha mais popular atualmente. Ele fornecem medidas extremamente precisas da distância entre o robô e o primeiro obstáculo em determinada direção. Ao varrer o laser pela cena, o espaço ao redor do robô pode ser diretamente observado como uma densa "nuvem" de pontos 3D que podem ser convertidos para modelos sólidos ou um conjunto de superfícies com um modesto processamento adicional. Para a navegação e desvio de obstáculos pode ser suficiente varrer o laser horizontalmente tendo como resultado um simples mapa 2D da área.

\begin{tabular}{c|ccccc}
\hline & laser & radar & sonar & câmera estéreo & câmera mono \\
\hline custo & alto & alto & médio & médio & baixo \\
precisão & muito alto & alto & baixo & médio & baixo a médio \\
alcance & curto & médio & curto & médio & médio \\
processamento & baixo & médio & baixo & alto & alto \\
\hline
\end{tabular}

Tabela 3.1: Sensores externos para SLAM

Infelizmente, um sistema típico baseado em laser custa mais de cinco mil dolares atualmente como indicado na tabela 3.1, de modo que não são uma opção viável para aplicações de baixo custo. Estas, normalmente, usam um conjunto de sonares, mas as informações que isto gera é muito grosseiro comparado com os laser, além de ser mais indireta, o que complica o processamento inicial.

O radar é uma outra opção com características semelhantes às do laser. O seu alto custo impede seu uso em aplicações mais populares mas existe muita experiência no uso militar e aeronáutico deste aparelho. Enquanto vegetação pode parecer um terreno sólido para o laser, o radar pode atravessá-la (dependendo da freqüência do equipamento e das caraterísticas das plantas como estudado em Matthies et. al. (2003)) e indicar obstáculos sólidos do outro lado. 


\subsection{Sistemas baseados em Visão}

A explosão do mercado consumidor de câmeras digitais (fotográficas, de vídeo, webcams e celulares mais sofisticados) na última década abaixou os preços dos sensores CCD e também dos CMOS ficando abaixo dos cem dolares e, em alguns casos, até dos dez dolares. Isso faz o uso de uma ou mais câmeras num robô uma escolha óbvia. Mas, dado o quanto do cérebro humano é dedicado ao processamento de imagens, fica claro que os recursos computacionais necessários para transformar as imagens de entrada em informação que pode se usar não são triviais.

Ao contrário do detetor de distância via laser, uma câmera não fornece nenhuma informação sobre a distância para os objetos. Ela fornece informações sobre luminosidade e cor para um grande número de pontos de uma cena ao mesmo tempo, e isso pode permitir aplicações que não são possíveis no mundo restrito dos sonares e lasers.

O ideal seria o projeto de um circuito integrado que combinasse a detecção da imagem com o preprocessamento da mesma Rodriguez-Vazquez et. al. (2001) de uma forma semelhante ao que faz o olho humano. Infelizmente, isso só seria prático para uma aplicação com larga escala de produção. Assim, projetos como este transferem dados serialmente de uma câmera "burra" para uma FPGA onde blocos dedicados de hardware precisam trabalhar muito para recuperar a estrutura 2D da imagem.

\subsection{1 "Sonares Visuais" baseados em aprendizado de máquina}

Para muitas aplicações de robótica móvel, é possível adotar várias restrições em relação ao ambiente visto pela câmera para facilitar a extração de informação sobre obstáculos:

- distância pequena e constante em relação ao solo: se não for uma aeronave não tripulada, o robô está quase sempre no chão.

- o solo é plano: isso é particularmente verdadeiro em ambientes internos, mas também vale em parte para calçadas e ruas. 
- o robô não se inclina em nenhuma direção: depende do solo ser realmente plano e não ter pequenas pedras ou buracos.

- obstáculos são perpendiculares ao solo e encostam neste: não vale para coisas como galhos de árvores ou topo de mesas mas quando estas coisas são mais altas que o robô elas deixam de ser um problema.

Quando estas coisas são todas verdadeiras, a maioria dos pixels da linha mais de baixo das imagens capturadas pela câmera são do chão. Seguindo verticalmente pixels com a mesma textura numa coluna até que mude a textura para outro padrão, pode ser determinado a linha da imagem que contém a base do obstáculo mais próximo em determinada direção. Por uma simples semelhança de triângulos, a distância entre o obstáculo e o robô é calculada. Aplicando este sistema para cada uma das a colunas da imagem se chega à informação equivalente à fornecida por um laser ou conjunto de sonares.

Técnicas evolutivas foram usadas em Martin (2006) para gerar os melhores algoritmos para este tipo de reconhecimento de padrões. Uma série de imagens de treinamento de ambientes com corredores e escritórios vistos da altura do robô foram manualmente marcadas pelos pesquisadores. Para cada coluna foi determinado a diferença de altura em pixels entre o obtido pelo algorítmo e o observado pelos seres humanos (que encontram facilmente onde o chão termina e a parede começa mesmo em fotos em preto e branco como estas). O critério de otimização era obter o menor erro para a soma de todas as colunas de todas as imagens de teste.

Em Michels et. al. (2005) foram usadas muitas imagens de ambientes externos para as quais a informação sobre a distância para os obstáculos de cada coluna foram obtidas por um sistema de laser. As faixas verticais da imagem foram codificadas com as saídas de um conjunto de filtros e uma simples regressão linear foi usada para treinar o sistemas para fornecer uma resposta mais próxima possível da do laser.

Este tipo de solução exige muita computação para a fase de treinamento, mas como esta não tem nenhuma limitação de tempo é possível usar computadores até mesmo relativamente modestos para realizá-la. A grande vantagem é que a fase de execução não envolve muitos cálculos (pelo menos quando comparada às técnicas descritas a seguir) e é possível usar um processador de baixo desempenho, mas com baixo custo e baixo consumo de energia. O maior 
problema desta alternativa é que a resposta é imprevisível se o robô encontrar imagens muito diferentes das usadas na fase de treinamento. Isso pode ocorrer se uma ou mais das restrições descritas não forem respeitadas ou mesmo devido a mudanças nos tipos de pisos.

\subsubsection{Visão Estéreo}
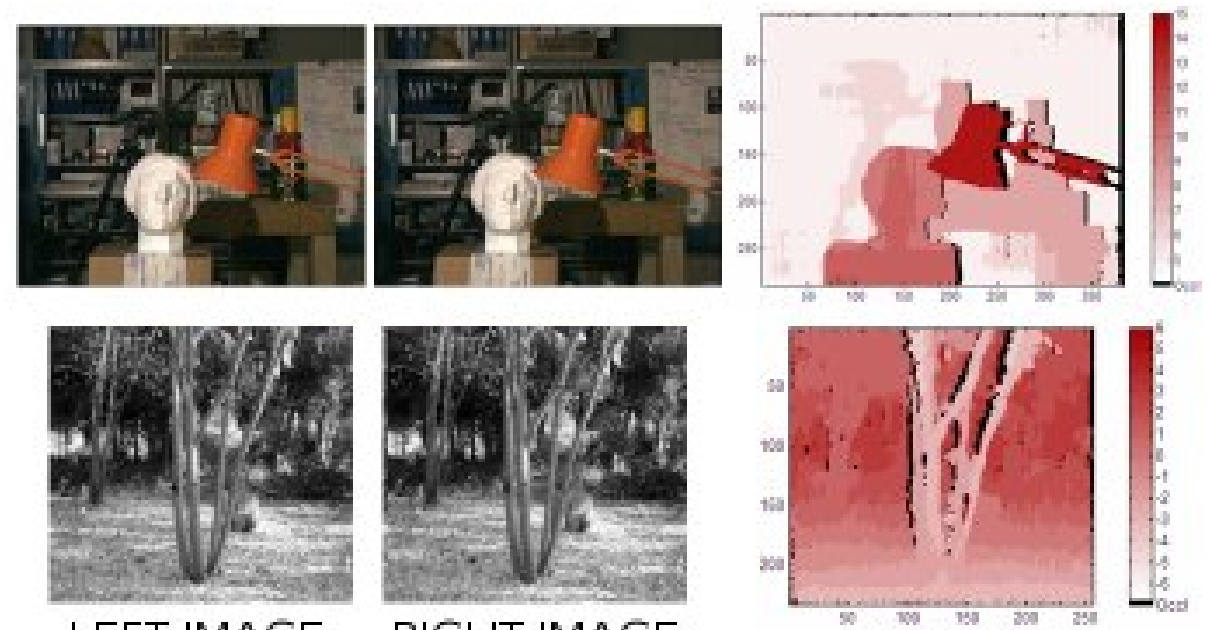

LEFT IMAGE

RIGHT IMAGE

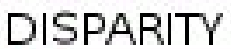

Figura 3.1: Calculo de pronfundidade dado pares de imagens usando o software livre openvis3D (http://code.google.com/p/openvis3d/)

Observando a navegação de seres humanos e outros animais, fica fácil perceber o papel importante da visão estereoscópica. Com duas ou mais câmeras com uma separação conhecida entre elas, um mesmo ponto do espaço tridimensional aparece em pixels diferentes das imagens captadas. A distância entre os pixels pode ser convertida em informação de profundidade por um processo semelhante ao dos métodos descritos logo acima, como mostra a figura 3.1.

Encontrar a correspondência entre pixels é bastante complicado. Com a restrição de que as câmeras estão perfeitamente paralelas e com o eixo horizontal de uma passando pela outra, os pixels correspondentes estarão na mesma linha da imagem, o que reduz bastante a busca necessária. Já em Lucas e Kanade (1981) era desenvolvida uma solução mais genérica, que é muito importante na prática em função da dificuldade mecânica de se manter as câmeras sempre totalmente alinhadas. Este sistema iterativo baseado na derivada da intensidade da imagem é capaz de tolerar translações em qualquer direção e até rotações e pode simultaneamente calcular as posições dos objetos na cena e o alinhamento real das câmeras. 


\subsubsection{Fluxo Óptico}

Movimentos de objetos no espaço tridimensional em relação à câmera provocam movimentos correspondentes em duas dimensões nas imagens capturadas, o que chamamos de fluxo óptico. Um conceito relacionado é o do fluxo de imagens, que representa os movimentos de pixels necessários para que uma imagem se transforme em outra. Dados vários pixels com exatamente o mesmo valor, fica claro que para um único fluxo óptico podem existir diferentes fluxos de imagem (mais de um movimento de pixel diferente resulta em imagens idênticas).

Para aplicações de compressão de filmes, o cálculo de um fluxo de imagens é tão bom quanto outro fluxo. Mas para extrair informações sobre o mundo externo seria necessário usar o fluxo óptico como ponto de partida. Infelizmente este é impossível de ser obtido usando apenas pares de imagens e por isso o resto deste texto seguirá o costume de se falar em fluxo óptico quando o que está sendo calculado é na verdade um fluxo de imagens.

Algumas aplicações do algorítmo de fluxo óptico na robótica móvel são:

- observação de obstáculos em rota de colisão com o robô usando a divergente do campo de fluxo óptico

- centralização em corredores pelo balanceamento do fluxo óptico na metade esquerda da imagem do o da metade direita

- segmentação de imagens usando as discontinuidades do fluxo óptico indicando um objeto se movendo em relação a um fundo mais distante

As duas primeiras aplicações foram demonstradas em Souhila e Karim (2007). Uma vantagem do fluxo óptico é que uma vez calculado ele pode servir de entrada para mais de uma aplicação ao mesmo tempo.

O fluxo óptico e a visão estéreo podem ser combinados para se aproveitar as vantagens de cada um de Nagy Koves Hrabar (2006). Neste caso um helicóptero autônomo usa o fluxo óptico para ficar no centro entre duas paredes enquanto voa em segmentos parecidos com corredores (típicos em ambientes urbanos com prédios altos) e depois muda para a visão estereo quando precisa lidar com obstáculos que se aproximam da frente da aeronave. Enquanto que a visão 
estéreo fornece os melhores resultados quando as câmeras estão paradas, o fluxo óptico é tanto mais preciso quando mais rápido se movimentar a câmera.

Horn e Schunck (1980) estabeleceram os princípios usados pelos algorítmos modernos de fluxo óptico. A equação 3.1 representa uma textura que não varia no tempo e que se move paralela ao plano da imagem que a está amostrando.

$$
\frac{\partial I}{\partial x} \frac{d x}{d t}+\frac{\partial I}{\partial y} \frac{d y}{d t}+\frac{\partial I}{\partial t}=0
$$

Chamando $d x / d t$ de $u$ e $d y / d t$ de $v$, o vetor $(u, v)$ representa o fluxo óptico em determinado ponto da imagem. Chamando as derivadas parciais de $I$ em $x, y$ e $t$ de $I_{x}, I_{y}$ e $I_{t}$, respectivamente, a mesma relação pode ser escrita como na equação 3.2.

$$
I_{x} u+I_{y} v+I_{t}=0
$$

Isto é usado na equação 3.3 para que a magnitude do fluxo óptico ao longo do gradiente de brilho seja calculado. Infelizmente não é possível calcular a magnitude do mesmo perpendicular ao gradiente do brilho (ao longo de linhas de brilho constante). O fato da equação 3.2 única ter duas incógnitas é a causa deste problema.

$$
|(u, v)|_{\text {gradiente de brilho }}=-\frac{I_{t}}{\sqrt{I_{x}^{2}+I_{y}^{2}}}
$$

A solução adotada em Horn e Schunck (1980) foi a de supor restrições adicionais aos vetores de fluxo óptico. No caso deles foi usado a idéia de que os vetores devem variar suavemente ao longo da imagem. Isto permite uma solução iterativa onde os vetores são calculados nos pontos onde o gradiente permite e em sucessivas passagens os vetores dos vizinhos também são calculados até que todos os valores desconhecidos sejam eliminados.

Um conjunto diferente de restrições leva a um algorítmo de fluxo óptico diferente, e este tem sido um tópico bastante explorado nas últimas décadas. Quando Barron et. al. (1994) fizeram uma comparação de qualidade de resultados de algorítmos de fluxo de dados, puderam agrupá-los em quatro grupos descritos a seguir. Tradicionalmente, todos os trabalhos desta área usaram imagens em preto e branco. Mas uma maneira alternativa de se ter elementos suficientes 
para resolver a equação 3.2 é o uso de um segundo canal independente para a imagem. Uma imagem colorida fornece três canais independentes, o que foi explorado em Golland e Bruckstein (1997) e recentemente testado em Aires et. al. (2008). A razão óbvia para preferir imagens monocromáticas é reduzir para um terço a quantidade de cálculos envolvidos. No caso de uma implementação em hardware, como deste trabalho, é possível ter três blocos iguais operando em paralelo para se obter os resultados de maneira igualmente rápida. Mas o custo da eletrônica é triplicado.

\section{Técnicas diferenciais}

O método original de Horn e Schunck (1980) e muitos dos que seguiram avaliam as derivadas das imagens de entrada para impor restrições adicionais. Algumas alternativas usam derivadas de segunda ordem. O grande problema de diferenciação numérica é que qualquer ruído terá um efeito exagerado nos resultados. Por isso sempre são usados filtros espaciais e temporais nas entradas para garantir que seja possível calcular as derivadas subtraindo valores de pixels vizinhos.

No cálculo iterativo da solução, geralmente existe algum parâmetro que pode ser ajustado para selecionar a velocidade de convergência como o $\alpha$ da equação 3.4. Uma velocidade alta reduz a quantidade de cálculos necessários mas pode gerar resultados piores. O uso de cem passagens por par de imagens é bem típico, o que inviabiliza a operação em tempo real. Note que não são usados $u$ e $v$ da passagem anterior e $\operatorname{sim} \bar{u}$ e $\bar{v}$ representando as médias regionais em torno de cada ponto.

$$
\begin{aligned}
& u^{k+1}=\bar{u}^{k}-I_{x}\left[\frac{I_{x} \bar{u}^{k}+I_{y} \bar{v}^{k}+I_{t}}{\alpha^{2}+I_{x}^{2}+I_{y}^{2}}\right] \\
& v^{k+1}=\bar{v}^{k}-I_{y}\left[\frac{I_{x} \bar{u}^{k}+I_{y} \bar{v}^{k}+I_{t}}{\alpha^{2}+I_{x}^{2}+I_{y}^{2}}\right]
\end{aligned}
$$

\section{Técnicas de convolução}

As técnicas de comparação de áreas comparam cada região de uma imagem com todas as possíveis regiões da outra para achar o deslocamento que gera o menor erro total. Este erro pode ser 
calculado de diversas maneiras, como com uma correlação cruzada, uma soma dos quadrados das diferenças ou soma dos valores absolutos das diferenças. Esta última opção foi a adotada neste trabalho por não envolver operações como multiplicações que são muito custosas quando implementadas em hardware.

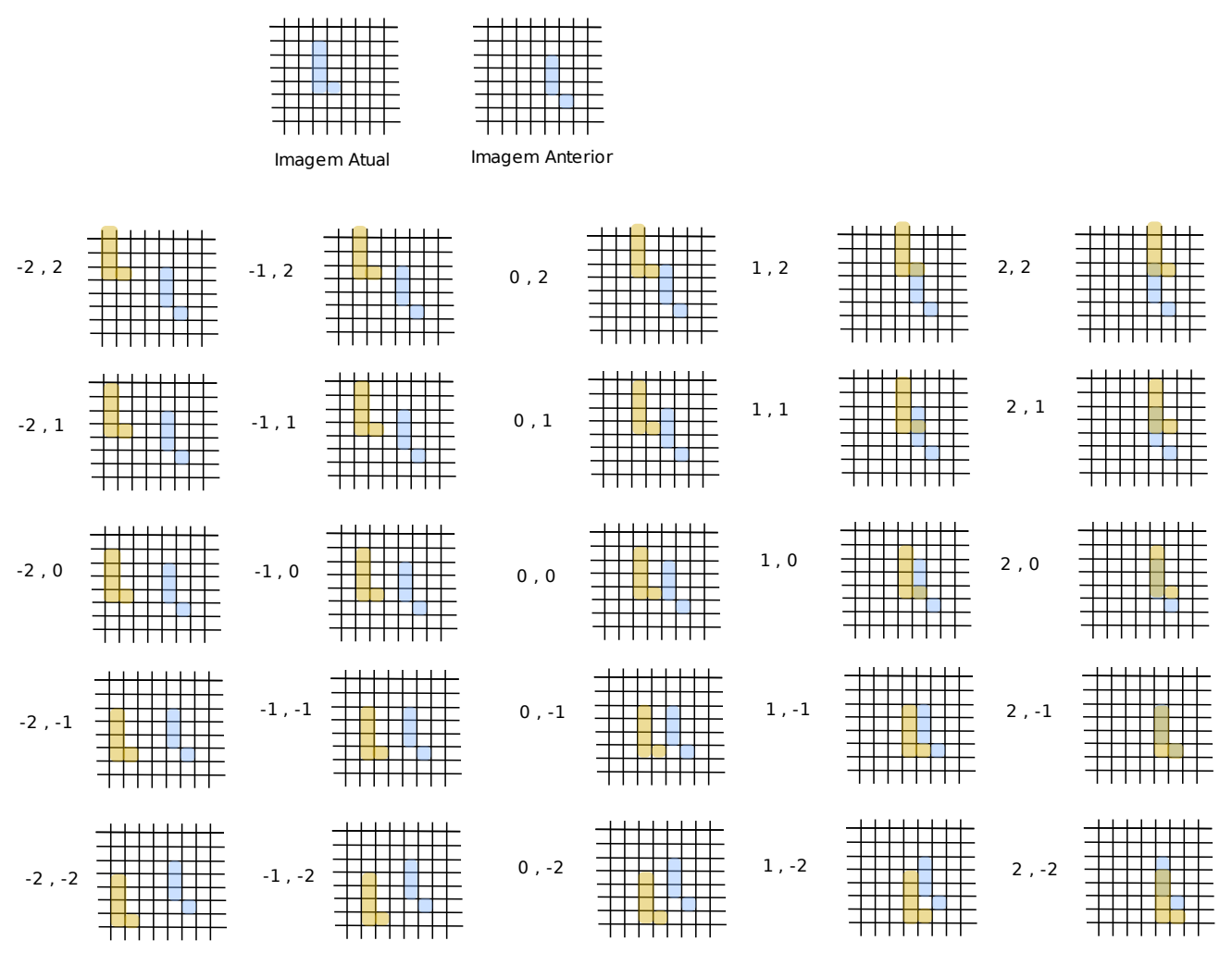

Figura 3.2: A parte de cima mostra dois pedaços de imagens a serem comparados e a parte de baixo mostra 25 deslocamentos possíveis

A figura 3.2 mostra a operação básica da correlação. Um pedaço da imagem atual é comparado com pedaços do mesmo tamanho na imagem anterior. Diferentes vetores de deslocamentos são experimentados para determinar o que reduz ao máximo as diferenças entre as duas imagens. Na figura a imagem atual deslocada é mostrada em outra cor para deixar mais claro o que está sendo comparado, mas na realidade os pontos devem ter cores semelhantes (como mostrado na parte de cima da figura). O deslocamento $(2,-1)$ da imagem atual faz com que ela tenha 4 pontos em comum com a imagem anterior, o que é o melhor resultado. O fluxo óptico é definido como o deslocamento de uma imagem para a seguinte, de modo que a resposta é 
$(-2,1)$. Este vetor é a resposta apenas para o ponto central dos trechos comparados e para cada outro ponto uma região do mesmo tamanho em torno deste ponto deve ser escolhida e todo o processo repetido. Neste projeto foram usadas áreas de apenas 3 por 3 pixels para comparação para reduzir a quantidade de hardware necessário uma vez que o ganho de precisão ao se passar de 3 por 3 para 5 por 5 é pequeno quando comparado com o aumento de 1 por 1 para 3 por 3 .

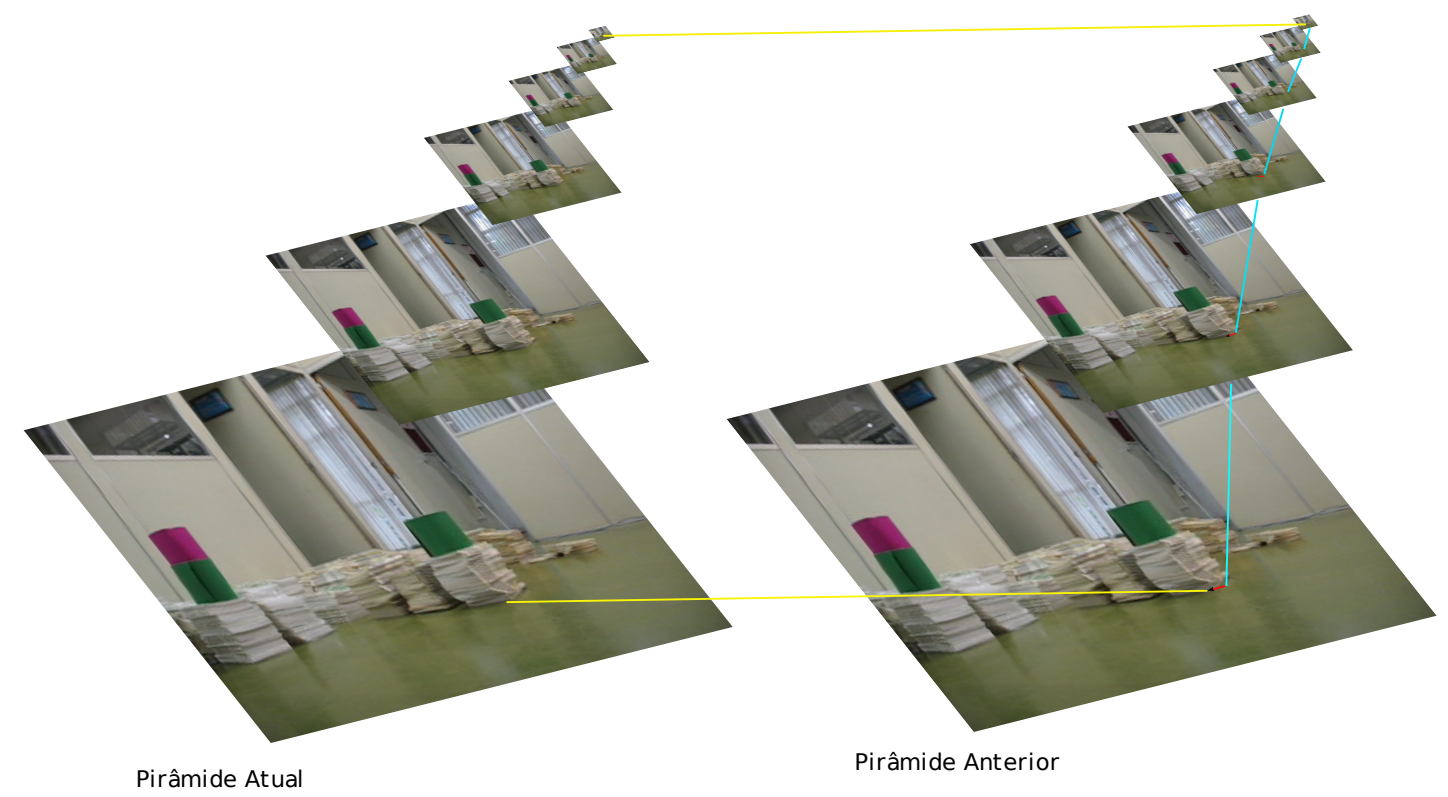

Figura 3.3: Uso de pirâmides de imagens para reduzir o espaço de busca para deslocamentos grandes

Como cada região de uma imagem é operada com cada região da outra imagem, a característica geral destes algorítmos é de uma convolução entre as duas imagens. O custo computacional desta busca completa é extremamente elevado. Uma solução, mostrada na figura 3.3, é trabalhar com uma pirâmide de imagens, cada nível com metade da resolução do nível mais de baixo. Deslocamentos de um pixel num nível correspondem a deslocamentos de 2 pixels no nível abaixo, e de 8 pixels três níveis abaixo. Existe uma perda de qualidade nos resultados comparado à busca completa, mas o número de testes cai de $N^{2}$ para aproximadamente 
$9 \frac{1-1 / 4^{\log _{2} N}}{1-1 / 4}$ no caso em que são feito 9 testes em cada ponto de cada nível, o que corresponde a uma busca apenas nos vizinhos imediatos de cada ponto. No caso de deslocamentos de até 32 pixels, seria necessário fazer $65 \times 65=4225$ comparações, cada uma das quais exige 27 subtrações e outras operações. Com as pirâmides são feitas $9 \times \frac{1-1 / 4^{6}}{3 / 4}=11.998$ comparações.

\section{Técnicas baseados em energia}

Os métodos baseados em frequiência passam os dados de entrada por uma série de filtros, cada um calibrado para uma escala e velocidade de translação de imagem diferentes. Observando a relação entre as energias de saída dos filtros é possível determinar as características da entrada.

O processamento em pirâmide também reduz bastante a quantidade de cálculos necessários para esta técnica. A alternativa seria um número maior de filtros com escalas cobrindo o tamanho completo das imagens. Considerando que normalmente os filtros de maior tamanho tem saída zero a maior parte do tempo mas são eles que ocupam a maior parte do processamento, é muito melhor usar filtros menores em níveis mais altos de uma pirâmide para se obter o mesmo resultado.

\section{Técnicas baseadas em fase}

Como no caso anterior, estas técnicas passam os dados de entrada por uma série de filtros mas é a resposta em fase a cada filtro que é relacionada ao fluxo óptico. Técnicas que observam passagens por zero são consideradas parte deste grupo.

\section{Comparação das técnicas}

Barron et. al. (1994) foi a primeira comparação detalhada e objetiva dos vários algorítmos de fluxo óptico. Para isso foi necessário adotar um esquema numérico de avaliação já que a solução de mostrar para observadores humanos uma forma visual dos resultados era muito subjetiva. Dados dois campos de fluxo ópticos gerados da mesma entrada, é possível subtrair o vetor de cada ponto para se obter o erro. Faz mais sentido, no entanto, observar separadamente erros na magnitude dos vetores e erros no ângulo destes mesmos vetores.

A figura 3.4 mostra um exemplo de representação de fluxo óptico. Como cada vetor ocupa 

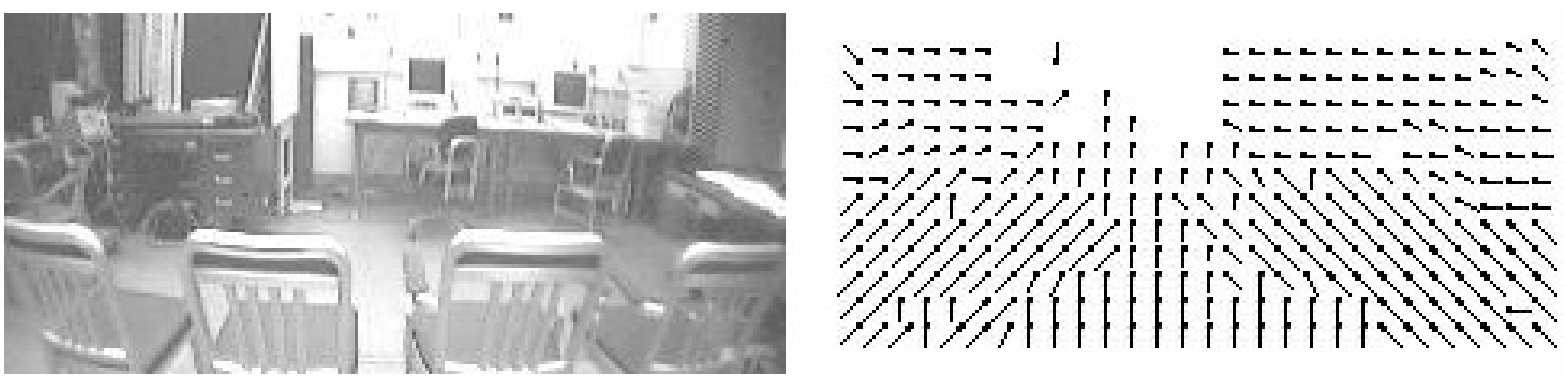

Figura 3.4: A foto da esquerda mostra umas cadeiras como vistas por um robô que se aproxima delas em Camus et. al. (1996) enquanto a da direita mostra os vetores de fluxo correspondentes (apenas em pontos bem separados para ficar mais claro)

diversos pontos na imagem para mostrar claramente seu tamanho e direção, apenas um subconjunto pode ser mostrado ao mesmo tempo. Esta é a representação esparsa do fluxo óptico. Nem todos os algorítmos calculam uma reposta para cada ponto e para os que trabalham com blocos de imagem esta representação é bem razoável. Uma alternativa é a representação densa no qual cada vetor é indicado por uma cor, o que torna possível mostrar um dado para cada pixel da imagem original. Esta é a opção usada neste trabalho com a legenda da figura 3.5 (a).

Uma complicação é a obtenção de dados sem erros para serem usados nestas comparações. Uma alternativa é o uso de imagens geradas por computador. Como existe o modelo em três dimensões que foi usado para criar a imagem, os movimentos verdadeiros no espaço são conhecidos e uma simples projeção no plano da câmera gera o fluxo óptico verdadeiro. Para os algorítmos testados são fornecidas apenas as imagens e suas saídas podem ser comparadas objetivamente com a resposta correta.

No caso de cenas naturais existem soluções para casos especiais. Em McCane et. al. (2001) foram selecionadas cenas com apenas objetos poligonais e côncavos e as cenas não tinham nenhum movimento além da própria câmera. Um programa desenvolvido por eles consegue, com a ajuda de um operador, calcular o verdadeiro fluxo óptico nestas condições.

Em Baker et. al. (2007) as cenas eram bem mais complexas com objetos flexíveis tais como panos. A solução encontrada foi cobrir os objetos com marcadores invisíveis à câmera usada para gerar os dados de teste. Ao mesmo tempo foi usada outra câmera de bem mais alta resolução e sensível apenas aos marcadores. Com estes dados foi possível calcular o verdadeiro fluxo óptico. Foram publicadas as imagens e respostas para várias cenas, enquanto que para outras cenas é necessário enviar os dados obtidos com um algorítmo a ser comparado para uma página 


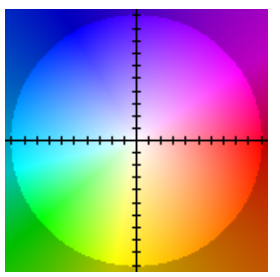

(a) Legenda

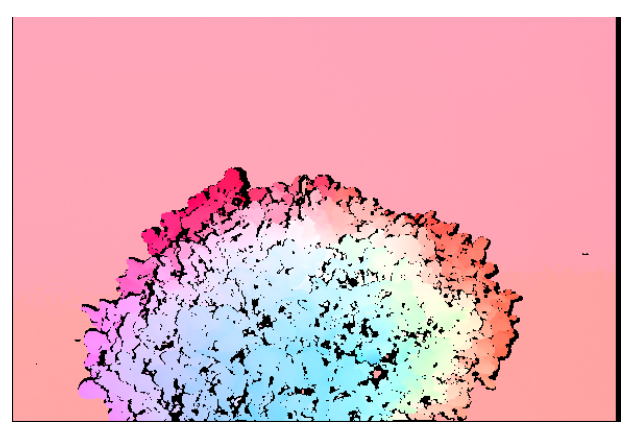

(b) Resposta

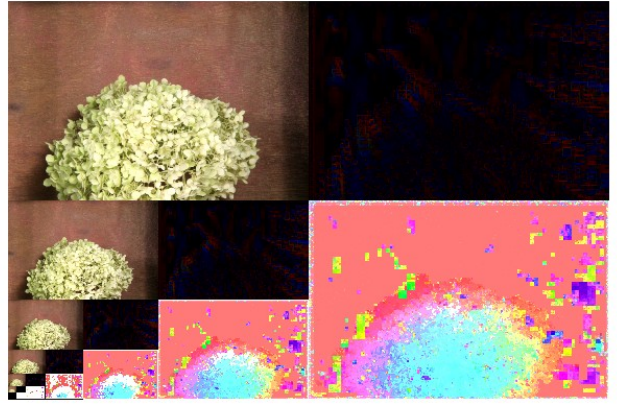

(c) Calculado

Figura 3.5: Representação de vetores de deslocamento com cores e teste do algorítmo

web criada pelos autores. As taxas de erros são geradas e disponibilizadas para o público.

A figura 3.5 (b) mostra a resposta esperada para o fluxo óptico entre os quadros 10 e 11 de um filme de uma planta aquática se movendo de uma maneira bastante complexa. As regiões em preto indicam pontos que estão encobertos numa imagem mas não na outra e para os quais não existe um fluxo óptico correto. A parte (c) da figura mostra o resultado do algorítmo deste trabalho, com a pirâmide obtida da imagem 11 à esquerda e a pirâmide do fluxo óptico à direita. Os ruídos na forma de blocos são provocados quando ocorre um erro num nível superior da pirâmide e este é ampliado nos níveis de baixo.

\section{Implementação em Hardware}

Röwekamp et. al. (1997) foi um dos primeiros estudos comparando alternativas de hardware para algorítmos de fluxo óptico. As FPGAs não foram consideradas por serem ainda muito pequenas na época.

Boa parte da pesquisa de arquiteturas de hardware para determinação de vetores de deslocamento foi feita com ênfase em compressão de vídeo, como em Yang et. al. (2009) ou Diaz et. al. (2006). Mas as diversas técnicas descritas anteriormente foram objeto de estudo para implementação em FPGAs em Arribas e Maciá (1998), Arribas e Maciá (2001) e Arribas e Maciá (2003). As limitações dos componentes disponíveis na época levaram a resultados como imagens de 50 por 50 pixels a 19 quadros por segundo. Os mesmos projetos teriam resultados bem mais usáveis se reimplementados hoje. 
Wei (2009) implementa um algorítmo de fluxo óptico baseado em tensores para representar movimentos. Com a mudança de uma placa padrão de desenvolvimento para outra com mais recursos, o algorítmo pode ser significativamente melhorado. A principal diferença na placa criada por um grupo de pesquisa da universidade do autor é a quantidade maior de memórias externas que podem ser usadas ao mesmo tempo pela FPGA. Um sistema de detecção de obstáculos usando um modelo de chão (explicado no fim deste capítulo) foi projetado mas não coube na mesma FPGA que o fluxo óptico apesar de ser um circuito relativamente pequeno.

\subsubsection{Detecção de Obstáculos usando Fluxo Óptico}

Uma vez obtido o fluxo óptico de uma seqüência de imagens, existem várias alternativas para se detectar obstáculos em rota de colisão com o robô. Cálculos de fluxo ótico não podem determinar distâncias absolutas para os objetos, uma vez que um objeto enorme (e muito longe que se aproxime rapidamente) se parece para um sistema de visão monocular exatamente igual a um pequeno objeto próximo e que se aproxime mais lentamente. Camus et. al. (1996) indica que nos dois casos o tempo para colisão seria exatamente igual, o que significa que a informação relativa já é suficiente para o sistema de desvio de obstáculos. Quando o fluxo óptico é provocado pelo movimento do próprio robô, todos os objetos tem a mesma velocidade de aproximação e neste caso é possível diferenciar objetos pequenos e próximos dos grandes e distantes.

\section{Divergente}

Qualquer campo vetorial pode ser expresso como a soma de três outros: uma média indicando a tendência geral do campo em torno de cada ponto, uma divergente indicando se os vetores estão entrando ou saindo do ponto e um rotacional que mostra se os vetores da região estão circulando em torno daquele ponto.

As operações de divergente e rotacional são definidas para campos vetoriais contínuos, as o fluxo óptico é discreto. Uma aproximação razoável é aplicar cada uma das quatro "máscaras" mostradas na figura 3.6 a uma região do campo. No caso da primeira máscara, por exemplo, uma linha horizontal passa pelo ponto para qual está sendo calculada a divergente e todos os vetores acima da linha são somados enquanto que os abaixo são subtraídos. O resultado é um 
vetor e o componente perpendicular à linha indica a tendência dos vetores de se afastarem (caso positivo) ou se aproximarem (negativo) da linha. Isto é parte da divergente. O componente paralelo à linha dá negativo se existe uma tendência dos vetores irem para para a esquerda na parte de cima e mais para a direita abaixo desta (uma rotação anti-horária).

Se a operação descrita acima for repetida para diferentes ângulos da linha de separação (os quatro mostrados na figura 3.6 são $0,90,135$ e 45 graus) e os resultados parciais somados, a divergência total e o rotacional total do campo em torno daquele ponto será obtido.
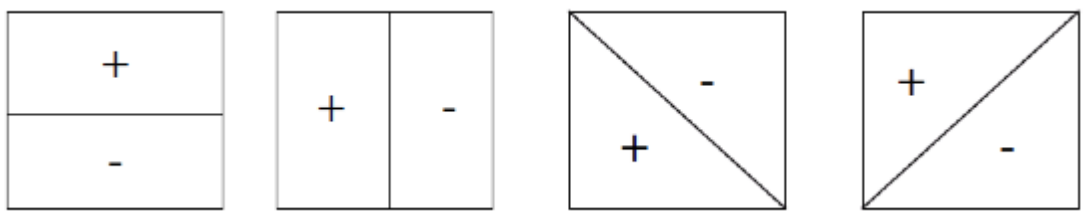

Figura 3.6: Máscaras usadas no cálculo da divergente e da rotacional

A figura 3.4 mostra um sistema bem sucedido de desvio de obstáculos que usava uma única câmera de uma estação de trabalho padrão (com capacidade computacional comparável ao processadores embarcados típicos de hoje) para calcular o fluxo ótico inteiramente em software Camus et. al. (1996). O movimento de pixels entre quadros era inicialmente calculado com apenas oito direções possíveis e apenas umas poucas magnitudes possíveis, que é a razão de saltos enormes no campo de fluxo mostrado à direita da figura 3.4. Um vetor de fluxo era calculado para cada pixel da imagem, mas a figura mostra apenas alguns deles para ficar mais legível. Alguns filtros simples, mas robustos, eram usados para se obter uma boa aproximação de um campo de fluxo contínuo, mas de resolução bem menor. Em seguida, todas as linhas eram descartadas (tendo contribuído para o passo dos filtros), menos a do meio que era a imagem dos obstáculos com a mesma altura que a câmera. A divergente dos vetores de fluxo era calculada e os maiores valores indicavam a direção de obstáculos que se aproximavam. Estas informações eram enviadas diretamente para o sistema de controle de direção.

\section{Foco de Expansão}

No caso onde a maior parte do fluxo óptico é causado pelo movimento para frente do próprio robô, este fluxo tem a maior parte dos vetores de deslocamento apontando para longe de um 
único ponto, que é conhecido como o "foco de expansão". Se não houver rotações ou deslocamentos laterais da câmera, este ponto deve ficar próximo do centro da imagem. Senão, uma simples contagem de sinais dos deslocamentos, como em Souhila e Karim (2007), pode indicar o novo foco. Outra alternativa é compensar o movimento da câmera para que o foco volte a estar no centro.

A relação entre a magnitude do vetor de deslocamento e a distância do ponto correspondente na imagem do foco de expansão indica quanto tempo este ponto levará para atingir o plano da câmera. Se isso ocorrer relativamente próximo do centro da imagem, então teremos uma colisão com o robô.

\section{Modelo do Chão}

Um obstáculo não muito interessante observado pelas técnicas anteriores é o próprio chão. Um ponto do chão visto pela câmera se aproximando vai, em determinado momento, passar por baixo do robô. O fluxo óptico gerado pelo chão é o procurado pela técnica do foco de expansão, com todos os deslocamentos se afastando de um ponto no horizonte. Em Wei (2009) isto foi aproveitado para a detecção de obstáculos. Supondo que o chão representa uma parte dominante da parte inferior das imagens, o componente vertical do fluxo óptico desta região é usado para calcular e compensar movimentos de rotação e translação da câmera. Regiões onde o componente vertical do fluxo óptico se conforma com o modelo do chão são consideradas como sendo partes do mesmo enquanto que as que tem um resultado diferente do esperado são marcadas como obstáculos. Um filtro temporal ajuda a eliminar falsos positivos. 


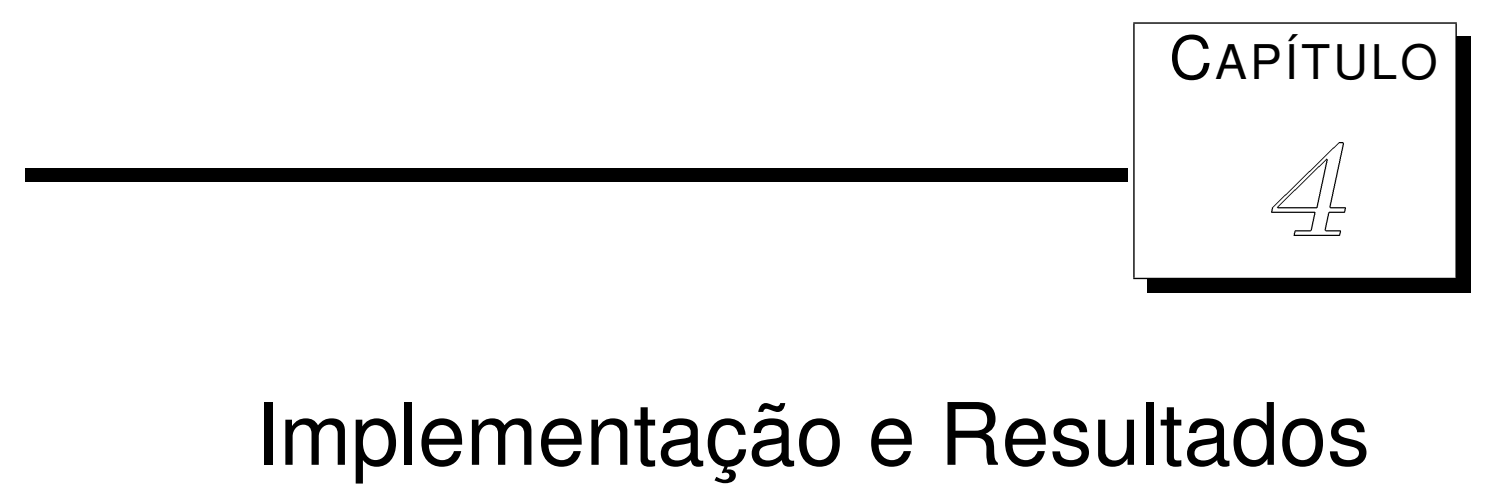

O desenvolvimento de software e hardware para a computação reconfigurável tradicionalmente passa por várias etapas usando ferramentas diferentes:

- a exploração de alto nível de alternativas para algorítmos usando um sistema como Matlab (ou Octave ou SciLab, que são os equivalentes em software livre)

- a simulação extensa da melhor opção usando uma linguagem como C para otimizar o desempenho em computadores convencionais

- implementação no computador reconfigurável com projeto ao nível de transferência de registradores (RTL) usando uma notação como VHDL ou Verilog

Este fluxo de trabalho estritamente seqüencial tem como desvantagem um tempo elevado de desenvolvimento. No caso de equipes separadas para as diferentes etapas, é possível chegar a uma solução (e ao mercado) mais cedo se o hardware e software forem desenvolvidos em paralelo.

No caso deste projeto existe muito pouco software como tal - o resto é apenas representação em alto nível do que virou hardware puro nas etapas seguintes. E como não existiram equipes, 
mas apenas um indivíduo, não existiu nenhuma ineficiência no desenvolvimento seqüencial. A alternância entre as etapas numa combinação de projeto de cima para baixo (descrito acima) e de baixo para cima, no entanto, foi de grande ajuda para evitar a exploração de algorítmos que não podem ser transformados em hardware na prática.

A primeira versão foi um diagrama de blocos de alto nível do hardware, mostrada na figura 4.1 e descrita em de Assumpção Júnior et. al. (2007) visava fazer parte de um sistema maior como o desenvolvido em Bonato (2008) com o módulo de desvio de obstáculos complementando a funcionalidade SLAM.

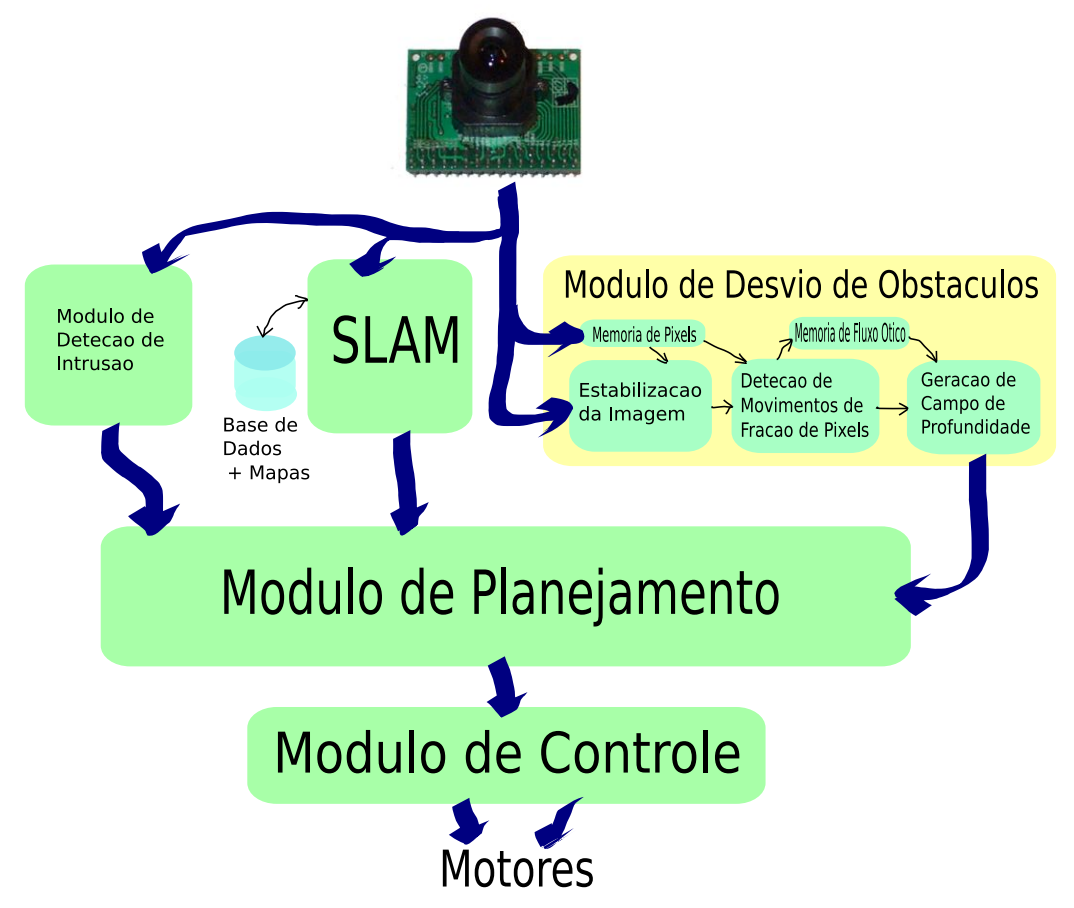

Figura 4.1: Diagrama de blocos do sistema de visão monocular dentro de um exemplo de sistema completo de controle robótico [versão de 2007]

A idéia era que com uma taxa de operação de 30 quadros por segundo ou mais, todos os fluxos ópticos teriam vetores de fração de pixel. No caso de movimentos laterais ou de rotações da câmera haveriam deslocamentos de muitos pixels. O primeiro bloco serviria para estabilizar a imagem compensando estes movimentos e ai todos os deslocamentos voltariam a ser de um pixel ou menos.

Para testar o algorítmo de cálculo de fluxo óptico para vetores de até um oitavo de píxel, foi escrito um programa em $\mathrm{C}$ capaz de receber dados de uma câmera ou de um arquivo com 
imagens previamente gravadas. Os filmes usados neste projeto foram obtidos pelo pessoal do Laboratório de Robótica Móvel (LRM) do ICMC-USP com um robô Pioneer 3 DX controlado manualmente via um joystick num ambiente com bastante obstáculos e objetos marcadores especiais (que são para outro projeto - aqui são apenas obstáculos como os demais).

O programa usa a biblioteca OpenCV apenas para ler e gravar arquivos de vídeo. Todo o processamento em si foi feito explicitamente para facilitar a tradução posterior para hardware. A busca binária por descolamentos de fração de píxel se mostrou um sucesso. Infelizmente, foram verificados deslocamentos muito maiores do que um pixel por quadro mesmo sem os problemas que o estabilizador de imagens deveria resolver.

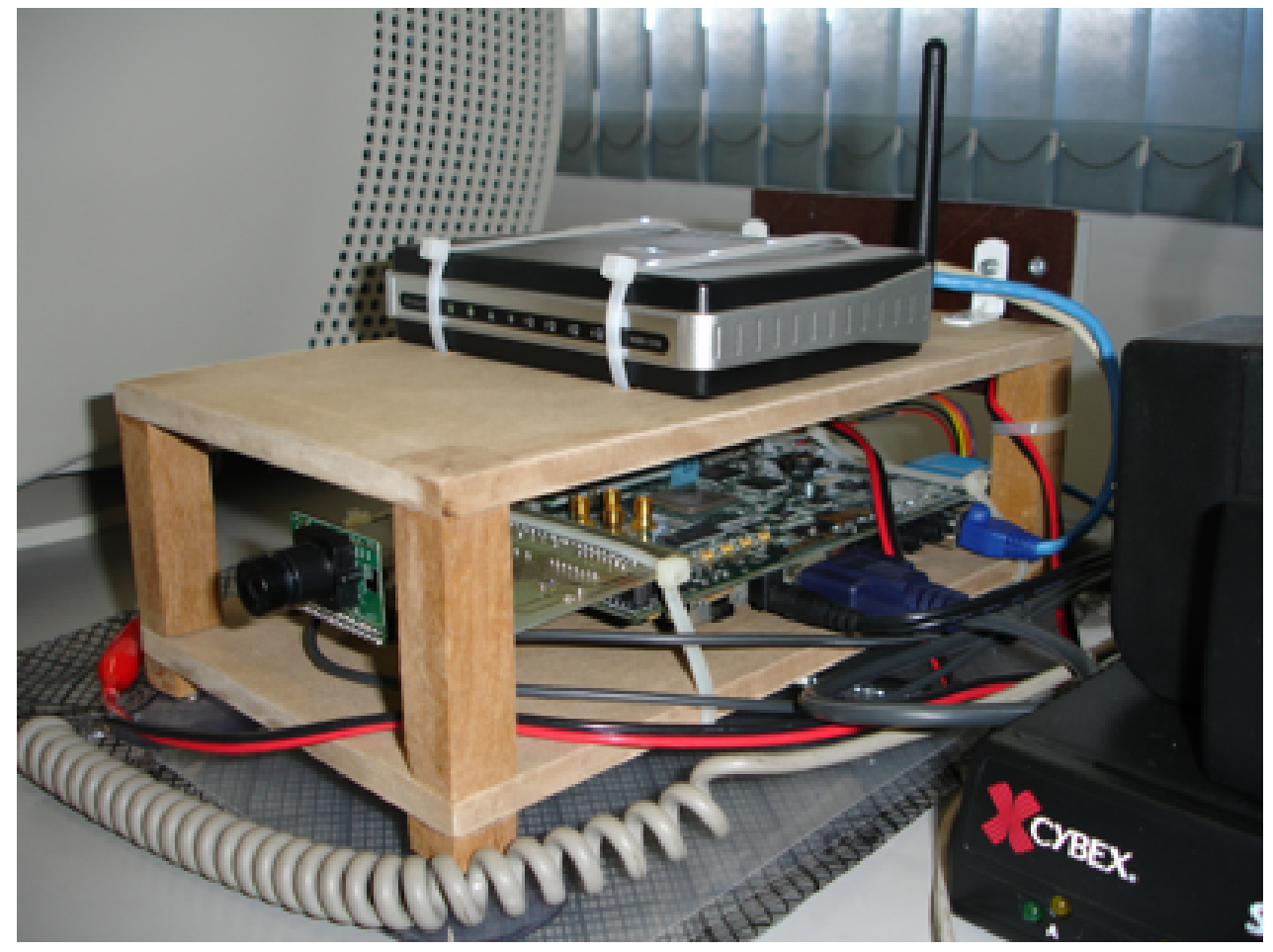

Figura 4.2: Placa de FPGA ML401 com câmera montada num suporte para uso em robôs

Uma segunda versão do diagrama de blocos do hardware foi desenvolvida e explicada em de Assumpção Júnior e Marques (2008). A principal mudança foi a inclusão de um circuito capaz de calcular fluxos de até 32 pixels por quadro em qualquer direção. O processador usado na época era o JOP (Java Oriented Processor do Schoeberl (2005)) para uma avaliação da tendência crescente do uso de Java em aplicações embarcadas. O resultado disso foi bem satisfatório, mas a quantidade bem pequena de software do projeto não justificava toda a complexidade do ambiente de desenvolvimento. O JOP foi mais tarde trocado por um processador bem mais 
simples e pequeno programado em linguagem de montagem (assembler).

A modificação do programa em C para testar o algorítmo de busca por múltiplos pixels se mostrou bastante complicada e foi decidido que seria melhor seguir o roteiro mencionado no início deste capítulo com o uso de uma linguagem como o Matlab. Foram avaliadas as opções de software livre Octave e SciLab (ambas bastante, mas não totalmente, compatíveis com o Matlab) e foi escolhido o Octave em função do manual mais didático deste.

\subsection{Octave}

As principais vantagens da linguagem de programação Octave, descrita em Eaton et. al. (2008), são sua interatividade e sua capacidade de manipulação de matrizes. Isto ela tem em comum com a antiga APL e a moderna FScript (apenas para Mac OS X), mas a Octave se destaca por ser quase totalmente compatível com o Matlab que é extensamente usado dentro das universidades.

O programa desenvolvido ficou bastante compacto e está inteiramente listado com explicações resumidas no apêndice A. Para que um filme possa ser processado, ele precisa ser convertido numa seqüência de arquivos no formato PPM, com um quadro por arquivo. Isto pode ser facilmente feito com um comando no Linux como:

ffmpeg -i MVI1020.AVI -f image2 mvi1020/robobib\%04d.ppm

Os resultados podem ser mostrados apenas na tela com o comando playtr ou também guardados em arquivos no formato JPEG com o comando savetr. A janela de saída mostra o quadro atual (tanto a imagem originalmente lida como as versões reduzidas para o processamento em pirâmide), o fluxo óptico com os vetores de deslocamento codificados como indicado na figura 3.5 e valores absolutos da divergente (em vermelho) e da rotacional (em verde). O nível de ruído é bastante elevado no resultado, mas as soluções melhores fazem múltiplas passadas pela imagem e isso não é possível para operação em tempo real (quando implementado em hardware, já que em Octave mesmo a solução adotada leva 200 segundos para calcular cada quadro num computador Intel Quad Core 2 de $2.33 \mathrm{GHz}$ ).

Para cenas onde o ruído do fluxo óptico calculado é bastante grande, fica difícil observar diretamente se a divergente resultante esta correta ou não (o rotacional também é calculado 


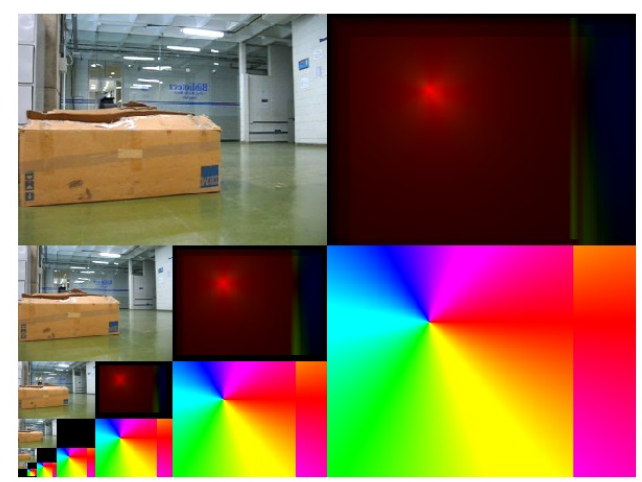

(a) Blocos de 11 por 11 pixels

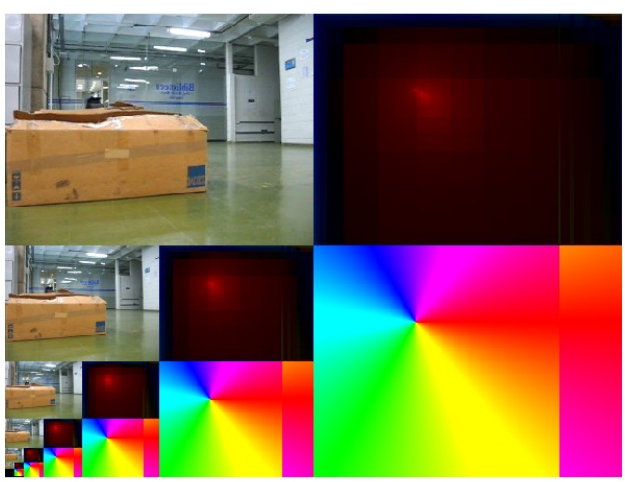

(b) Blocos de 3 por 3 pixels

Figura 4.3: Teste do Cálculo da Divergente

e exibido, mas o seu valor não interessa para o desvio de obstáculos). Por isso foi criada a opção de trocar o fluxo óptico por um valor conhecido através de uma pequena alteração no programa como mostra a figura 4.3. O fluxo óptico artificial tem deslocamentos se afastando de um único ponto e uma faixa à direita onde o componente vertical é espelhado. Os resultados de cada nível da pirâmide são combinados com os obtidos nos níveis superiores. Isto compensa parcialmente o uso de regiões muito pequenas para o cálculo, como mostra o lado direito da figura onde são usados blocos de 3 por 3 pixels ao invés de 11 por 11 (que é inviável para uma implementação em hardware). Isto permitiu a eliminação de vários pequenos erros (o principal estava na exibição dos resultados e não no cálculo em si). Uma versão do fluxo óptico artificial com todos os deslocamentos rotacionados em 90 graus permitiu encontrar erros no cálculo do rotacional (que nem é usado neste projeto).

A capacidade de manipulação de matrizes do Octave foi fundamental para que diferentes idéias pudessem ser rapidamente testadas. A operação com pirâmides de imagens sem complexas manipulações de ponteiros e alocações/dealocações manuais típicas do C permitiram o teste do algorítmo de buscas multipixels. Por outro lado, falta desempenho para o uso intenso do programa depois de pronto.

Uma operação como $b=a(:, 4: 6,:)$ para indicar que apenas 3 linhas da matriz $a$ serão usadas nas etapas seguintes é muito mais fácil de ser entendida do que os complexos loops equivalentes em $\mathrm{C}$, mas implica em muitas cópias de dados enquanto a versão em $\mathrm{C}$ opera com os dados nos seus locais de origem. Com os processadores rápidos e memórias lentas de hoje, 


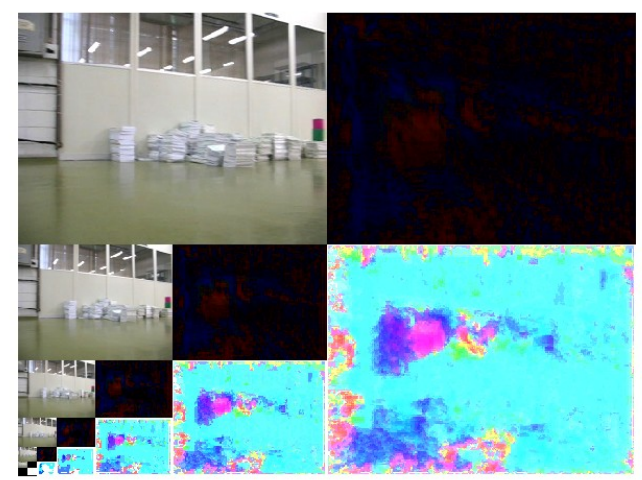

(a) Sem filtro temporal

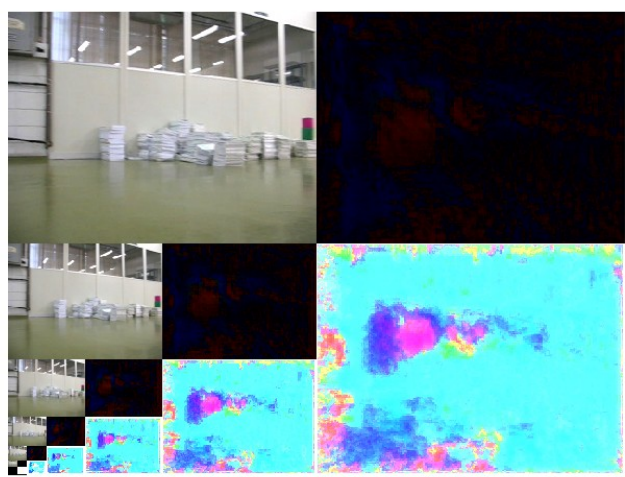

(b) Com filtro temporal

Figura 4.4: Teste do Filtro Temporal

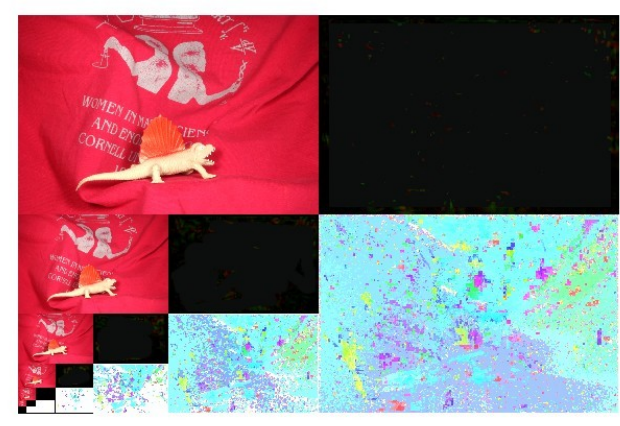

(a) Sem filtro espacial

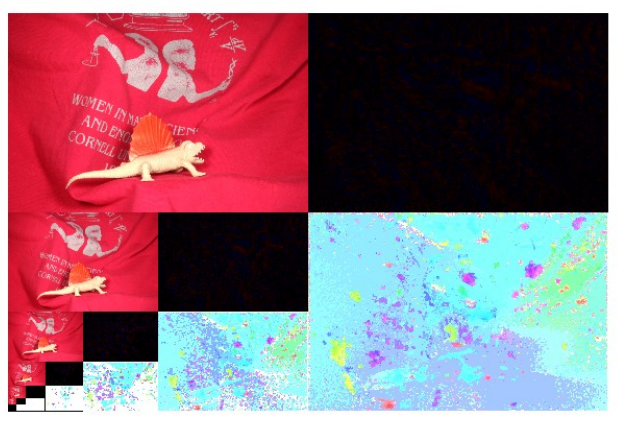

(b) Com filtro espacial

Figura 4.5: Teste do Filtro Espacial

cada cópia extra pesa bastante.

\subsubsection{Filtros}

O fluxo óptico calculado pelo algorítmo de correlação usando pirâmides faz uma única passagem por esta pirâmide, mas gera um resultado bem mais ruidoso do que métodos iterativos. A figura 4.4 mostra o resultado de um filtro temporal. A idéia de se fazer uma média entre o resultado atual e o dos quadros anteriores é que o fluxo óptico não deve variar bruscamente no tempo.

Dada a natureza do ruído, que é de grandes blocos com erro bastante grande comparado a valores corretos típicos, o filtro temporal não mostrou bons resultados. Como seu uso complicaria bastante o acesso à memória, que já é o fator limitante do projeto, ele foi rejeitado.

A figura 4.5 mostra o resultado da aplicação de um filtro espacial ao fluxo óptico. Neste caso 
foi escolhido um filtro de Gauss de 7 por 7 elementos. Muitos dos algorítmos alternativos de fluxo óptico são inteiramente baseados na idéia de que o fluxo óptico deve ter uma coerência espacial bem grande, o que não é levado em conta num algorítmo de correlação. O filtro espacial, especialmente quando aplicado a cada nível da pirâmide antes dos seus resultados servirem de entrada para o nível seguinte, serve para combinar as vantagens das diferentes técnicas. Infelizmente o aumento no custo computacional é significativo (e também de acesso à memória, mas muito menos que o filtro temporal) e a melhora nos resultados não foi considerada suficiente para justificar sua inclusão.

\subsection{TkGate}

$\mathrm{Na}$ ausência de ferramentas que transformem automaticamente descrições como a desenvolvida em Octave em bits para a programação dos circuitos reconfiguráveis (o conjunto de ferramentas da Xilinx para processamento digital de sinais inclui a possibilidade de trabalhar diretamente com descrições em Matlab, mas apenas para projetos bem limitados), a solução é criar manualmente no nível de transferência de registradores (RTL) um projeto que tenha a mesma funcionalidade.

Uma complicação é verificar que o re-projeto foi bem sucedido. Os simuladores trabalham com formas de onda e neste nível de detalhe é quase impossível verificar que a operação é a desejada. No caso de um processador lendo de um teclado e escrevendo numa tela, por exemplo, teria que ser escrito um segundo circuito para fazer o papel do mundo externo. Este circuito de teste teria uma lista de "vetores" a serem aplicados ao processador que, se não tiver nenhum erro, deve operar como uma pessoa apertando uma ou duas teclas. Outro conjunto de testes pode comparar a saída com resultados esperados, mas normalmente poucos vetores são criados para um projeto por ser um processo tão trabalhoso.

Existem simuladores como o LogicWorks e TkGate onde o usuário pode interagir com o sistema sendo simulado através de chaves simuladas e os resultados são exibidos em LEDs simulados. Em uma das demonstrações do TkGate um processador é ligado a um terminal serial virtual e quando o programa simulado envia dados para esta porta serial, os caracteres correspondentes simplesmente aparecem na janela do terminal. Isso é muito mais fácil de verificar 


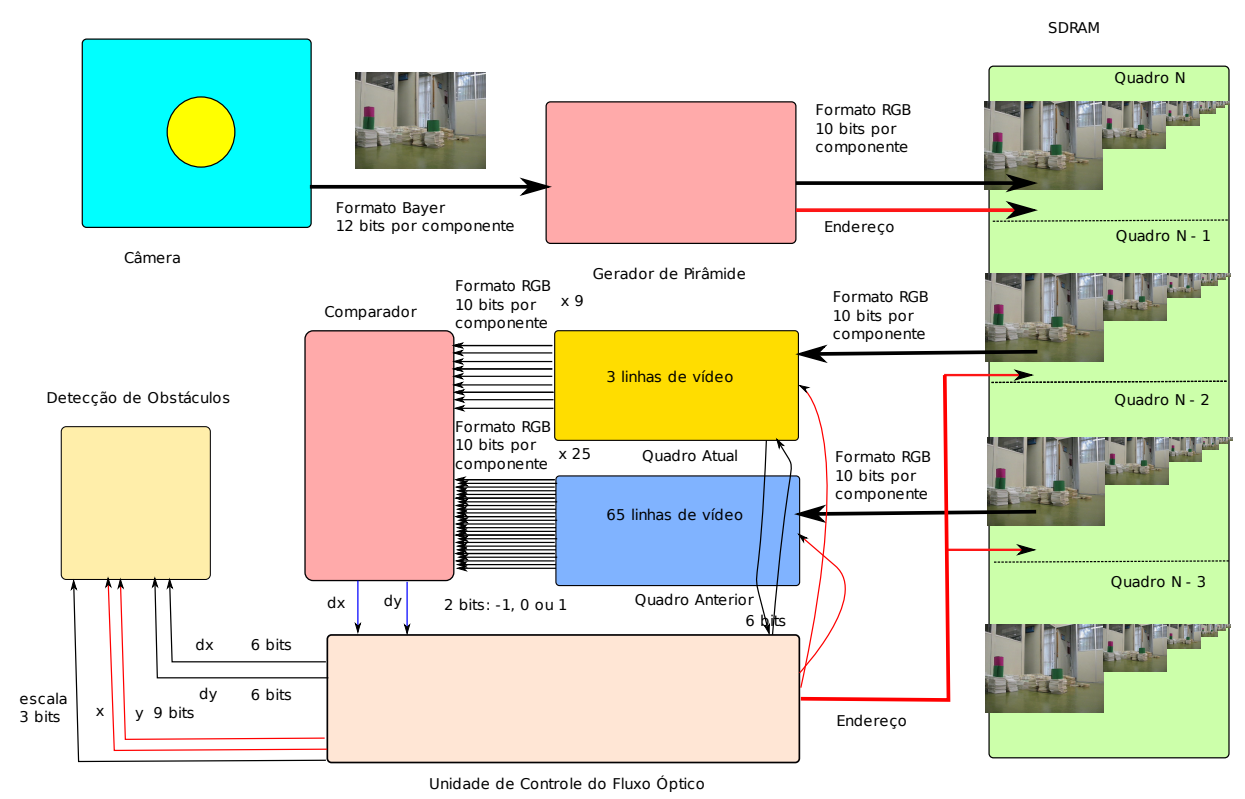

Figura 4.6: Diagrama de blocos do algorítmo de fluxo óptico

do detalhadas formas de onda. E para responder ao processador, basta teclar algo no terminal virtual.

Uma grande vantagem do TkGate é que pode ser estendido com novos dispositivos periféricos virtuais (VPD). A parte de interface com o usuário é escrita em Tk/Tcl e a parte que se comunica com o resto do circuito simulado é escrita em Verilog. Neste projeto esta funcionalidade permitiu simulações onde tanto a entrada (câmera) como saída (LCD) são imagens.

Os blocos que implementam o algorítmo de fluxo óptico e detecção de obstáculos estão indicados na figura 4.6. Enquanto na implementação em Octave usou números normalizados entre -1 e 1 sempre que possível, a versão em hardware usa pequenos números inteiros (com sinal ou não, dependendo de cada caso). Existem técnicas para se determinar a precisão necessária em cada parte do algorítmo, mas neste caso não foram necessárias pois os valores são bem óbvios.

A câmera tem uma interface de 12 bits pela qual ela envia dados a uma taxa de $96 \mathrm{MHz}$. Ela pode ser configurada para enviar uns poucos quadros de alta resolução por segundo ou um número maior de quadros de resolução reduzida. A redução de resolução pode ser feita pulando linhas e/ou colunas, fazendo uma média de linhas e/ou colunas ou deixando uma borda maior do que a normal em torno da imagem capturada. Um problema da câmera usada com o kit DE2 
é que ela foi projetada para ser uma câmera fotográfica e não de vídeo. Uma vez disparada a captura de imagem, uma opção faz com que cada linha seja amostrada num momento diferente. Para uma cena estática isso não tem nenhum efeito, mas qualquer objeto se movendo vai aparecer "quebrado". Uma outra opção inicia a amostragem de todas as linhas ao mesmo tempo, mas ai as linhas ficam expostas por tempos diferentes. Este modo foi projetado para uso com um obturador externo para bloquear a luz depois de um tempo, o que não é o caso deste kit. A solução adotada neste projeto foi usar a resolução mais baixa possível (640 por 480) que tem o tempo de amostragem mais curto e separar a amostragem de um quadro e o seguinte por um intervalo razoável (30 quadros por segundo ao invés dos 150 que seria possíveis a esta resolução).

As informações vindas da câmera são convertidas do formato Bayer (R, G1, B, G2) de 12 bits por componente para um formato RGB de 10 bits por componente usando a média de G1 e G2 e e simplesmente eliminando os dois bits menos significativos. Uma memória no gerador de pirâmide guarda duas linhas da imagem e vai calculando uma versão reduzida à medida em que a linha par vai chegando. Cada pixel da versão reduzida é uma média de quatro pixels (dois de cada linha) da imagem original. A memória do bloco também armazena duas linhas da versão reduzida, e à medida em que a linha par desta vai sendo calculada uma versão ainda mais reduzida é gerada. Este processo ocorre em seis níveis. Quando a linha par de um nível começa a ser calculada, a linha par é enviada para o endereço correto na memória. Da mesma forma, o início da geração de uma linha ímpar faz a linha par ser transferida para a memória principal. A transferência em blocos seqüenciais razoavelmente grandes aproveita melhor as características das SDRAMs do que acessos individuais.

A memória externa é dividida em quatro regiões iguais de 512KB cada uma, que são suficientes para guardar pirâmides de 320 por 240,160 por 120,80 por 60,40 por 30,20 por 15 e 10 por 7 pixels de 4 bytes cada um. Note que as imagens originais de 640 por 480 não são usadas. Sempre que uma nova amostragem é iniciada na câmera, uma das regiões de memória é definida como sendo a atual. É para ela que o gerador de pirâmide envia seus resultados. Supondo que esta seja a região 1 , então a região 0 é definida como a imagem anterior (e neste instante a pirâmide lá está completa) e a região 3 é definida com a anterior a esta. O algorítmo do fluxo óptico vai comparar a pirâmide em 0 com a em 3. Quando o próximo quadro começar 
a ser capturado (na região 2) o fluxo óptico vai comparar a região 1 com a 0.

A comparação no algorítmo de fluxo óptico é um grande circuito combinacional que será descrito mais adiante. Ele tem como entrada nove pixels completos de uma imagem e vinte e cinco pixels da anterior. Cada pixel tem 32 bits (mas apenas 30 são usados), o que representa um total de 1020 novos bits a cada ciclo de operação. Para fornecer esta quantidade enorme de informações são usadas duas memórias especializadas. A primeira guarda três linhas da imagem atual e tem nove saídas enquanto que a segunda guarda 65 linhas da imagem anterior e tem 25 saídas. Os pixels da imagem atual são lidos em seqüência e apenas a linha anterior e a seguinte são necessárias para a região de 3 por 3 em torno to pixel atual. Já na imagem anterior, qualquer deslocamento de até 32 pixels pode ser exigido. Com estas memórias internas, cada pixel é escrito uma vez (pelo gerador de pirâmide) e lido duas vezes (uma como quadro atual e outra como quadro anterior pelo fluxo óptico) da memória externa. Sem elas, cada pixel seria escrito uma vez e lido até 28 vezes, o que exigiria uma interface com a memória externa muito mais difícil de ser implementada.

A saída do comparador é um vetor com dois componentes de dois bits cada, representando $-1,0$ ou 1. O resultado do nível da pirâmide foi usado para calcular o endereço da memória do quadro anterior e é combinado com este resultado para se obter o deslocamento para este nível. O resultado é armazenado na memória de quadro atual se este não for o nível mais baixo. De qualquer forma, o resultado também é enviado para o bloco de detecção de obstáculos na forma de um vetor de deslocamento de dois componentes de 6 bits cada (de -32 a +32 ), um vetor com as coordenadas de pixel para o qual vale esta resposta (um vetor de dois componentes de 9 bits cada - o que permite imagens de até 512 por 512) e um indicador de nível de pirâmide de 3 bits (0 a 5). Em princípio seria possível enviar apenas o vetor de deslocamento se o projeto do fluxo óptico e da detecção de obstáculos concordarem quanto à ordem na qual os resultados são gerados e consumidos. A transmissão explícita das coordenadas permite uma certa independência dos dois blocos (desde que a detecção de obstáculos tenha uma memória interna suficientemente grande) que facilita a experimentação de alternativas. 


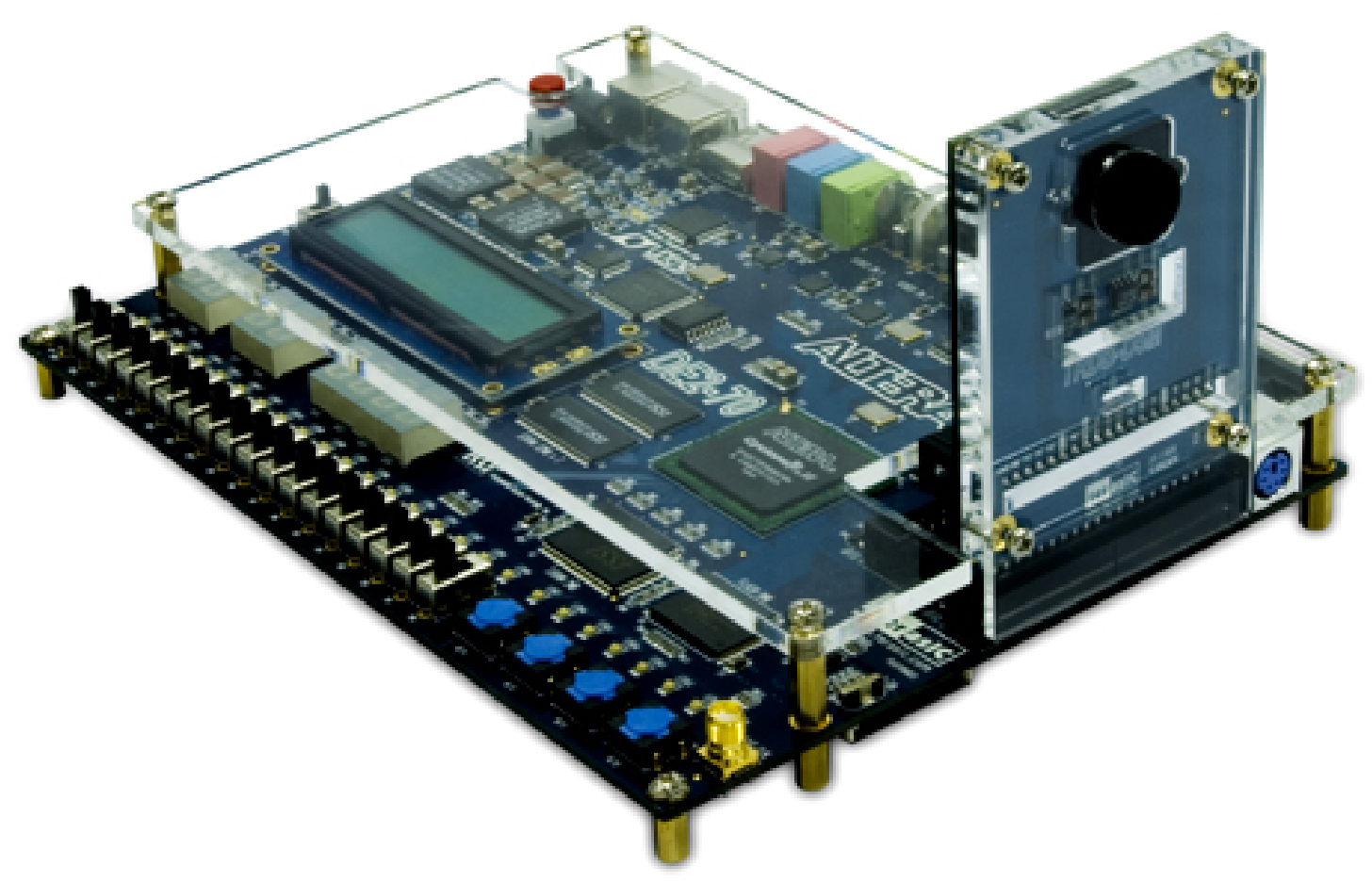

Figura 4.7: Placa de desenvolvimento DE2-70 de Terasic com câmera

\subsubsection{Placa de desenvolvimento DE2}

Para usar a placa da figura 4.7 neste projeto, foi escrito um pequeno conversor em Tcl que transforma a descrição de um circuito que tenha sido testado no TkGate para uma forma que seja aceita pelas ferramentas da Altera. Esta descrição inclui não apenas o circuito a ser programado dentro da FPGA mas também elementos da placa como chaves, LEDs e VPDs como mostrado na figura 4.8. Isto não atrapalha a compilação do projeto pois as ferramentas da Altera permitem que seja definido qual bloco deve ser considerado o de mais alto nível, que neste case é o com nome "cyclone".

Além do "cyclone", o diagrama de blocos mostra um oscilador de $50 \mathrm{MHz}$, quatro chaves, duas memórias SDRAM, uma câmera, um terminal serial e uma saída de cristal líquido. Também tem um bloco que liga as duas intefaces de dados de 16 bits das SDRAMs na interface de 32 bits da FPGA. O “concat” normal do TkGate não é bidirecional, infelizmente.

O modelo Verilog da SDRAM foi obtido da Micron e adaptado para as memórias da placa DE2-70. Este modelo é totalmente voltado para a simulação, o que não é um problema uma vez 


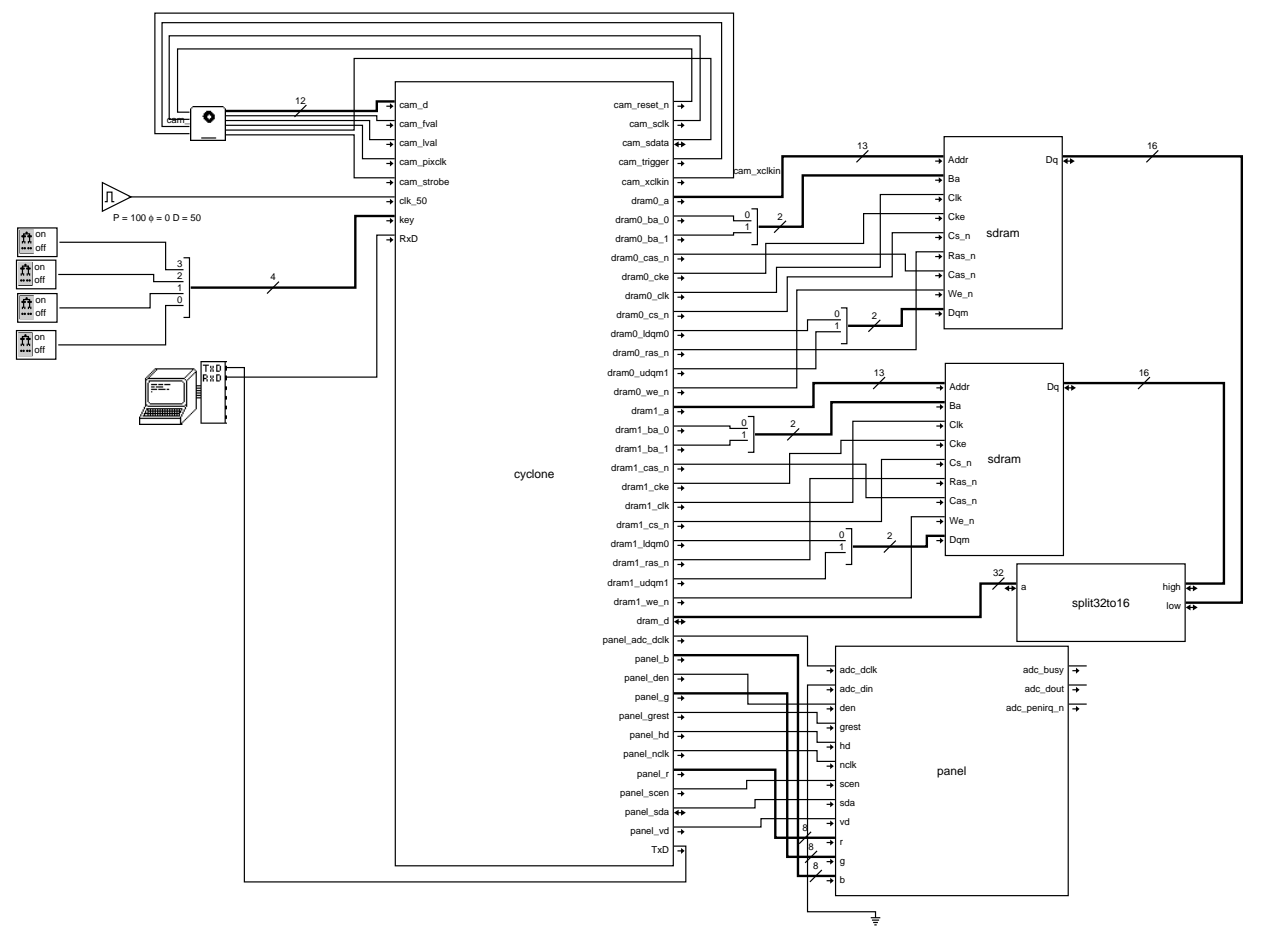

Figura 4.8: Diagrama de blocos da placa de desenvolvimento DE2-70 de Terasic com câmera e tela de cristal líquido 
que ele é externo à FPGA.

O oscilador e as chaves são componentes padrão do TkGate e o terminal é uma adaptação do exemplo de VPD que vem no TkGate. Naquele VPD a interface com o resto de circuito é paralela, o que não é interessante para o teste de uma UART implementada na FPGA e em software. Uma pequena alteração transformou a interface do terminal em serial no estilo RS-232 mas sem sinais de controle. Quando a simulação ocorre, uma janela se abre onde aparece o texto de qualquer caracter representado pelas formas de onda corretas no sinal TxD e qualquer tecla pressionada enquanto o cursor está nesta janela provoca as formas de onda correspondentes no sinal RxD.

A simulação da câmera recebe o nome de um ou mais arquivos de imagem. Cada arquivo é mostrado numa janela e o ponto que está sendo enviado para o resto do circuito é indicado. Apenas um conjunto bem limitado dos registradores e opções foram implementados e o seu conteúdo é manipulado com as formas de onda corretas na interface $I^{2} C$.

Este VPD converte os arquivos lidos para a resolução selecionada da câmera (no momento sempre 640 por 480 independentemente dos valores dos registradores) e envia no formato Bayer ( $\mathrm{R}, \mathrm{G} 1, \mathrm{~B}, \mathrm{G} 2)$ com os dois primeiros componentes nas linhas ímpares e os dois últimos nas pares.

O bloco de saída LCD é um VPD desenvolvido para simular a tela de cristal líquido. Ao receber as formas de onda corretas, ele exibe numa janela a imagem correspondente. Opcionalmente, a seqüência de imagens pode ser gravada em disco como um filme, que depois pode ser visto em tempo real. Este bloco também recebe sinais correspondentes à interface sensível ao toque, mas no momento ignora totalmente estes sinais. Tem uma interface $I^{2} C$ mas a maioria dos registradores que podem ser escritos por esta são ignorados.

\subsubsection{FPGA}

O diagrama de blocos da figura 4.9 corresponde ao diagrama de mais alto nível da figura 4.6. Um elemento novo é o processador, que é usado para programar os registradores da câmera e LCD. O controlador de memória SDRAM e o multiplexador de 3 portas para que o mesmo seja partilhado estão apenas implícitos no diagrama de mais alto nível. A saída para o LCD também 


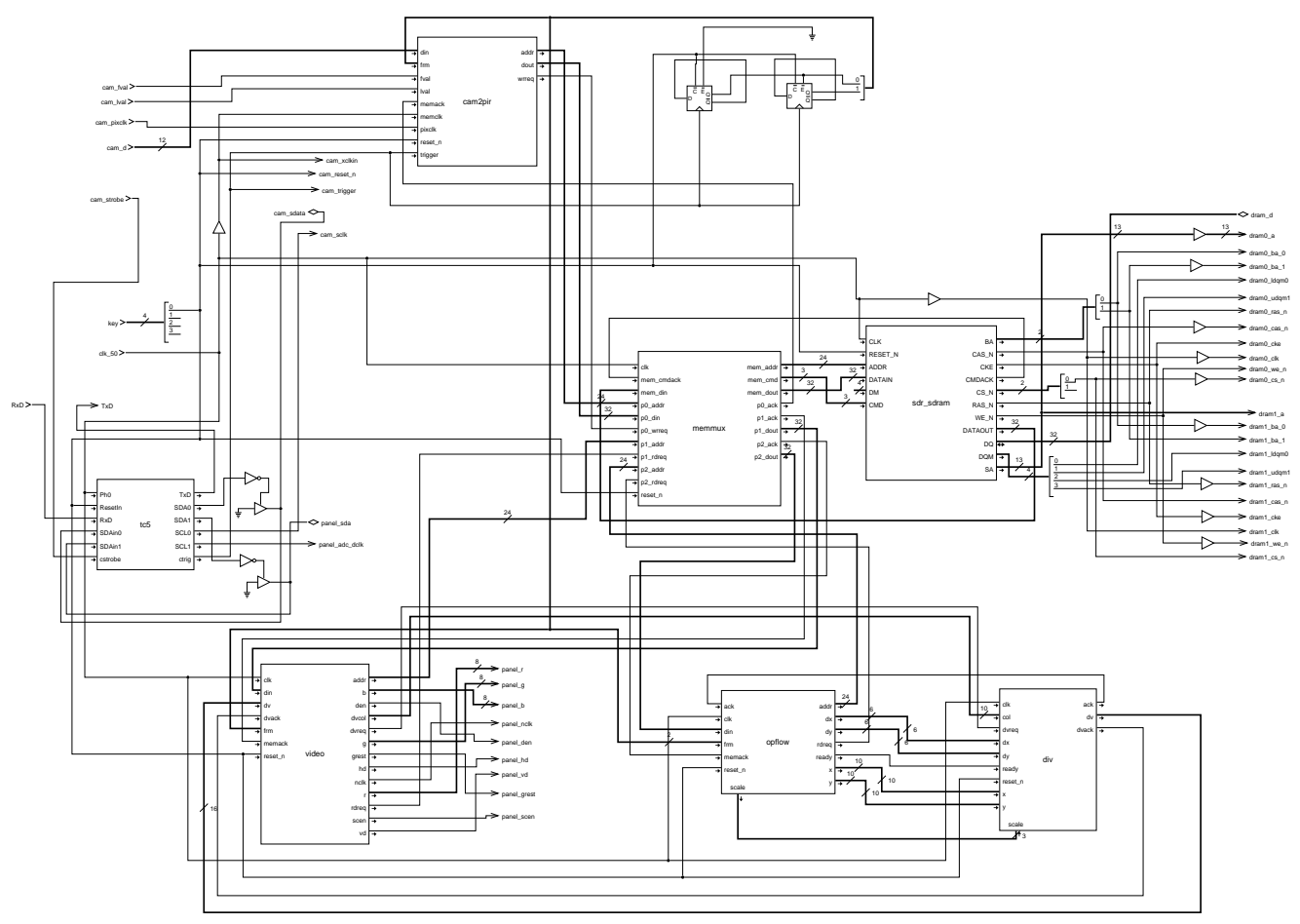

Figura 4.9: Diagrama de blocos do circuito implementado na FPGA 
não estava indicada neste.

O controlador de memória SDRAM usado é o fornecido pela própria Altera. Ele permite transferências em bloco, o que aumenta a eficiência das memórias. Mas apenas aceita um novo comando depois de encerrado o anterior, o que cria intervalos nos quais a memória fica inoperante. O ideal seria um controlador mais sofisticado que operasse com uma sequiência completa de comandos, mas para este projeto esta limitação foi parcialmente contornada pelo uso de blocos grandes nas transferências aproveitando as memórias internas da FPGA.

Apenas uma das chaves da placa foi usada. Ela serve para inicializar todo o sistema. Dois flip flops servem como um contador para selecionar o quadro $\mathrm{N}$ a ser escrito pelo gerador de pirâmide e os quadros $\mathrm{N}-1$ e N-2 a serem lidos pelo bloco de fluxo óptico. A saída de LCD usa parte do quadro N-1 para gerar sua imagem combinada com o resultado do detector de obstáculos.

\section{Processador}

Vários processadores foram avaliados ao longo deste projeto: Leon 3 (Sparc da Agêncial Espacial Européia), Plasma (MIPS com limitações), JOP (processador Java para aplicações de tempo real), OpenRISC e ZPU (processador compacto e lento mas compatível com GCC). Não foram consideradas soluções fechadas, como o Microblaze da Xilinx ou Nios II da Altera, para que o projeto pudesse ser portado para diferentes placas de FPGA, o que se mostrou uma grande vantagem na mudança da ML401 para DE2-70 perto do fim do projeto.

Como a funcionalidade necessária do processador acabou sendo bem reduzida (apenas a programação via $I^{2} C$ dos registradores da câmera e do LCD), foi escolhido um processador extremamente simples projetado pelo Chuck Thacker da Microsoft Research. O TC5 (Tiny Computer 5), mostrado na figura 4.10, tem apenas um fluxo de dados mas não uma unidade de controle. Os bits da instrução, detalhados na figura 4.11, atuam diretamente sobre o hardware.

O objetivo inicial deste processador era ser algo simples o suficiente para ser compreendido por estudantes do colegial, mas não trivial demais para ser interessante. Ele aproveita as memórias de bloco das FPGAs para operar com o menor número de registradores possível.

Este processador é programado em linguagem de montagem (assembler) e foi usado como 


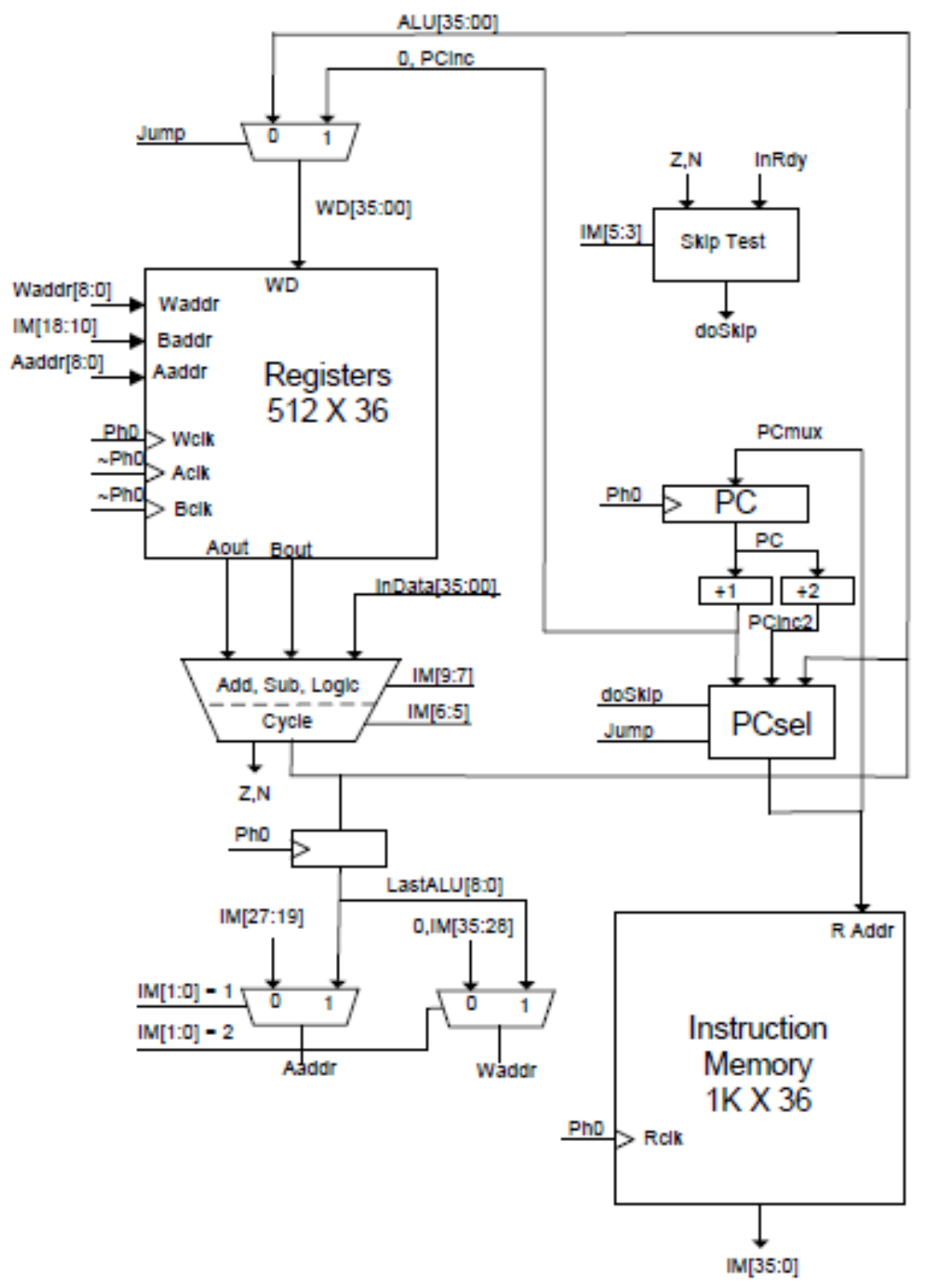

Figura 4.10: Diagrama de blocos do processador

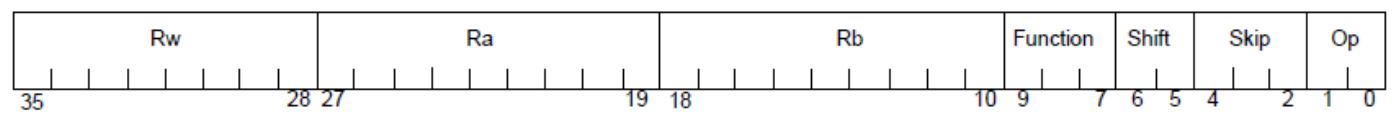

\begin{tabular}{|c|c|c|c|}
\hline Function: & Shift: & Skip: & Op: \\
\hline $0: A+B$ & 0 : No shift & $0:$ Never & 0: ALUop: \\
\hline $1: A-B$ & 1: RCY 1 & 1: ALU $<0$ & $\mathrm{RF}[\mathrm{Rw}]<=$ Shift(F(RF[Ra], RF[Rb])), Skip if condition \\
\hline 2: A \& B & 2: RCY 9 & $2: A L U=0$ & 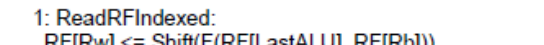 \\
\hline 3: A \& InData & 3: RCY 18 & 3: InRdy & $\begin{array}{l}\mathrm{RF}[\mathrm{RW}]<=\text { Shirt(t(RF[LastALU], RF }[\mathrm{Rb}]) \text { ), } \\
\text { Skip if condition }\end{array}$ \\
\hline 4: A|B & & 4: Always & \\
\hline 5: $\mathrm{A} \mid \sim \mathrm{B}$ & & 5: $A L U>=0$ & 2: WriteRFIndexed: \\
\hline $6: A \wedge B$ & & $6: \mathrm{ALU} \# 0$ & $\begin{array}{l}\text { RFip if condition } \\
\text { Skirt( } F(R F[R a], R F[R b]) \text {, }\end{array}$ \\
\hline 7: A\& B & & 7: InRdy & 3: Jump: $R F[R w]<-P C+1, P C<-F(R F[R a], R F[R b])$ \\
\hline
\end{tabular}

Figura 4.11: Instruções do processador 
parte de um circuito de teste da placa BEE3 do projeto RAMP onde implementa por software uma interface serial (UART) e outra $I^{2} C$. Assim, este código pode ser aproveitado com poucas adaptações neste projeto.

Na versão atual do circuito da FPGA, o processador não recebe informações do detector de obstáculos. Se isto for alterado, ele poderá enviar estas informações para um PC pela porta serial. Para a comunicação com o software Player, é mais conveniente uma interface Ethernet e implementação completa do padrão TCP/IP. Neste caso seria melhor usar um processador mais sofisticado para o qual este software já tenha sido implementado.

\section{Fluxo Óptico}

A figura 4.6 mostra detalhes do algorítmo de fluxo óptico que não são vistos no circuito da FPGA, mas a figura 4.12 apresenta estes mesmos detalhes. A unidade de controle, implementada em Verilog, não faz parte desta explicação pois o foco é apenas o fluxo de dados. As duas memórias (do quadro atual e do anterior) podem ser vistas na figura, bem como o comparador, mas entre estes aparecem blocos que não fazem parte da figura de alto nível. Quando a unidade de controle envia um endereço para as memórias, o pixel indicado e mais 8 (ou mais 24) outros aparecem nas saídas. Mas a ordem na qual aparecem normalmente não correspondem à ordem esperada pelo comparador. Assim, o bloco rot9 pode rotacionar um grupo de 3 por 3 pixels por 0,1 ou 2 pixels horizontalmente e por 0,1 ou 2 verticalmente. O rot 25 faz a mesma coisa com rotações de 0 a 4 pixels em cada eixo.

\section{Comparador}

O comparador implementa num único passo a função mostrada na figura 3.2. para regiões de comparação de 3 por 3 pixels e deslocamentos de no máximo um pixel. Para isso, precisa receber um bloco de 3 por 3 pixels do quadro atual e outro de 5 por 5 pixels do anterior. Existem nove deslocamento possíveis e circuitos paralelos calculam o erro usando as diferenças absolutas para cada um dos casos. Nove circuitos de comparação de erro avaliam se o seu caso é menor do que seus predecessores. Se sim, ele envia o seu erro e seu deslocamento em direção à saída. Se não, e erro e deslocamento da entrada são passados adiante. O primeiro circuito da cadeia 


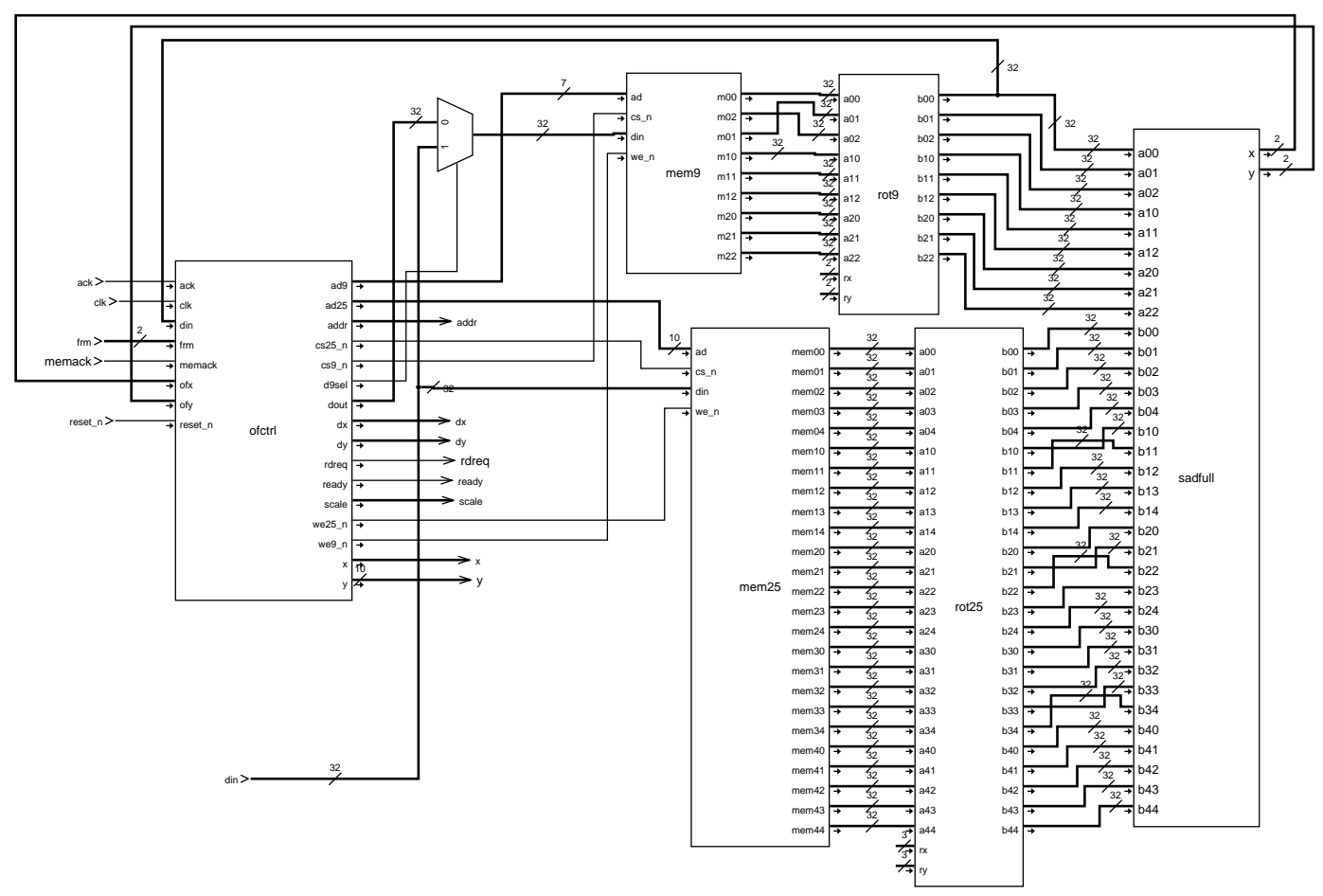

Figura 4.12: Diagrama de blocos do Fluxo Óptico 


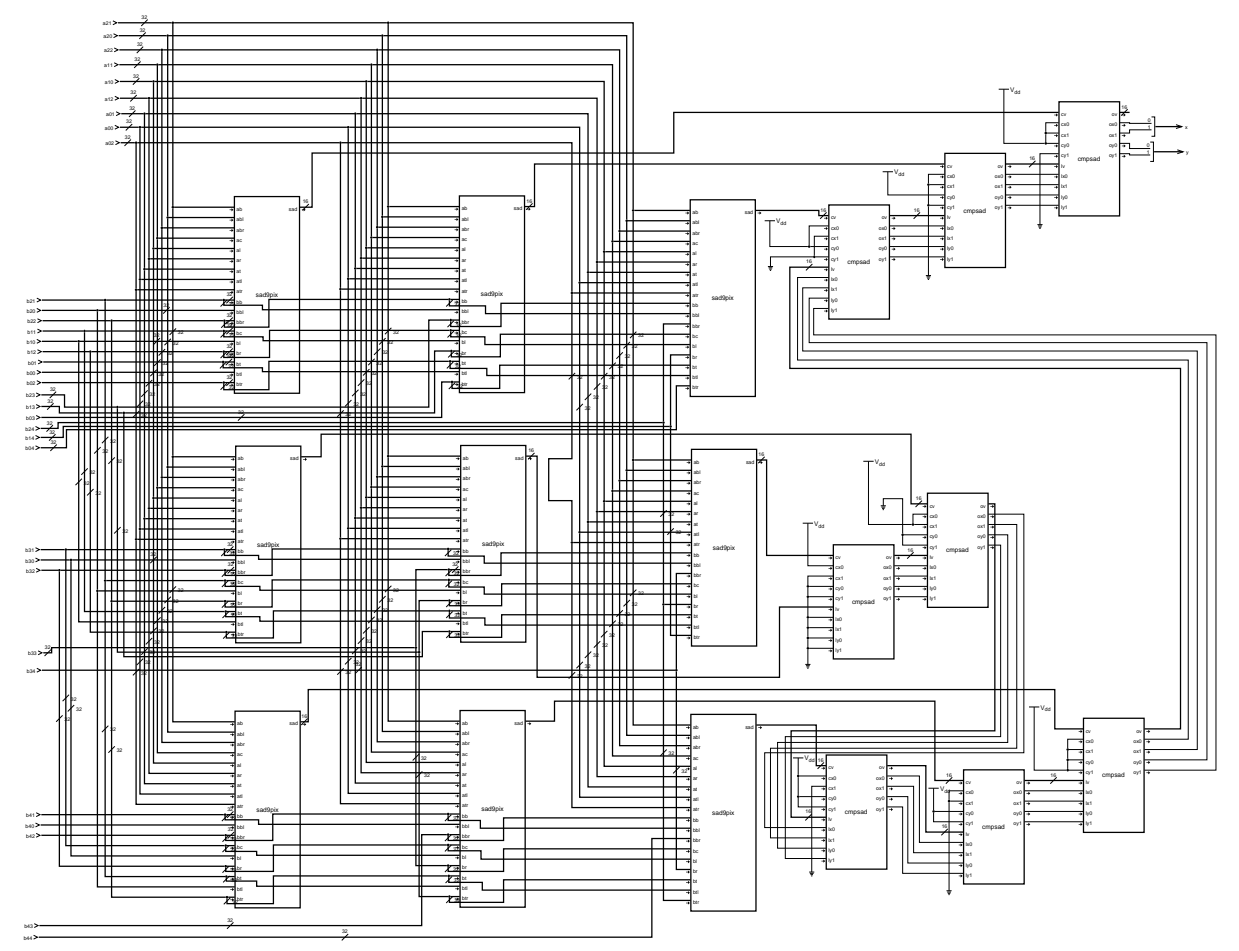

Figura 4.13: Diagrama de blocos do Comparador

é o de deslocamento zero para que em caso de empate seja dado preferência a deslocamentos menores.

O elemento mais básico do comparador é o circuito de diferença absoluta, mostrado na figura 4.14. Como o TkGate tem somadores mas não subtradores, uma das entradas (escolhida arbitrariamente) é invertida e o sinal de entrada "vai um" é sempre acionado, o que gera o complemento de dois daquela entrada.

Um segundo somador não tem nenhum efeito quando o bit mais significativo do resultado é zero (resultado positivo), mas subtrai o resultado de zero quando este bit é um (resultado negativo). A saída final é sempre um valor positivo - a diferença absoluta das entradas. Por isso não faz diferença qual das entradas foi invertida, ao contrário de uma subtração simples.

Como os pixels são representados em 32 bits, são necessárias três cópias dos circuito da figura 4.14 para fazer a diferença de cada um dos componentes ( $R, G$ e B) como mostra a figura 4.15. Os dois bits mais significativos de cada pixel são descartados e os demais divididos 


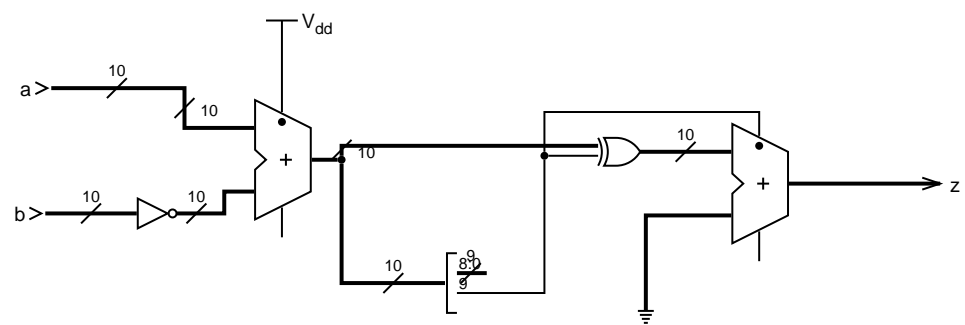

Figura 4.14: Diagrama de blocos da Diferença Absoluta 


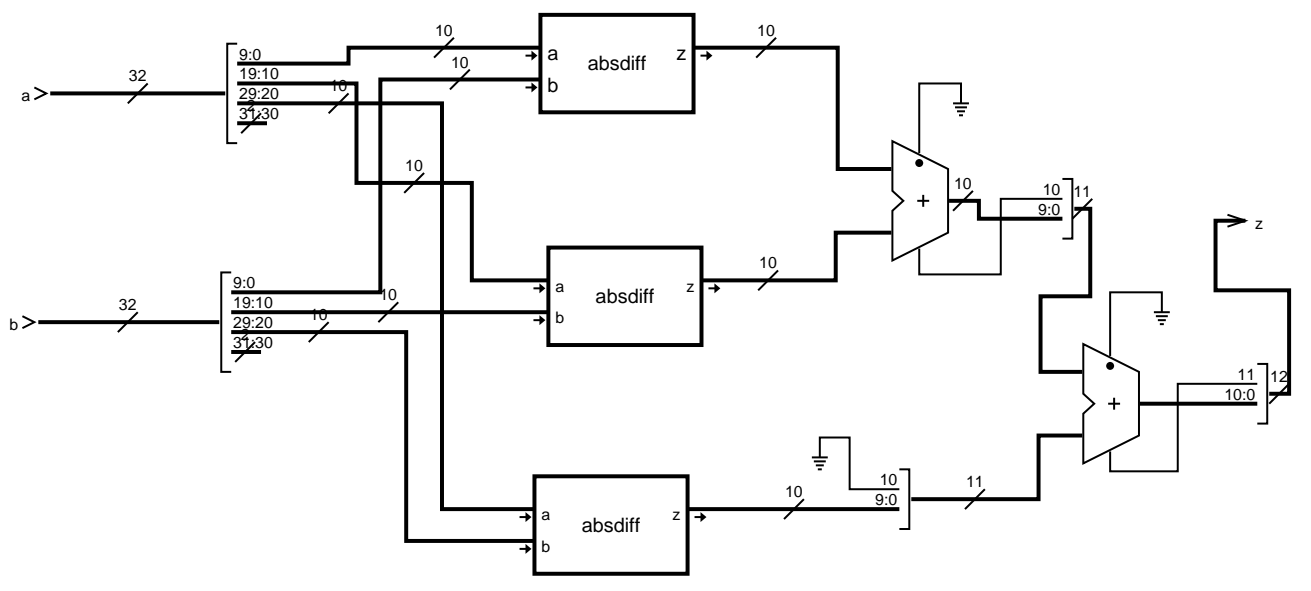

Figura 4.15: Diagrama de blocos da Diferença de Pixels

em três grupos de 10 bits cada. As 3 diferenças absolutas de 10 bits são somadas para um resultado final de 12 bits.

Dado dois grupos de 3 por 3 pixels, o circuito da figura 4.16 usa nove cópias do circuito de 4.15 para obter um erro total para os 27 pares de componentes da região sendo testada. Cada soma aumenta o número de bits do resultado em um, com o resultado final de 16 bits.

Com nove circuitos iguais a este, é possível comparar um bloco de 3 por 3 pixels da imagem atual com todas os nove blocos de 3 por 3 pixels da imagem anterior representando deslocamentos de até um pixel em cada direção, como mostrado na figura 4.13. Com nove valores de erro calculados ao mesmo tempo, fica fácil selecionar o menor deles.

O circuito de comparação é totalmente combinacional, sendo a seleção do menor valor por uma seqüência de nove comparadores um gargalo bastante óbvio. A velocidade de operação desta parte do projeto é de apenas $17 \mathrm{MHz}$ na FPGA Cyclone II. Seria fácil aumentar significativamente a velocidade do comparador dividindo-o em estágios de um pipeline e trocando a 


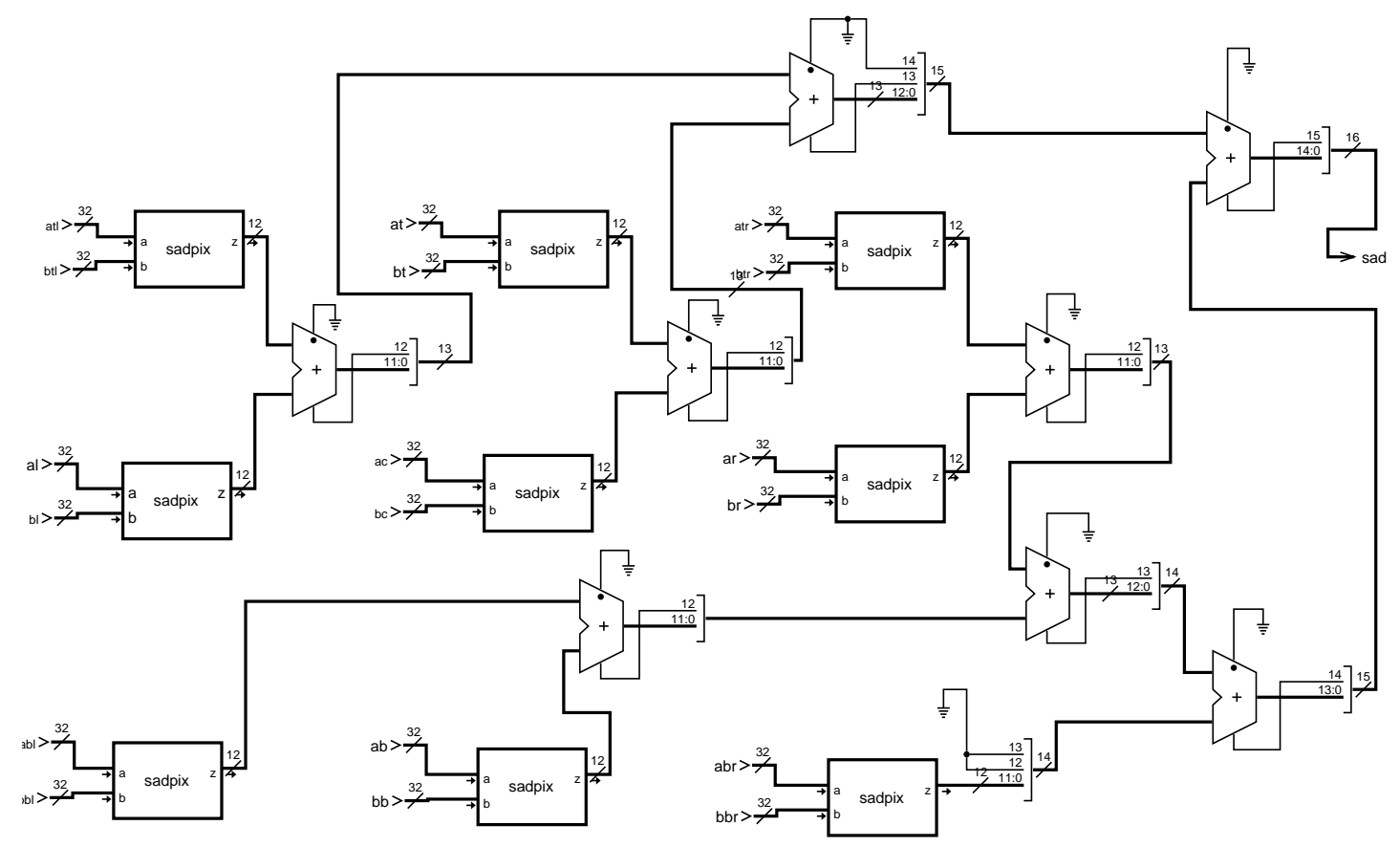

Figura 4.16: Diagrama de blocos da Diferença de Blocos de Pixels 
busca seqüencial do menor erro por um esquema em árvore binária. Mas dado que para funcionar em tempo real é necessário processar $(320 \times 240+160 \times 120+80 \times 60+40 \times 30+20 \times$ $15+10 \times 7) \times 30=3$ Mpixels / segundo, o circuito atual já é cinco vezes mais rápido do que o necessário e por isso nenhuma destas melhorias foram feitas até o momento.

As memórias internas da FPGA estão bem longe de ser o gargalo em termos de desempenho. Elas poderiam fornecer seus conjuntos de pixel a taxas superiores a $200 \mathrm{MHz}$. O grande fator limitante é sua quantidade. Uma memória de bloco com 4Kbits é capaz de armazenar apenas 128 pixels, e a Cyclone II 70 da placa de desenvolvimento tem um total de 250 destas.

\begin{tabular}{c|c}
\hline Bloco & Memórias de 4Kbits \\
\hline gerador de pirâmide & 10 \\
processador & 12 \\
3 linhas do quadro atual & 18 \\
65 linhas do quadro anterior & 200 \\
detecção de obstáculos & 8 \\
saída de LCD & 1 \\
\hline
\end{tabular}

Tabela 4.1: Uso da memória interna da FPGA

A tabela 4.1 mostra como estas memórias de bloco são usadas pelos diferentes componentes da implementação em hardware do fluxo óptico e detecção de obstáculos. Para linhas de 320 pixels, seria necessário usar 212 blocos, e não apenas os 200 mostrados na tabela. A solução encontrada foi varrer a imagem verticalmente, de modo que a memória apenas precisa armazenar 65 colunas de 240 pixels cada. Infelizmente isso faz o envio de dados para a memória do quadro atual ocorrer em blocos de apenas 3 palavras por vez, o que reduz a eficiência do controlador de memória. Dado que a taxa de 30 quadros por segundo deixa a memória livre por tempo suficiente para poder lidar com tal ineficiência. esta opção foi considerada preferível a se reduzir cada linha para apenas 300 pixels.

\subsection{Comparação dos Resultados}

As três implementações dos algorítmos são comparadas na tabela 4.2. Os custos e a potência de um PC necessário para executarem as versões em Octave e em C dos algorítmos variam bastante, de modo que os valores mostrados na tabela são aproximações muito grosseiras. Os 
valores para a implementação em FPGA são para uma versão industrializada da placa, e não de um kit de desenvolvimento.

\begin{tabular}{c|ccc}
\hline & Octave & $\mathrm{C}$ & TkGate \\
\hline tempo para calcular um quadro & $200 \mathrm{~s}$ & $20 \mathrm{~s}$ & $34 \mathrm{~ms}$ \\
tempo de desenvolvimento & pouco & médio & médio \\
representação numérica & ponto flutuante & ponto fixo & inteiros \\
custo do hardware & $\$ 1000,00$ & $\$ 1000,00$ & $\$ 200,00$ \\
potência do hardware & $>100 \mathrm{~W}$ & $>100 \mathrm{~W}$ & $<10 \mathrm{~W}$ \\
\hline
\end{tabular}

Tabela 4.2: Implementações dos Algorítmos

O tempo mostrado para calcular um quadro na implementação de hardware reflete a taxa de 30 quadros por segundo adotada. $\mathrm{O}$ hardware em si é capaz de operar em tempos bem menores que este, sendo o maior gargalo a transferência de dados entre a FPGA e a memória externa. 


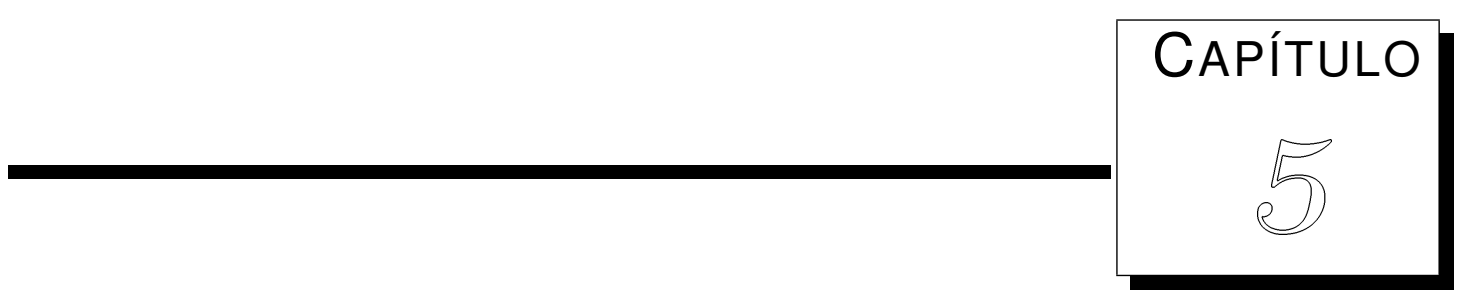

\section{Conclusões}

O uso da Computação Reconfigurável para viabilizar aplicações embarcadas com demanda computacional muito grandes para computadores tradicionais foi demonstrada com a implementação de algorítmos de fluxo óptico num único circuito integrado reprogramável.

A implementação em FPGA do fluxo óptico opera em tempo real consumindo uma fração da energia do mesmo algorítmo operando num PC tradicional em função da paralelização das operações mais críticas. Isto, no entanto, complica o projeto em função da elevação do número de acessos simultâneos à memória. Neste trabalho foram usadas as memórias internas da FPGA para resolver este problema e a quantidade destas passou a ser o fator limitante do tamanho de imagens que podem ser processadas.

\subsection{Contribuições deste trabalho}

A contribuição mais imediata deste projeto é a implementação em hardware do algorítmo de fluxo óptico que poderá ser incorporado a novos projetos no futuro. O sistema completo também pode ser incluído como uma caixa preta que funciona como substituto do sonar ou do laser num robô móvel. 


\subsection{Trabalhos futuros}

O projeto desenvolvido neste trabalho deverá ser refeito com as ferramentas do RoboArch, descritas em Bonato e Marques (2009), quando estas estiverem prontas para serem testadas. Esta versão alterada do bloco de fluxo de dados e do bloco de divergente passarão a ser componentes da biblioteca do RoboArch para uso tanto em simulações a nível de transações (TLM) quanto a nível de transferência de registradores (RTL).

Outra direção planejada é a extensão da compilação adaptativa para a reconfiguração dinâmica de sistemas. Em de Assumpção Júnior (1994) foi estudado como usar a compilação adaptativa para calibrar o nível de paralelismo de uma mesma aplicação para diferentes plataformas. Com a computação reconfigurável, o grau de paralelismo do hardware deixa de ser uma constante e existe a possibilidade de dedicar determinada área do circuito reprogramável a um processador genérico num momento (rodando programas otimizados pela compilação adaptativa tradicional) e a uma implementação dedicada de um algorítmo (como o deste trabalho) no momento seguinte. 


\section{Referências Bibliográficas}

Aires, K. R. T.; Santana, A. M.; Medeiros, A. A. D. Optical flow using color information: preliminary results. Em: SAC '08: Proceedings of the 2008 ACM symposium on Applied computing, New York, NY, USA: ACM, 2008, pgs. 1607-1611.

Arribas, P. C.; MACIÁ, F. M.-H. Fpga implementation of the horn and shunk optical flow algorithm for motion detection in real time images. Em: Dcis'98 Proceedings, XIII Design of circuits and integrated systems conference. 1998. pgs. 616-621.

ARribas, P. C.; MACiÁ, F. M. H. Fpga implementation of camus correlation optical flow algorithm for real time images. Em: Beauchemin, S. S.; Nouboud, F.; Roth, G., eds. Vision Interface Proceedings VI2001, 14th International Conference on Vision Interface. 2001. pgs. 7-9.

Arribas, P. C.; Maciá, F. M. H. Fpga implementation of santos-victor optical flow algorithm for real time image processing: an useful attempt. Em: LOPEZ, J. F.; Montiel-Nelson, J. A.; Pavlidis, D., eds. Society of Photo-Optical Instrumentation Engineers (SPIE) Conference Series, vol. 5117 de Presented at the Society of Photo-Optical Instrumentation Engineers (SPIE) Conference. 2003. pgs. 23-32.

DE AssumpÇão JÚnior, J. M. Adaptive compilation in the merlin system for parallel machines. Em: WHPC'94 Proceedings - IEEE/USP International Workshopon High Performance Computing. 1994. pgs. 155-166. 
DE AssumpÇÃo Júnior, J. M.; MARques, E. A hardware implementation of obstacle avoidance using monocular vision. Em: ROBOCONTROL'08 Workshop: 3rd applied robotics and collaborative systems engineering with emphasis in industrial applications and educational environments. 2008.

DE AssumpÇão Júnior, J. M.; Wolf, D.; MARques, E. Towards a hardware accelerated obstacle avoidance system for mobile robots using monocular vision. Em: Proceedings of SIES07 - IEEE Second International Symposium on Industrial Embedded Systems. 2007.

Baker, S.; Scharstein, D.; Lewis, J. P.; Roth, S.; Black, M. J.; Szeliski, R. A database and evaluation methodology for optical flow. Em: Proceedings of the Eleventh IEEE International Conference on Computer Vision, 2007.

Barron, J. L.; Fleet, D. J.; Beauchemin, S. S. Performance of optical flow techniques. International Journal of Computer Vision, vol. 12, no. 1, pgs. 43-77, Janeiro, 1994.

BonAto, V. Proposta de uma arquitetura de hardware em fpga implementada para slam com multi-câmeras aplicada à robótica móvel. 2008. Tese de doutorado, ICMC Universidade de São Paulo, 2008.

Bonato, V.; Marques, E. Roboarch: A component-based tool proposal for developing hardware architecture for mobile robots. Em: SIES, IEEE, 2009, pgs. 249-252.

Disponível em: <http://dblp.uni-trier.de/db/conf/sies/sies2009. html> .

Bouwens, F. J.; Berekovic, M.; Kanstein, A.; Gaydadjiev, G. N. Architectural exploration of the ADRES coarse-grained reconfigurable array. Em: Proceedings of International Workshop on Applied Reconfigurable Computing, 2007, pgs. 1-13.

Burger, D.; Keckler, S.; Sankaralingam, K.; Nagarajan, R. Trips processor reference manual. Relatório técnico TR-05-19, Department of Computer Sciences, The University of Texas at Austin, 2005. 
Camus, T.; CoOmbs, D.; Herman, M.; Hong, T.-H. Real-time single-workstation obstacle avoidance using only wide-field flow divergence. Em: ICPR '96: Proceedings of the International Conference on Pattern Recognition (ICPR '96) Volume III-Volume 7276, Washington, DC, USA: IEEE Computer Society, 1996, pg. 323.

Clark, J. H. The geometry engine: A vlsi geometry system for graphics. IEEE Computer Graphics, vol. 16, no. 3, pgs. 127-133, Julho, 1982.

Compton, K.; Hauck, S. Reconfigurable computing: A survey of systems and software. ACM Computing Surveys, vol. 34, no. 2, pgs. 171-210, Junho, 2002.

Diaz, J.; Ros, E.; Mota, S.; Pelayo, F.; Ortigosa, E. M. Subpixel motion computing architecture. Em: IEE Proceedings - Vision, Image, and Signal Processing, vol. 153. 2006. pgs. 869-880.

EAton, J. W.; BAteman, D.; HAUberg, S. Gnu octave manual version 3. Network Theory Ltd., 2008.

Everett, H. R. Sensors for mobile robots: Theory and application. AK Peters. Ltd, 1995.

Golland, P.; Bruckstein, A. M. Motion from color. Comput. Vis. Image Underst., New York, NY, USA: Elsevier Science Inc., vol. 68, no. 3, pgs. 346-362, Dezembro, 1997.

HARTENSTEIN, R. A decade of reconfigurable computing: a visionary retrospective. Em: DATE '01: Proceedings of the conference on Design, automation and test in Europe, Piscataway, NJ, USA: IEEE Press, 2001, pgs. 642-649.

Horn, B. K.; Schunck, B. G. Determining optical flow. Relatório técnico AIM 572, Cambridge, MA, USA, 1980.

LuCAS, B. D.; KAnADE, T. An iterative image registration technique with an application to stereo vision. Em: Proceedings of Imaging Understanding Workshop, 1981, pgs. 121-130. 
Martin, M. C. Evolving visual sonar: Depth from monocular images. Pattern Recognition Letters: Evolutionary Computer Vision and Image Understanding, vol. 27, no. 11, pgs. 1174-1180, Agosto, 2006.

Matthies, L.; Bergh, C.; Castano, A.; Macedo, J.; Manduchi, R. Obstacle detection in foliage with ladar and radar. Em: DARIO, P.; CHATILA, R., eds. ISRR, Springer, 2003, pgs. 291-300 (Springer Tracts in Advanced Robotics, vol.15).

Disponível em: <http://dblp.uni-trier.de/db/conf/isrr/isrr2003. html>.

McCane, B.; Novins, K.; Crannitch, D.; Galvin, B. On benchmarking optical flow. Comput. Vis. Image Underst., New York, NY, USA: Elsevier Science Inc., vol. 84, no. 1, pgs. 126-143, Agosto, 2001.

Michels, J.; SAXENA, A.; NG, A. Y. High speed obstacle avoidance using monocular vision and reinforcement learning. Em: ICML '05: Proceedings of the 22nd international conference on Machine learning, New York, NY, USA: ACM, 2005, pgs. 593-600.

de Nagy Koves Hrabar, S. E. Vision-based 3d navigation for an autonomous helicopter. 2006. Tese de doutorado, University of Southern California, 2006.

OKAZAKI, S.; KYO, S.; HIDANO, F. Imapcar: a highly parallel integrated memory array processor for in-vehicle image recognition applications. Em: 13th World Congress and Exhibition on Intelligent Transport Systems and Services, 2006.

Pittman, R. N.; LYNCH, N. L.; FORIN, A. emips, a dynamically extensible processor. Relatório técnico MSR-TR-2006-143, 2006.

Rodriguez-Vazquez, A.; Espejo, S.; Dominguez-Castro, R.; Carmona, R.; LiNAN, G. Cmos design of focal plane programmable array processors. Em: ESANN'2001 Proceedings - European Symposium on Artificial Neural Networks. 2001. pgs. 57-62.

Röwekamp, T.; Platzner, M.; Peters, L. Specialized architectures for optical flow computation: A performance comparison of asic, dsp, and multi-dsp. Em: In Proceedings of the 8th ICSPAT, 1997, pgs. 829-833. 
Sankaralingam, K.; Singh, V.; Keckler, S.; Burger, D. Routed inter-alu networks for ilp scalability and performance. Em: International Conference on Computer Design (ICCD), 2003.

SchoEberl, M. Jop: A java optimized processor for embedded real-time systems. 2005 . Tese de doutorado, Vienna University of Technology, 2005.

SEDCOLE, N. P. Reconfigurable platform-based design in fpgas for video image processing. 2006. Tese de doutorado, Department of Electrical and Electronic Engineering, Imperial College of Science, Technology and Medicine, University of London, 2006.

So, H. K.-H. Borph: An operating system for fpga-based reconfigurable computers. 2007. Tese de doutorado, Engineering - Electrical and Computer Sciences, University of California, Berkeley, 2007.

Souhila, K.; KARIM, A. Optical flow based robot obstacle avoidance. International Journal of Advanced Robotic Systems, vol. 4, no. 1, pgs. 13-16, Março, 2007.

Teixeira, M. A. Técnicas de reconfigurabilidade dos fpgas da família apex $20 \mathrm{k}$ - altera. 2002. Dissertação de mestrado, ICMC - Universidade de São Paulo, 2002.

Thacker, C.; McCreight, E.; Lampson, B.; Sproull, R.; Boggs, D. Alto: A personal computer. Em: Siewiorek, D. P.; Bell, C. G.; Newell, A., eds. Computer Structures: Principles and Examples. Second ed.. New York: McGraw-Hill, also Xerox PARC report CSL-79-11, August 1979, 1981. pgs. 549-572.

Thrun, S.; Burgard, W.; Fox, D. A probabilistic approach to concurrent mapping and localization for mobile robots. Machine learning, vol. 31, no. 1-3, pgs. 29-53, Abril, 1998.

Thrun, S.; Montemerlo, M.; Dahlkamp, H.; Stavens, D.; Aron, A.; Diebel, J.; Fong, P.; Gale, J.; Halpenny, M.; Hoffmann, G.; Lau, K.; Oakley, C.; Palatucci, M.; Pratt, V.; Stang, P.; Strohband, S.; Dupont, C.; Jendrossek, L.-E.; Koelen, C.; Markey, C.; Rummel, C.; van Niekerk, J.; Jensen, E.; AlesSandrini, P.; Bradski, G.; Davies, B.; Ettinger, S.; Kaehler, A.; Nefian, A.; 
Mahoney, P. Winning the darpa grand challenge. Journal of Field Robotics, Junho, 2006.

WEI, Z. Real-time optical flow sensor design and its application on obstacle detection. 2009. Tese de doutorado, Department of Electrical and Computer Engineering - Brigham Young University, 2009.

Wilkes, M.; StRInger, J. Microprogramming and the design of the control circuits in an electronic digital computer. Em: Proceedings of the Cambridge Philosophical Society, reprinted as chapter 11 in: D.P. Siewiorek, C.G. Bell, and A. Newell. Computer Structures: Principles and Examples. New York: McGraw-Hill, 1982. Also reprinted in: M.V. Wilkes, "The Genesis of Microprogramming,"IEEE Annals of the History of Computing, v. 8, n. 3, 1986, pp. 116-126., 1953, pgs. 230-238.

WilKeS, M. V. The best way to design an automatic calculating machine. Em: Report of the Manchester University Computer Inaugural Conference, reprinted in: MV Wilkes, "The Genesis of Microprogramming,"IEEE Annals of the History of Computing, v. 8, n. 3, 1986, pp. 116-126., 1951, pgs. 16-18.

Wong, S.; VAssiliadis, S.; Cotofana, S. D. Microcoded reconfigurable embedded processors: Current developments. Em: Embedded Processor Design Challenges: Systems, Architectures, Modeling, and Simulation - SAMOS, Springer-Verlag Lecture Notes in Computer Science (LNCS) Vol. 2268, 2001, pgs. 207-224.

XILINX Virtex-4 configuration guide. Relatório técnico UG071, 2007.

YAnG, G.; Chen, W.; Zhou, Q.; ZhAnG, Z. Optical flow approximation based motion object extraction for mpeg-2 video stream. Real Time Image Processing, vol. 4, no. 4, pgs. 303-316, Novembro, 2009. 


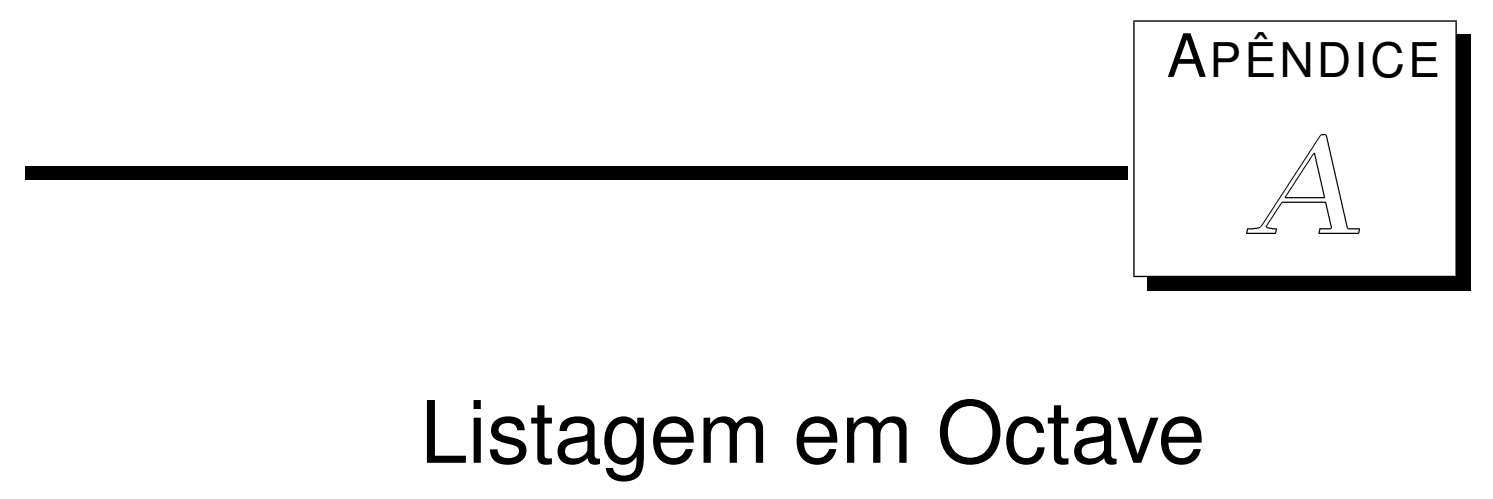

Segue a coleção de programas usados para testar o algorítmo de fluxo óptico e divergente. Os programas em si não estão comentados mas neste apêndice cada função segue um breve texto explicativo.

\section{A.1 Fluxo Óptico}

A função opflow da figura A.1 é bem típica do processamento em pirâmide desta aplicação. Cada uma das entradas, prev e current, contém uma célula com uma seqüência de imagens onde cada uma é a versão da anterior mas com metade da resolução. Cada pixel da sexta imagem representa um bloco de 32 por 32 pixels da primeira. As imagens são matrizes de 3 dimensões, representando a altura, a largura e a tripla R, G, B. A função simplesmente delega o processamento real de cada matriz para a função op flowMat.

A saída desta função é também uma célula de seis elementos representando uma pirâmide, mas neste caso cada matriz de 3 dimensões representa a altura, a largura e a dupla $d x$ e $d y$ indicando o vetor de deslocamento de cada píxel. Para o processamento intermediário, os deslocamentos representam um número inteiro de pixels. Mas este função normaliza os deslocamentos 


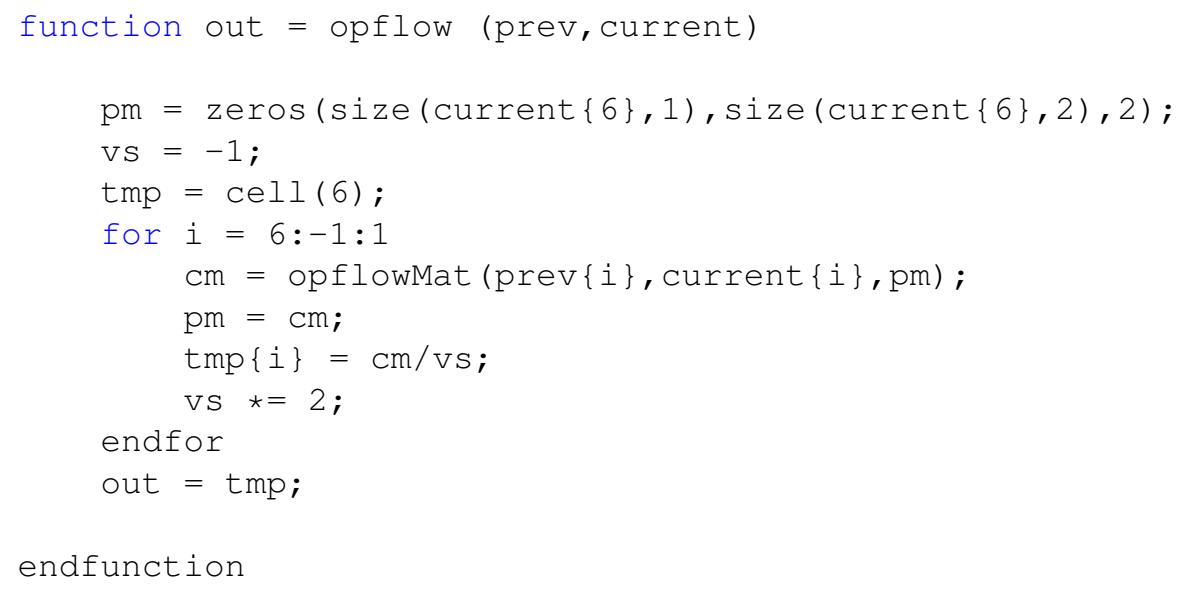

Figura A.1: Fluxo óptico de um par de pirâmides de imagens

na saída para valores de -1 a 1 usando a variável vs. Todo o cálculo é feito de como levar um píxel do quadro atual para um do anterior e os valores negativos de $v s$ mudam isso para a direção convencional do fluxo óptico.

A operação da função mostrada na figura A.2 é uma comparação do bloco atual de 3 por 3 pixels (por 3 - o R, G, B) com todos os nove blocos de mesmo tamanho num bloco de 5 por 5 pixels (por 3) da imagem anterior. O vetor de deslocamento que leva ao bloco com a menor suma de diferenças absolutas é a resposta. A ordem da busca começa pelo centro (deslocamento $0,0)$ para que no caso de empate seja dada preferência para o caso de nenhum movimento ou movimentos pequenos.

Na figura A.3, as entradas prev e current são imagens completas enquanto higher representa o fluxo óptico já calculado para o nível superior da pirâmide. Para cada ponto deste nível, o resultado correspondente é usado como ponto central do bloco de 5 por 5 pixels da imagem anterior que será usado na busca. O resultado do nível mais alto tem que ser multiplicado por 2 para fazer sentido neste nível.

O valores da borda não podem ser calculados, nem de qualquer ponto cujo deslocamento faria o bloco de 5 por 5 cair fora dos limites. O primeiro caso é compensado copiando os valores próximos da borda para a borda.

É muito difícil encontrar erros no cálculo da divergente sem um controle maior dos seus dados de entrada. A função op flowMat da figura A.3 não oferece este controle já que seus resul- 


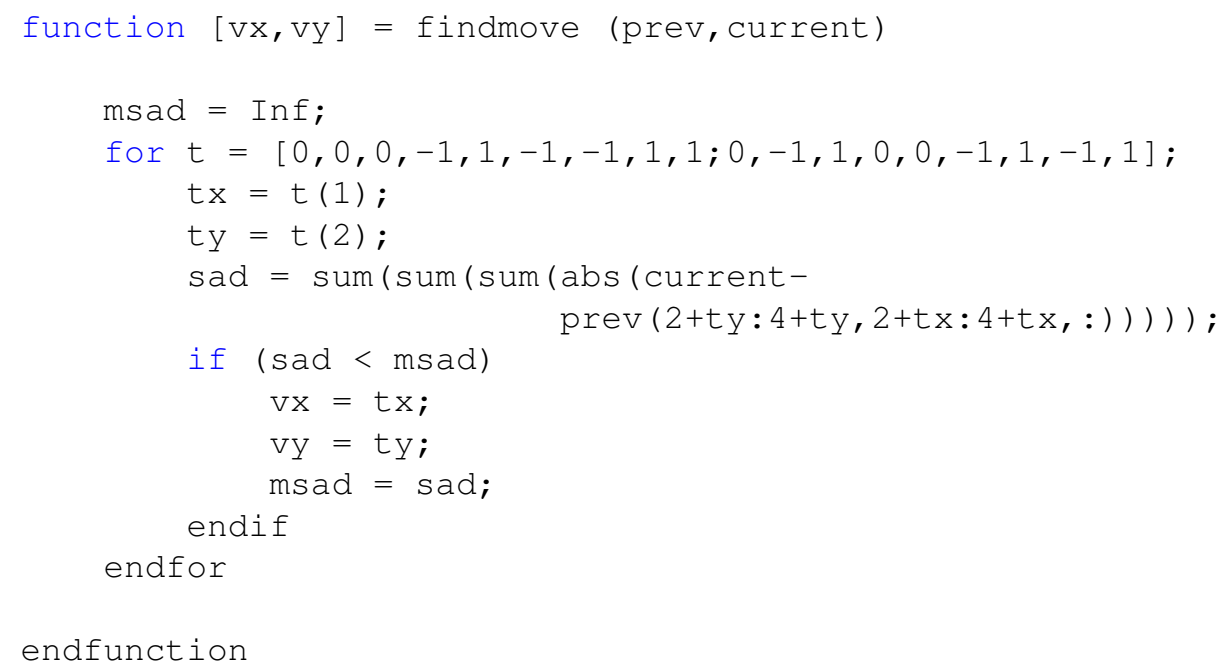

Figura A.2: Encontra a melhor aproximação de 3 por 3 pixels da imagem atual numa área de 5 por 5 na imagem anterior

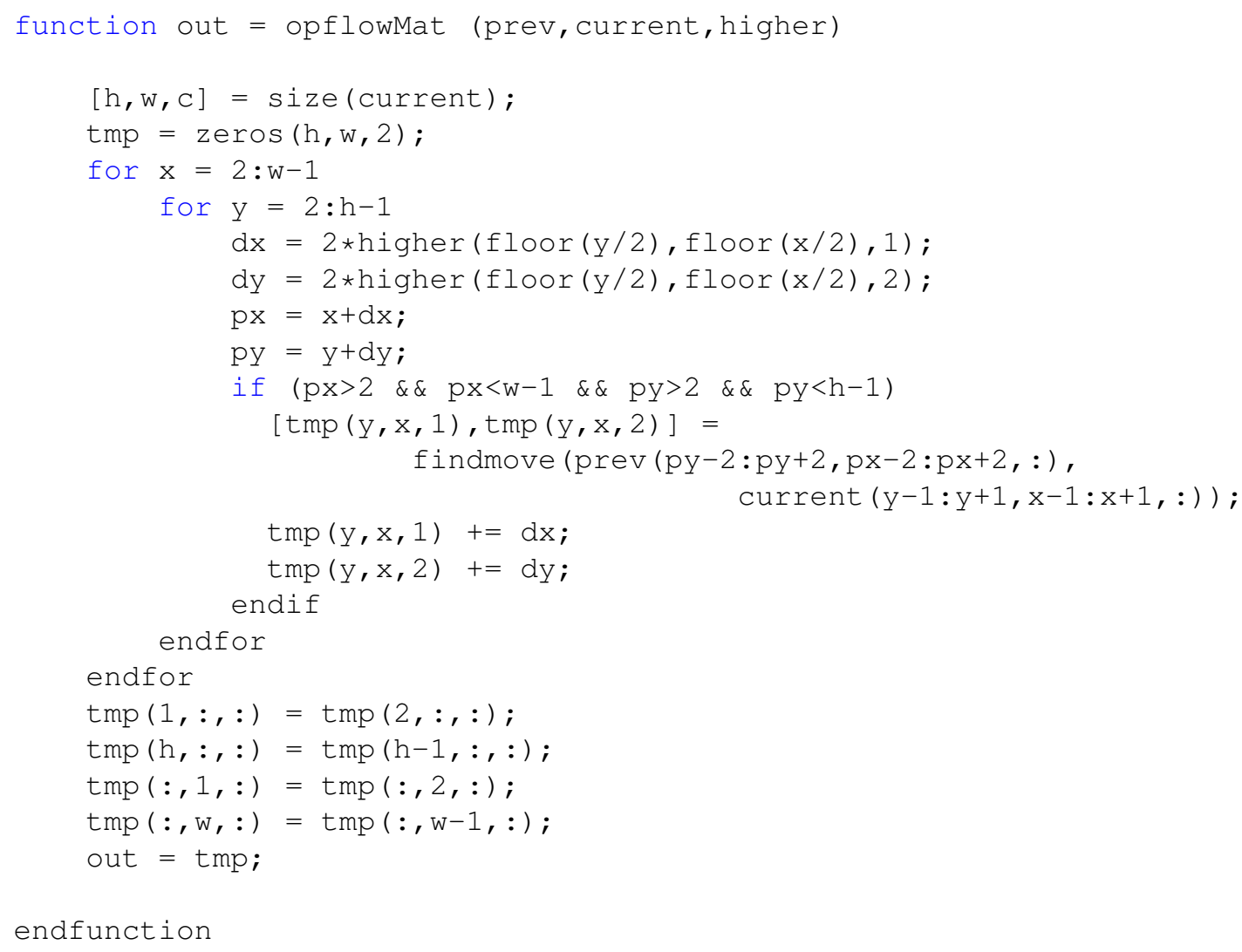

Figura A.3: Fluxo óptico de um par de imagens 


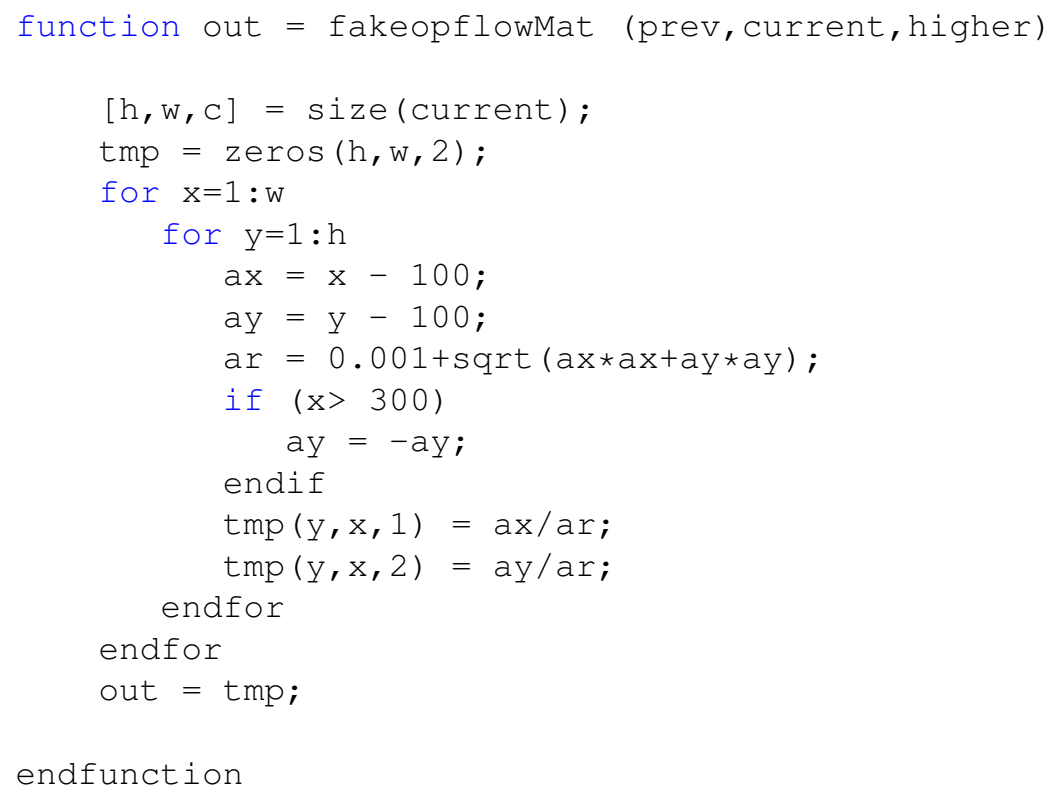

Figura A.4: Fluxo óptico falso para testar divergente

tados dependem totalmente das imagens de entrada. A função fakeopflowMat da figura A.4 é uma alternativa que gera uma saída bem conhecida com um ponto de alta divergência e uma linha que "reflete" verticalmente os vetores para gerar um componente rotacional.

Não foi incluída uma chamada a esta função dentro de op flow pois foi considerado preferível altera-lá sempre que fosse feito um teste. Esta alteração é a troca da chamada a opflowMat por fakeopflow Mat e a eliminação da atualização de vs (esta função já gera valores normalizados e ignora totalmente os resultados dos níveis mais altos, mas recebe higher por compatibilidade com opflowMat).

\section{A.2 Divergente}

Na figura A.5 se repete o processamento em pirâmide do nível mais alto para o mais detalhado usando uma função auxiliar para cuidar de cada nível.

A função divof Mat da figura A.6 aproxima o divergente e rotacional do campo vetorial trabalhando com blocos de 3 por 3 centrados no ponto de interesse. Usando deslocamentos de matrizes, todos os resultados são calculados em paralelo. Dado a relação da direção y das imagens com os índices da primeira dimensão das matrizes, o sentido de up e down e vários 


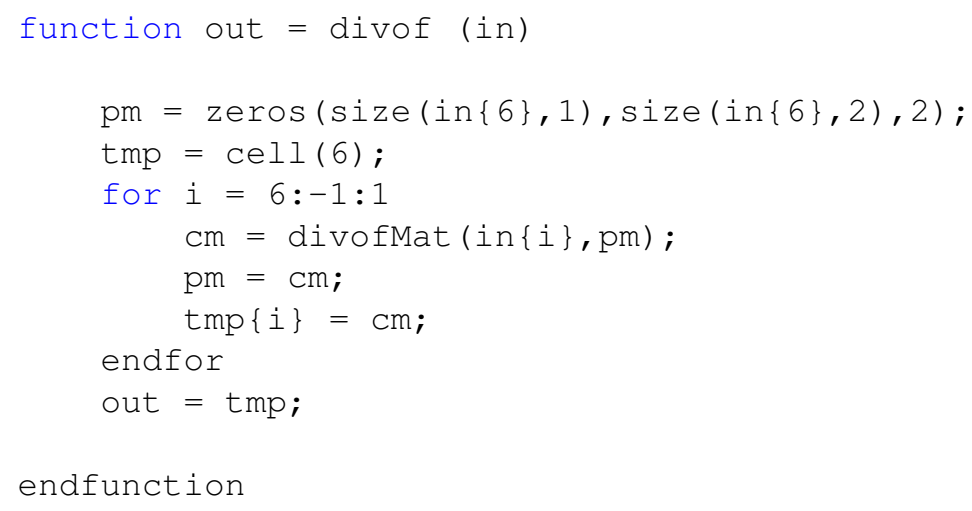

Figura A.5: Divergente de um par de pirâmides de fluxos ópticos

ângulos envolvidos nestes cálculos ficam invertidos. Os resultados são divididos por 29, que é o maior valor possível para div ou rot já que o maior valor possível para $m h, m v, m d 1$ e $m d 2$ é 6 .

A função da figura A.7 calcula para cada ponto uma aproximação do divergente e do rotacional do campo vetorial de entrada naquele ponto. São usados blocos de 11 por 11 pontos, o que pode ser facilmente alterado trocando-se os valores de blksz (que tem que ser ímpar para que haja um ponto no meio). Os resultados são muito melhores que os da função da figura A.6 de modo que esta função pode substituí-la para testes, mas não é pratico tentar uma implementação em hardware com blocos tão grandes.

Um conjunto de oito máscaras são usados por esta função e são calculadas pela função setupmasks na primeira vez que são usadas. Se o dado de entrada não tiver pelo menos quatro blocos de altura então zeros são devolvidos como resposta. Quatro resultados parciais são calculados usando duas máscaras cada um e os seus componentes são combinados no divergente e no rotacional.

No final o maior valor obtido é determinado para que a resposta possa ser normalizada para melhor visualização. O valor obtido no nível imediatamente maior da pirâmide é combinado com maior peso na resposta para que divergentes gerados pelas bordas de um objeto tenham um impacto seu interior.

As mascaras calculadas na figura A.8 possuem o mesmo tamanho que o bloco usado para a avaliação da divergente e seu valor é 1 nos pontos que devem participar de determinado cálculo 


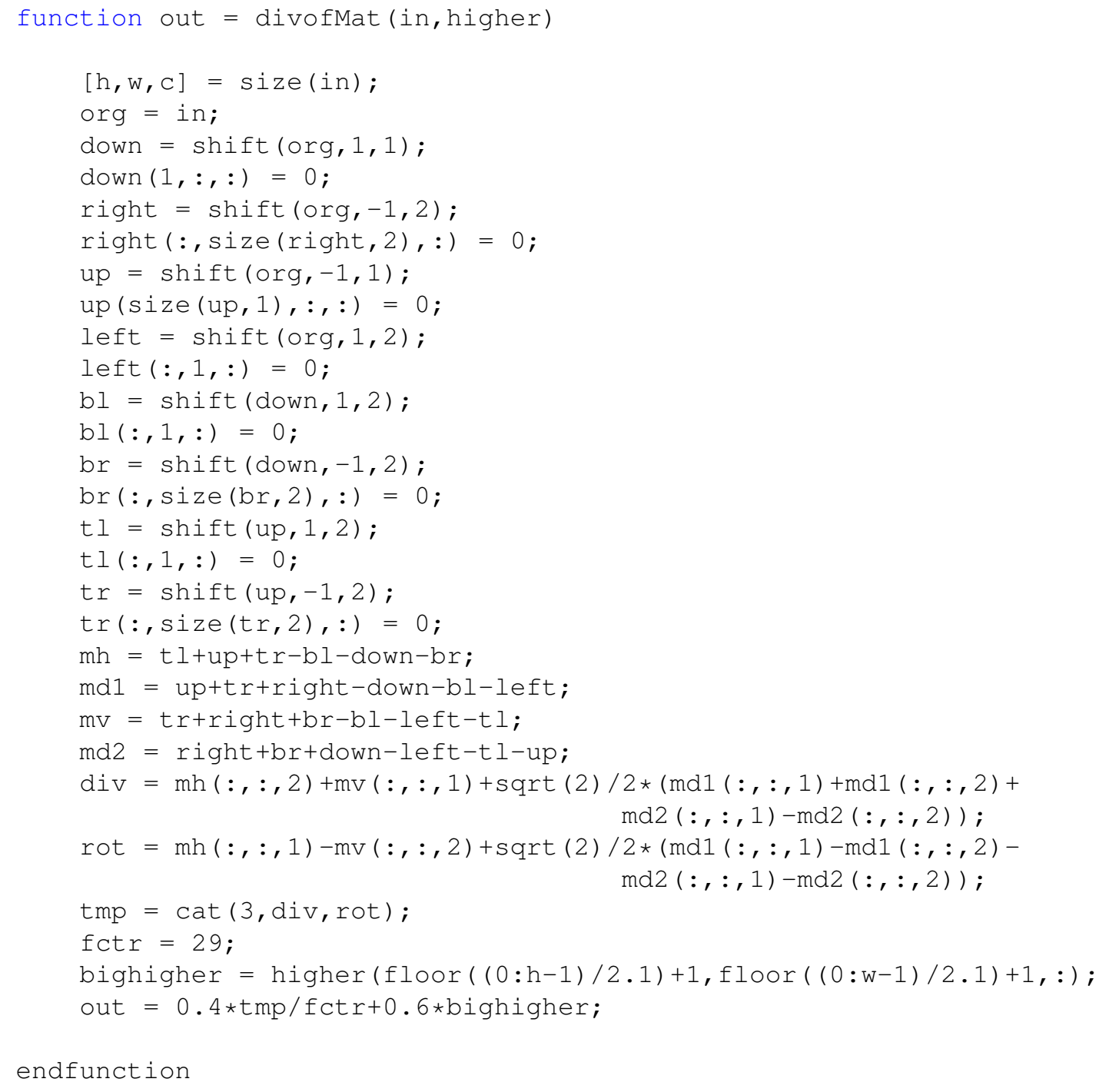

Figura A.6: Divergente de um par de fluxos ópticos com blocos de 3 por 3 pixels 


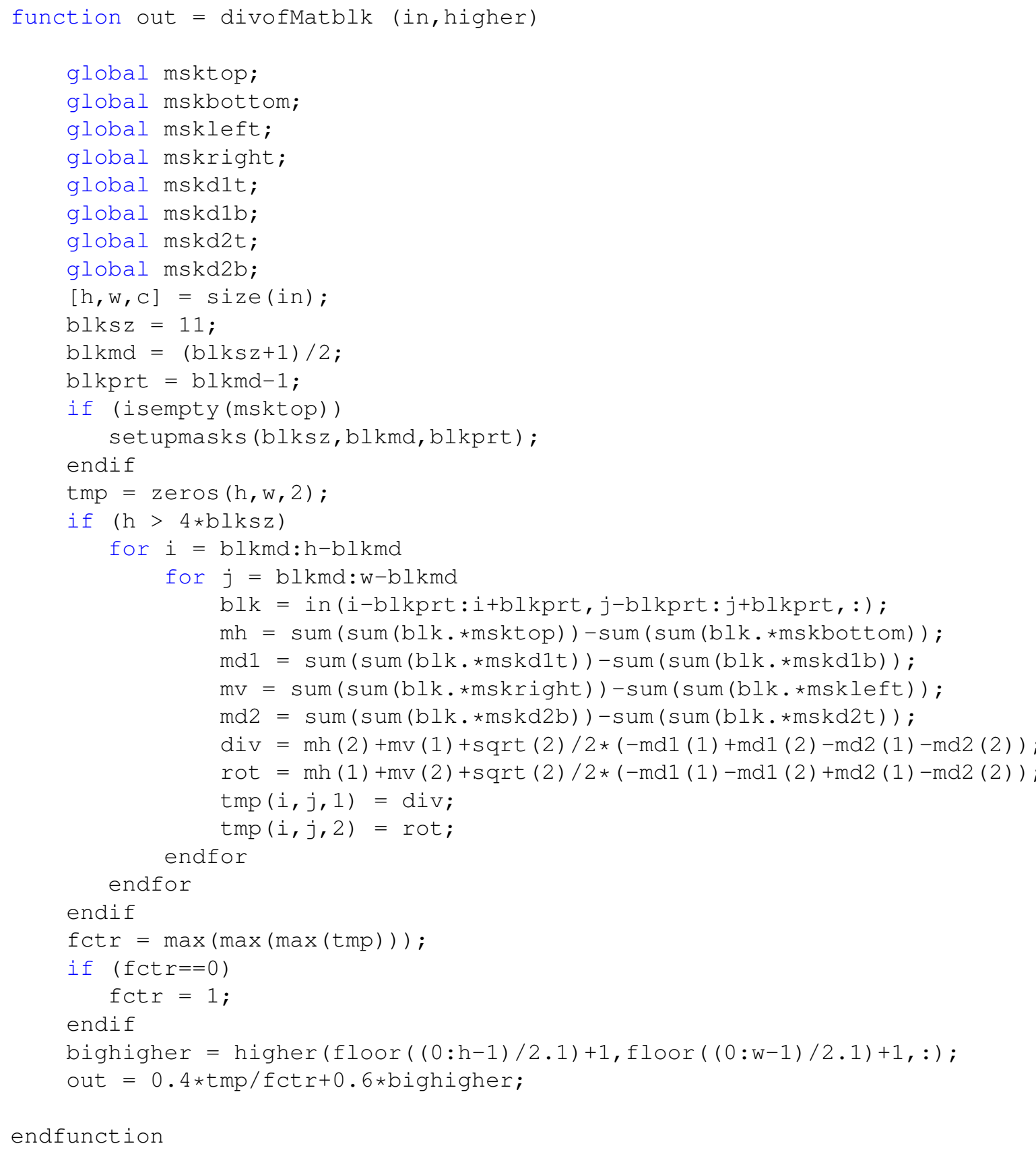

Figura A.7: Divergente de um par de fluxos ópticos com blocos de 11 por 11 pixels 
e 0 para os demais. Um para de máscaras como a de cima e a de baixo (msktop e mskbottom respectivamente) não cobrem todos os pontos possíveis, mas o eixo central é deixado de fora.

\section{A.3 Representação via Cores}

Os vetores de deslocamento do fluxo óptico são representados por cores como definido por Baker et. al. (2007). Já para o divergente é diretamente representado pelo componente vermelho enquanto que o rotacional pelo verde.

A função da figura A.9 calcula as cores de cada nível da pirâmide de fluxos ópticos.

A função mostrada na figura A.10 calcula as cores de cada ponto de um campo vetorial representando um fluxo óptico.

A figura A.11 mostra a função que calcula a cor correspondente a um vetor de deslocamento. O vetor é primeiro transformado para coordenadas polares. O ângulo resultante é dividido em seis regiões onde cada componente de cor $(\mathrm{R}, \mathrm{G}$ e B) é 0 em duas, máximo em outras duas e uma transição linear nas demais. Cada componente é defasado 120 graus em relação aos outros.

A saturação é máxima para vetores unitários e mínima (branco) para vetores nulos. Vetores fora do círculo unitário ficam mais escuros mas com saturação máxima. Para facilitar a visualização de vetores pequenos, a linha 9 aplica como se fosse um fator gama de correção.

A função da figura A.12 normalmente não é usada pelo programa mas permite ao usuário visualizar o círculo de cores definido na função anterior. O uso de dois dados de entrada para o tamanho permite a criação de figuras não quadradas, mas isso não é muito interessante.

A figura A.13 mostra a função que simplesmente aplica a transformação de cores para divergente e rotacional em cada nível de uma pirâmide.

Valores positivos da divergente são indicados por pontos vermelho, negativos em azul e os valores absolutos da rotacional (não usados neste projeto) aparecem em verde calculados na função da figura A.14. 


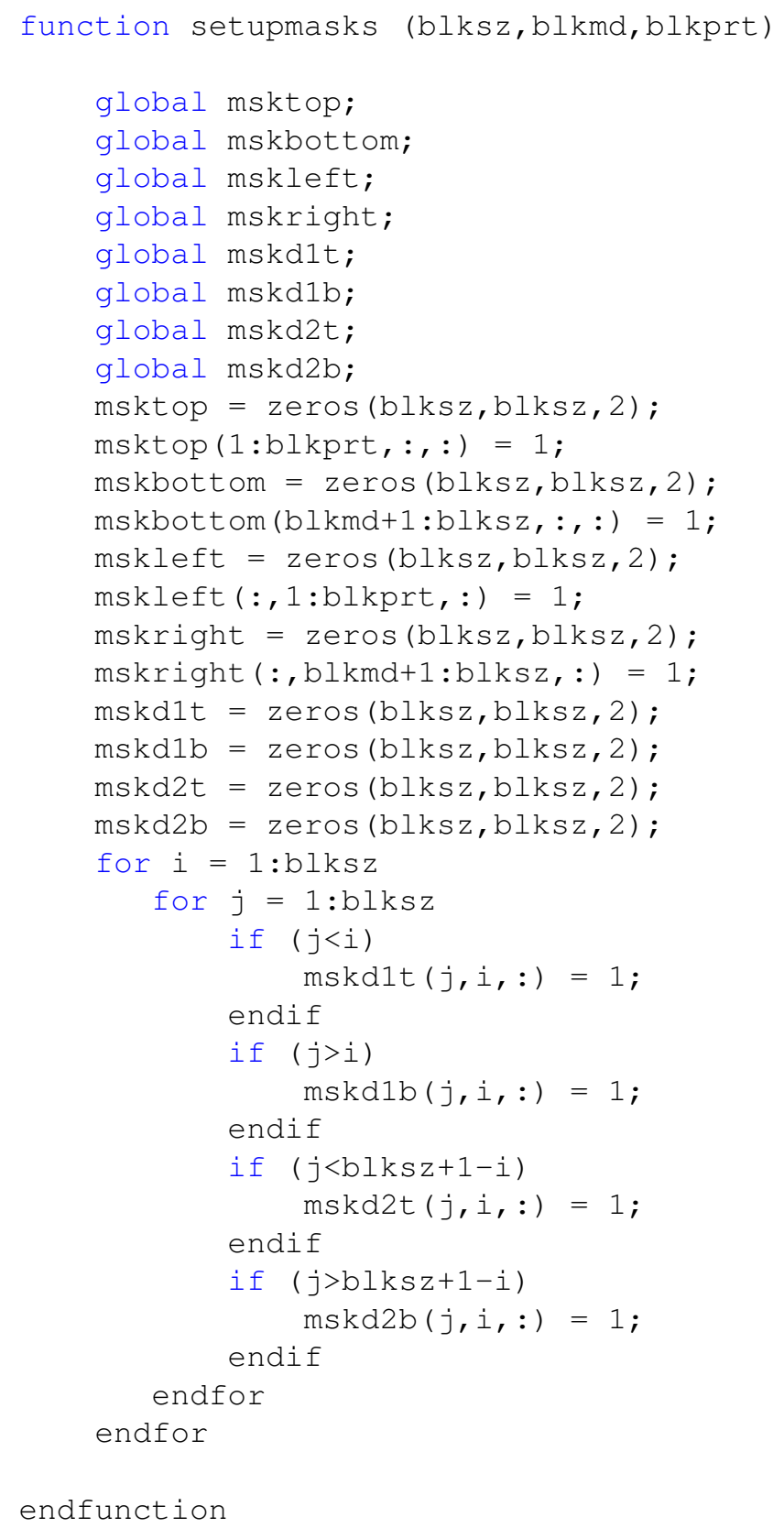

Figura A.8: Inicializa dados usados na figura A.7

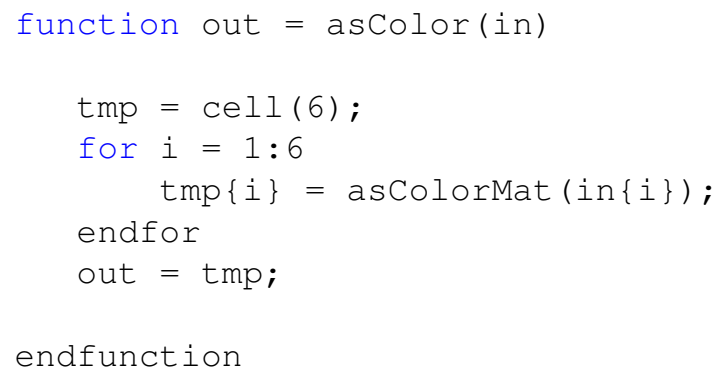

Figura A.9: Fluxo óptico de uma pirâmides de imagens representado por cores 


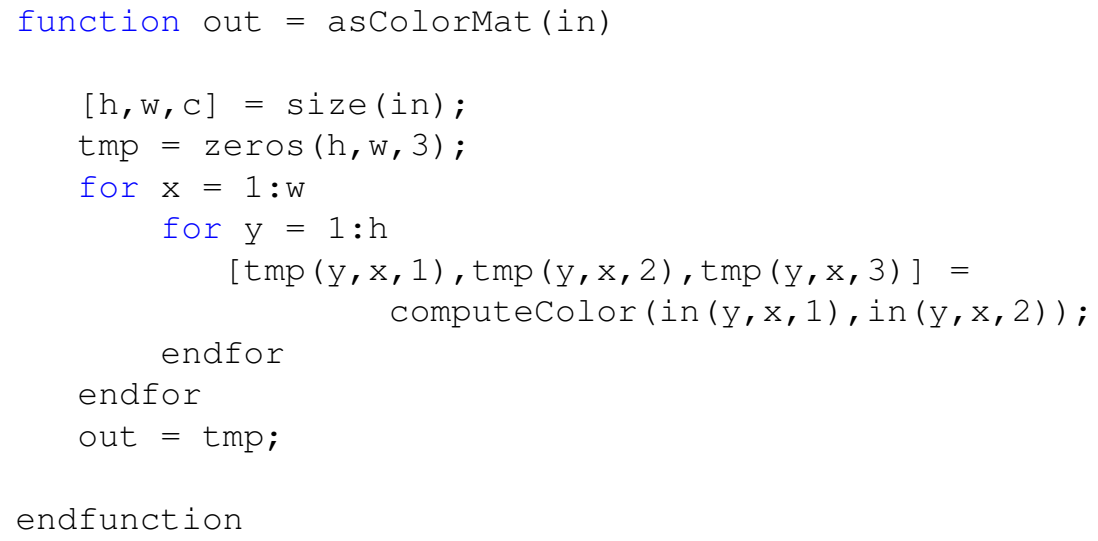

Figura A.10: Fluxo óptico de uma imagem representado por cores

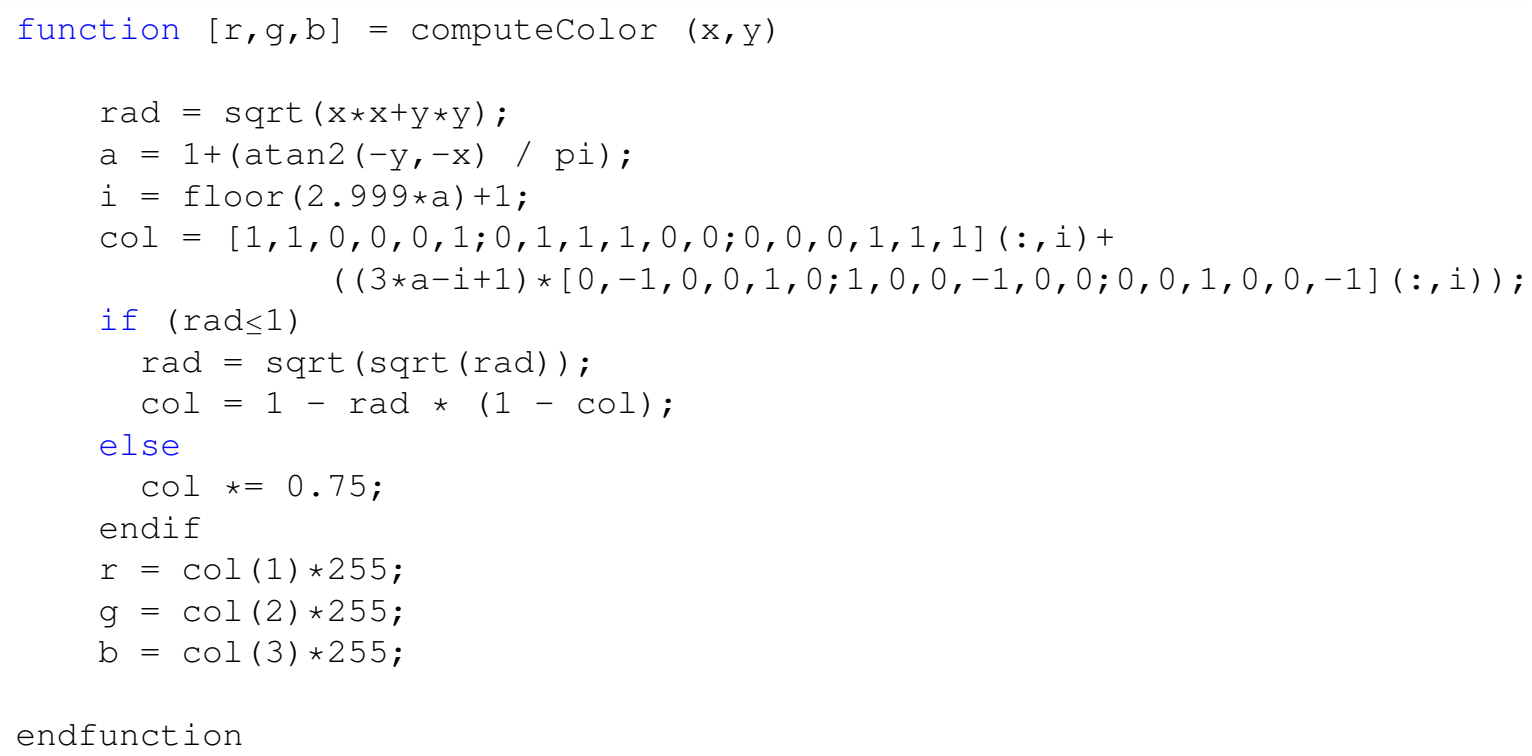

Figura A.11: Cor correspondente a um deslocamento

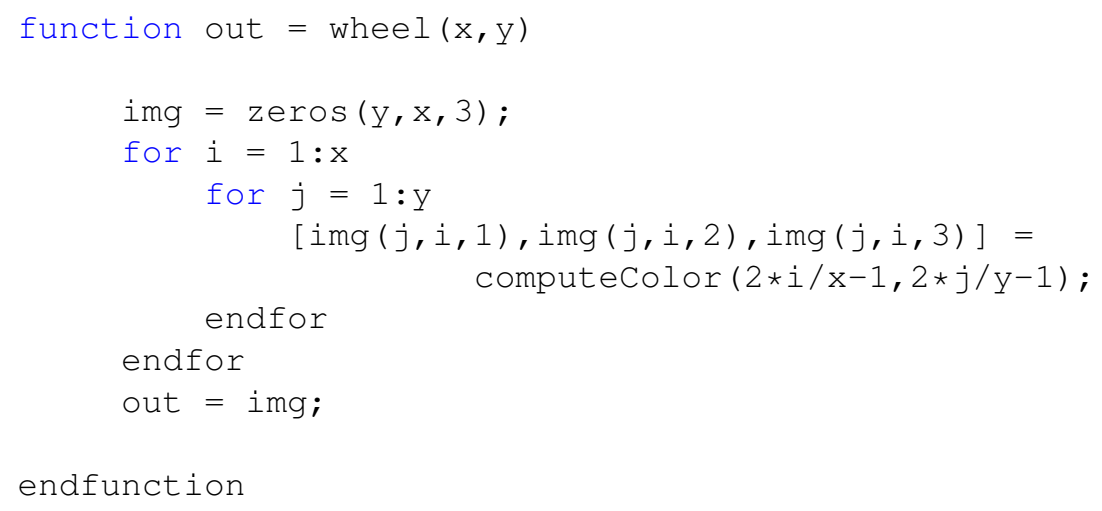

Figura A.12: Legenda para a representação de vetores de deslocamento como cores 


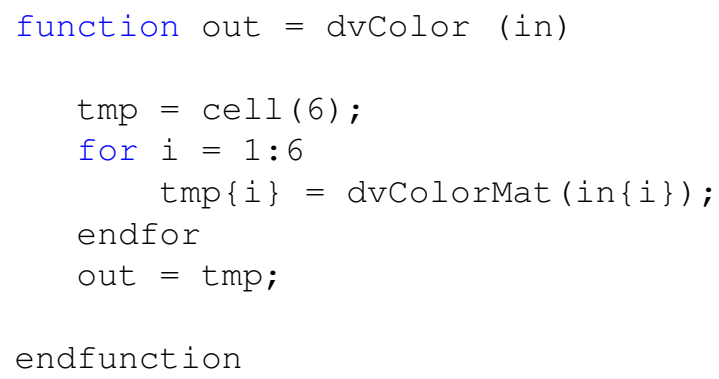

Figura A.13: Divergente de uma pirâmide de fluxos ópticos representados por cores

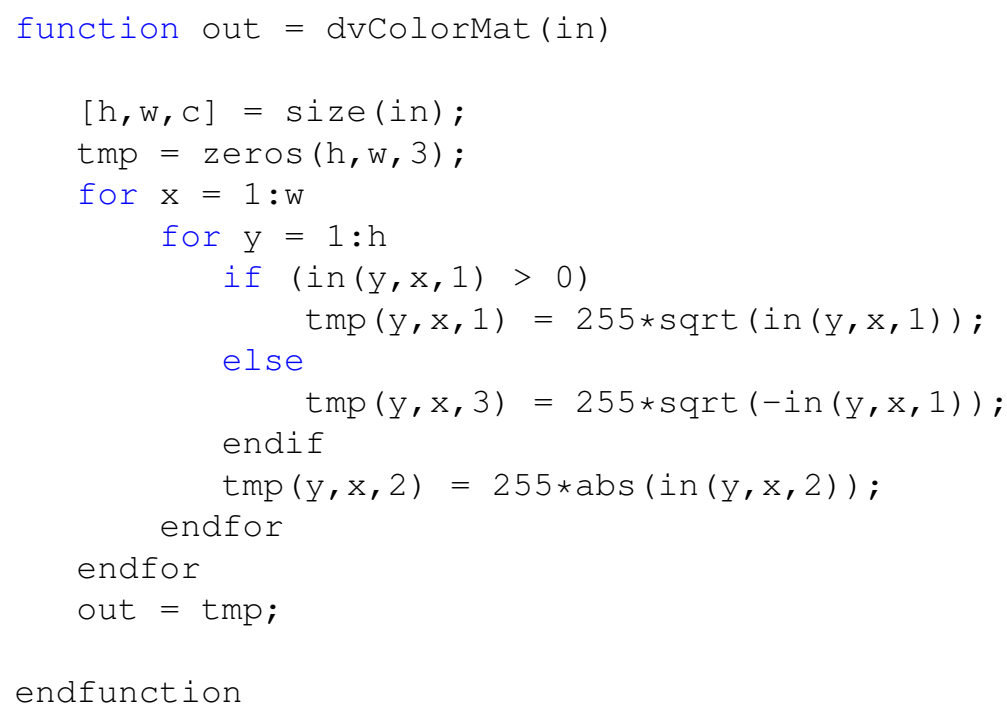

Figura A.14: Divergente de um fluxo óptico representado por cores 


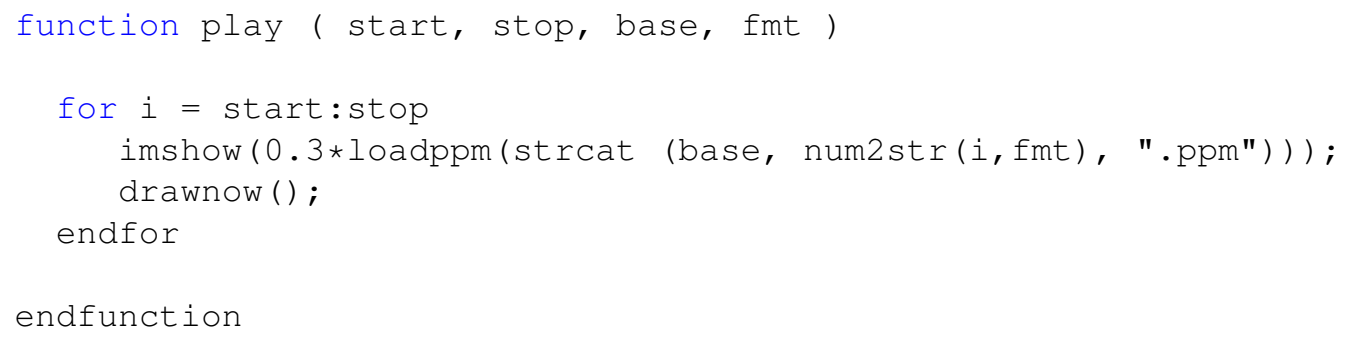

Figura A.15: Toca um filme

\section{A.4 Leitura de Arquivos}

A função da figura A.15 permite visualizar as imagens de entrada. Apenas os quadros entre start e stop são mostrados. Cada imagem é um arquivo cujo nome começa com o texto indicado em base seguindo pelo número do quadro atual no formato fmt (geralmente algo como "\%02d"para dois digitos decimais com zero à esquerda quando menos que 10) e finalmente terminados com o tipo de arquivo, que é PPM. O formato PPM tem várias opções, mas apenas a versão P6 é aceita pela função loadppm (descrita mais adiante).

As imagens ficam claras demais quando usadas diretamente no comando imshow e por isso estão sendo ajustadas por um fator de 0,3 aqui.

A variação da função da figura A.15 mostrada na figura A.16 gera a pirâmide de imagens correspondente a cada quadro lido e aplica a transformação definida na figura A.18. Esta transformação depende tanto do quadro atual que acabou de ser lido como do anterior. No caso do primeiro quadro não existe um anterior e o próprio é usado no lugar.

Para gerar um nível mais alto da pirâmide, a função da figura A.17 faz uma simples média dos quatro pixels correspondentes na imagem de entrada.

A função da figura A.18 combina 3 pirâmides completas numa única imagem. Uma é o dado de entrada e os outros são os resultados do fluxo ótico e da divergente/rotacional.

A figura A.19 mostra a função que coloca o conjunto de imagens de uma pirâmide dentro de outra maior com o deslocamento indicado. Todos os pontos fora da imagem menor são zero para que várias imagens geradas por esta função possam ser facilmente combinadas. Apenas 3 cantos são válidos como deslocamento pois o outro é usado para colocar os níveis mais altos (e 


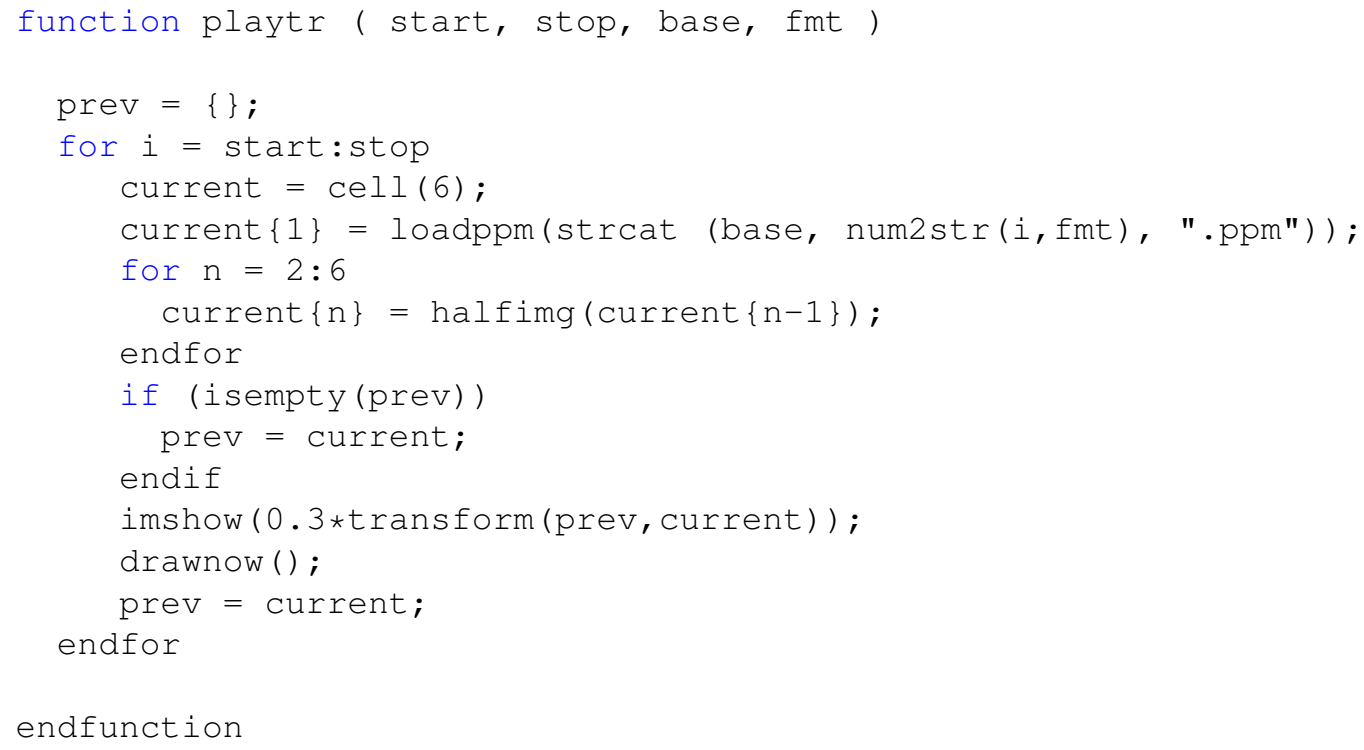

Figura A.16: Toca um filme calculando o fluxo óptico de um quadro para outro e a divergente

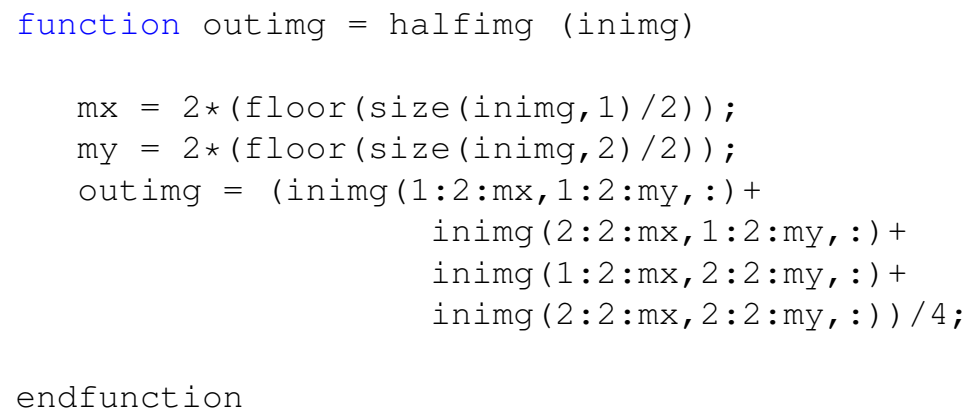

Figura A.17: Divide a resolução de uma imagem por dois usando uma média simples

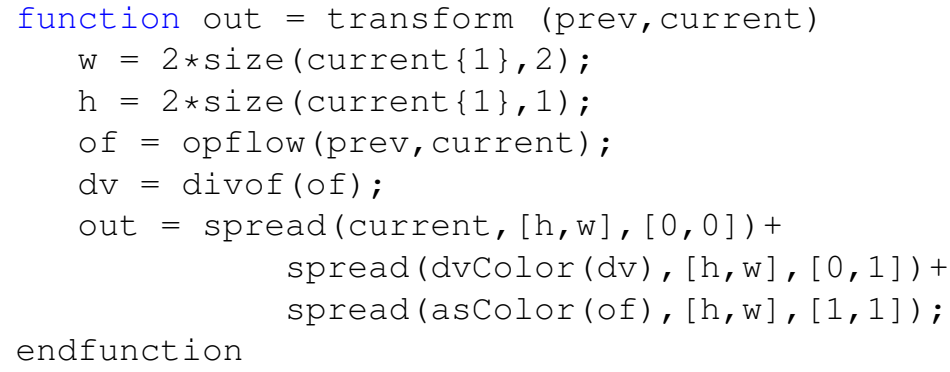

Figura A.18: Combina pirâmides de entrada e de saída numa única imagem 


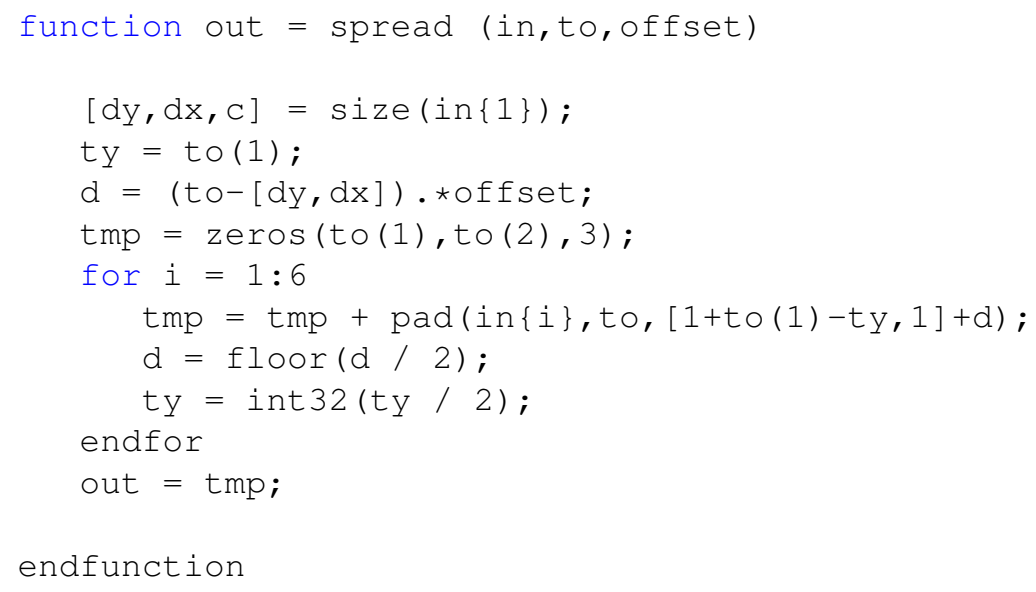

Figura A.19: Espalha os elementos de uma pirâmide por uma imagem maior

de menor tamanho) da pirâmide. Este aproveitamento de espaço é semelhante aos "mip maps" da computação gráfica.

Usada pela função da figura A.19, a pad da figura A.20 coloca quatro blocos de zeros ao redor de uma imagem para que ela fique com o tamanho indicado. Se o deslocamento indicado fizer a imagem menor encostar numa das quatro bordas da imagem maior, um ou dois dos blocos de zero não serão necessários.

Quase idêntica à função playtr da figura A.16, a da figura A.21 recebe uma entrada a mais indicando o início do nome de arquivos a serem gerados para cada quadro de entrada. Teoricamente seria melhor usar o formato PNG mas o Octave reduz muito o número de cores causando grande perda na qualidade das imagens. Apesar do fator de compressão do formato JPEG, este se mostrou uma opção melhor, especialmente se os quadros forem ser combinados num filme MPEG.

Os arquivos PPM são muito simples e por isso são usados aqui. Por não terem compressão costumam ser umas 10 vezes maiores que outras opções. O início é um texto identificando a versão (apenas a P6 é aceita aqui), o tamanho da imagem e o valor máximo dos dados de cor. Em seguida vem os próprios dados com a cor de cada pixel, um byte por componente.

A maior complicação da função da figura A.22 está nas linhas 41 a 44 onde a ordem das informações lidas é trocada para ficar de acordo com as outras operações de imagem do Octave. 


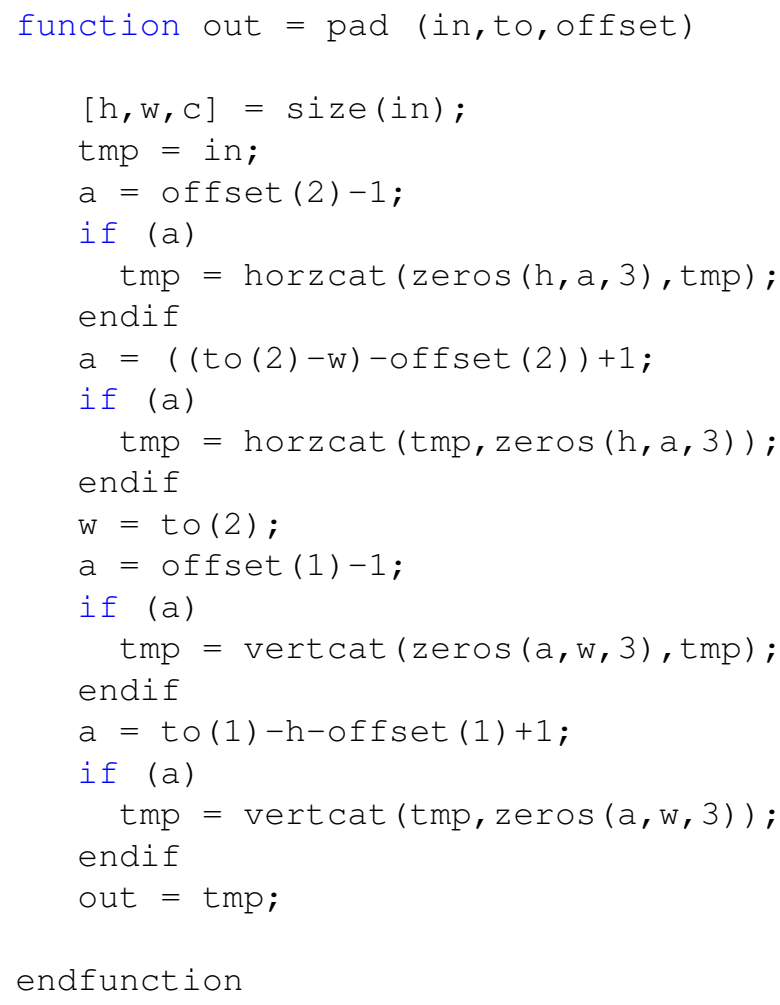

Figura A.20: Embute uma imagem numa maior usando zeros

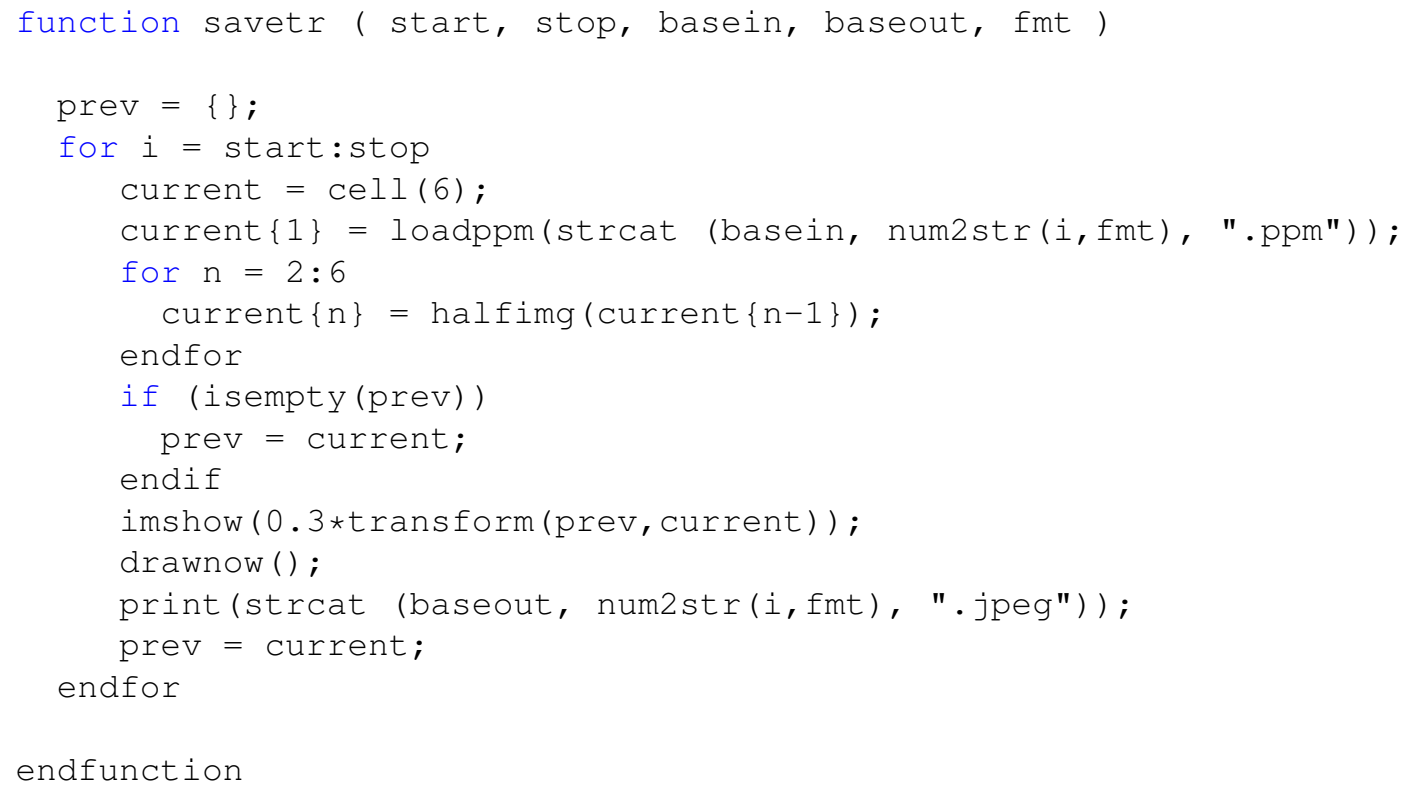

Figura A.21: Como da figura A.16 mas salva cada quadro num arquivo 


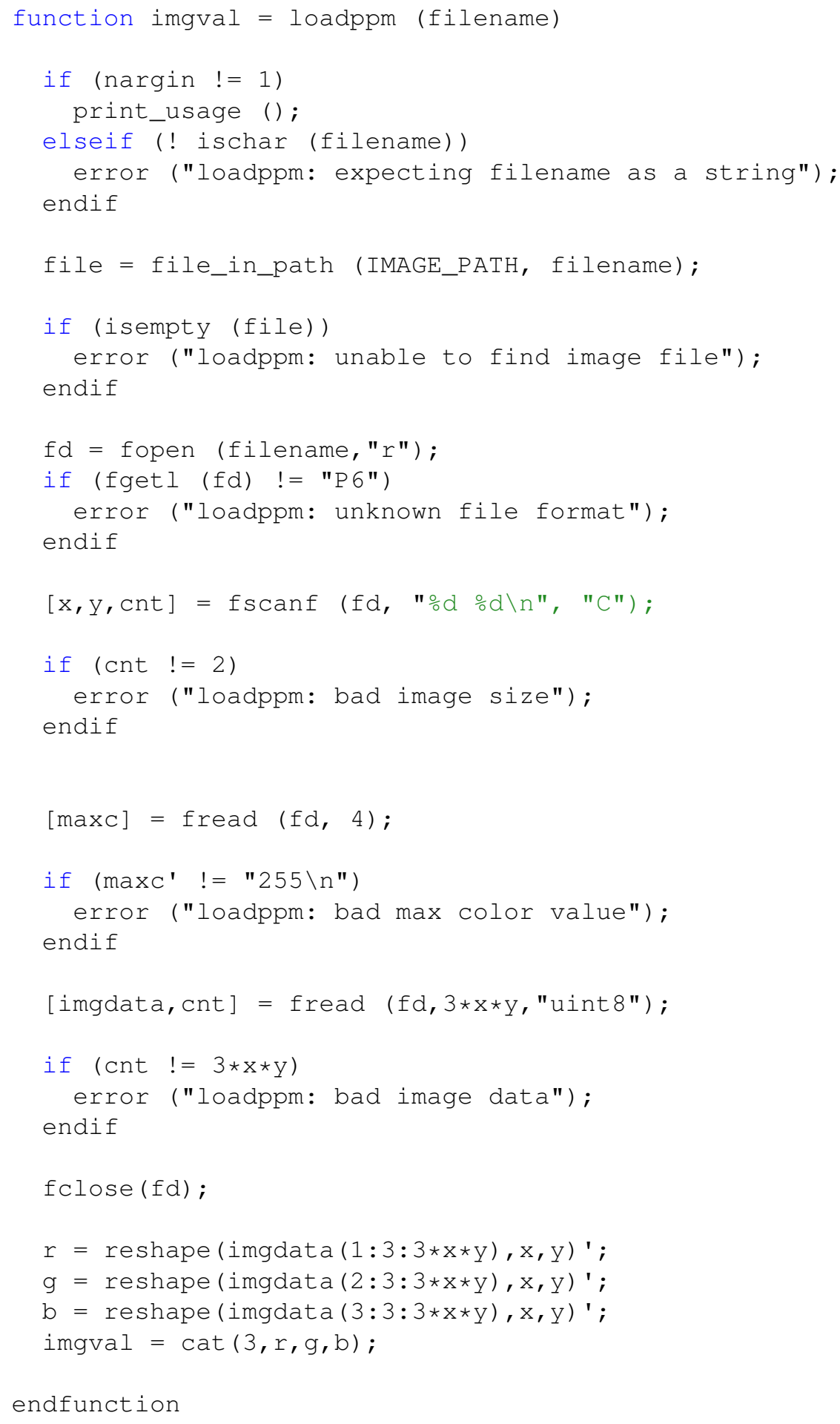

Figura A.22: Lê arquivos no formato PPM 